\title{
ASSESSMENT OF AUTOMATED PRESSURIZED LIQUID EXTRACTION METHOD FOLLOWED BY ENZYME-LINKED IMMUNOSORBENT ASSAY FOR MONITORING AIR-BORN DIOXINS
}

By

\author{
MARYAM MORADI \\ B.Eng., Sharif University of Technology, Iran, 1994 \\ A thesis \\ Presented to Ryerson University \\ In partial fulfillment of the \\ Requirement for the degree of \\ Master of Applied Science \\ in the Program of \\ Environmental Applied Science and Management
}

Toronto, Ontario, Canada, 2015

(C) Maryam Moradi 2015 


\section{AUTHOR'S DECLARATION FOR ELECTRONIC SUBMISSION OF A THESIS}

I hereby declare that I am the sole author of this thesis. This is a true copy of the thesis, including any required final revisions, as accepted by my examiners.

I authorize Ryerson University to lend this thesis to other institutions or individuals for the purpose of scholarly research.

I further authorize Ryerson University to reproduce this thesis by photocopying or by other means, in total or in part, at the request of other institutions or individuals for the purpose of scholarly research. I understand that my thesis may be made electronically available to the public. 


\title{
ABSTRACT \\ Assessment of automated pressurized liquid extraction method followed by enzyme-linked immunosorbent assay for monitoring air-born dioxins
}

\author{
Maryam Moradi \\ Master of Applied Science \\ Environmental Applied Science and Management \\ Ryerson University \\ 2015
}

An automated procedure of sample preparation using pressurized liquid extraction (PLE) was developed for subsequent analysis by enzyme-linked immunosorbent assay (ELISA) for dioxins detection in ambient air samples collected from Burlington Ontario. Ambient air samples were collected from particle-phase using glass fibre filters (GFF) and from gas-phase using polyurethane foam from November 2014 to February 2015. The PLE extracts were cleaned up with acid silica followed by carbon mini-column. The average concentration of dioxins in particle phase was found to be $9.96 \pm 4.5 \mathrm{fgTEQ} / \mathrm{m}^{3}(\mathrm{n}=10)$. This empirical finding is in agreement with high resolution gas chromatography -high resolution mass spectrometry (GC-MS) mean result of $10.04 \pm 2.9 \mathrm{fgTEQ} / \mathrm{m}^{3}(\mathrm{n}=5)$. However, due to the limited sample size correlation between the two methods cannot be statistically established. The higher concentration of dioxins in Burlington, a city with heavy industry, was expected comparing the finding from previous study for downtown metropolitan Toronto $\left(7.6 \pm 2.0 \mathrm{fg} \mathrm{BEQ} / \mathrm{m}^{3}\right)$. Development of this method relied on calibration test, recovery test and Certified Reference Material (CRM) evaluation. Calibration test was successful in terms of developing standard curve with results within one standard deviation of the mean concentration of calibration standards. ELISA result on CRM was acceptable. Recovery test on extended toluene evaporation to half an hour or higher increased the recovery from $45 \%$ to an average of $82.4 \%$ for high concentrations and $89 \%$ for medium concentration of dioxins spike. The results of this study illustrate that PLE / ELISA can substitute for GC-HRMS as a cost effective screening tool to determine the dioxins concentration in ambient air. 


\section{ACKNOWLEDGEMENT}

I would like to sincerely acknowledge my supervisors Dr. Ching Lo and Dr. James Li for their encouragement, support and guidance throughout my research. My acknowledgement is also extended to Environment Canada Clean Air Regulatory Agenda and Environment Canada Organics Analysis Laboratory members for their technical support: Richard Park, Cecilia Shin, Nick Alexandrou and Nan Zi. A huge thank to Dr. Liisa Jantunen in Environment Canada for providing sampling instruments, Quintin Rochford in Canadian Centre for Inland Waters for supporting in sample collection, and Brian Sunga for his inputs on statistical analysis. My special thanks goes to Dr. Hayley Hung in Environment Canada for providing me the instruments, information and general inspiration. Final thanks goes to my thesis defence committee members Dr. Lynda McCarthy, Dr. Darko Joksimovic and the chair of my committee, Dr. Cory Searcy for their interest and input to my work.

This research could not have been possible without the funding of Dr. James Li and Ryerson graduate scholarship program.

Finally, I would like to thank my family Majid, Kasra and Bardia Abbasi for their patience, encouragement and support of all kinds. 


\section{TABLE OF CONTENTS}

Author's declaration for electronic submission of a thesis ................................................ ii

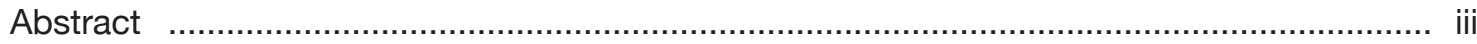

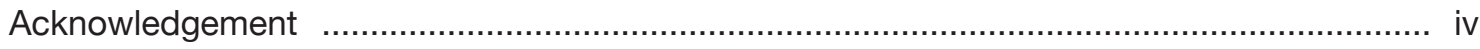

\section{CHAPTER ONE}

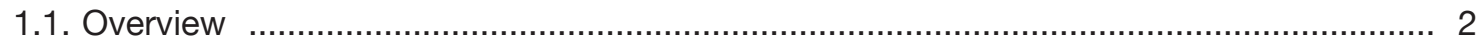

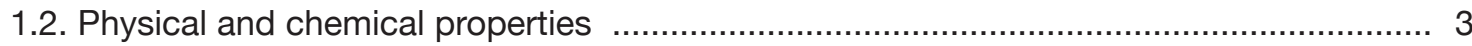

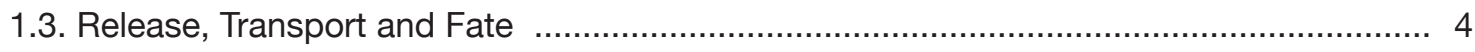

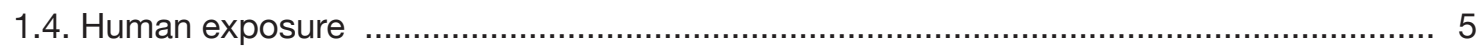

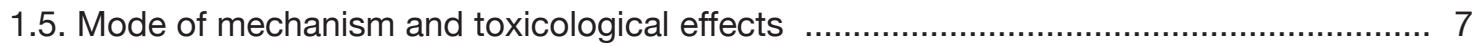

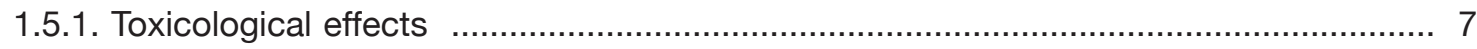

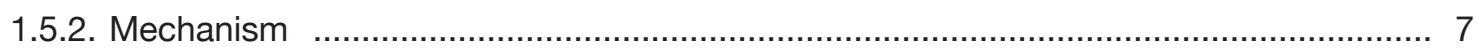

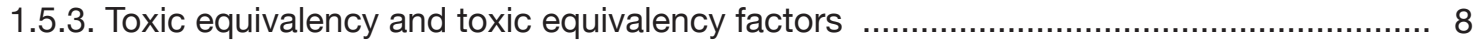

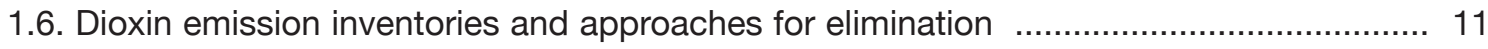

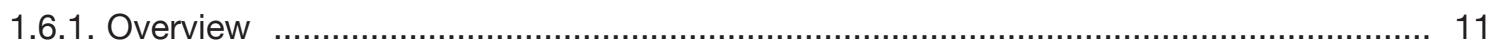

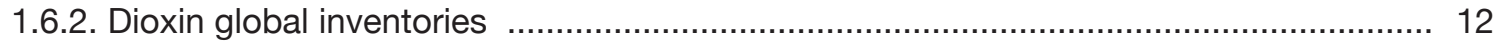

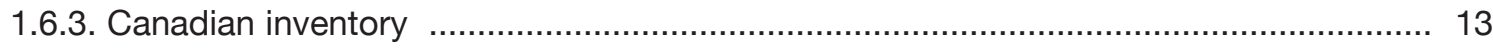

1.6.3.1. Pulp and paper boilers burning salt laden wood ............................................... 14

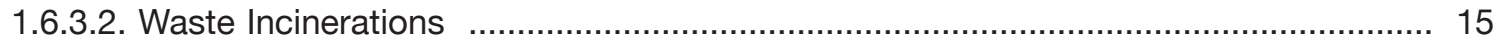

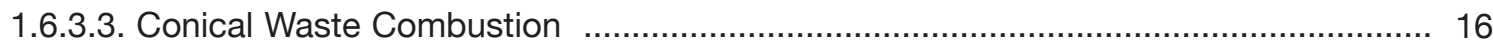




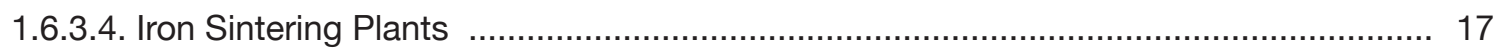

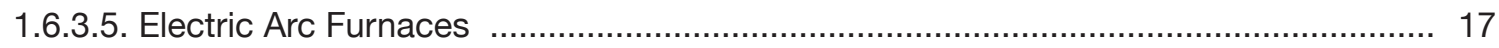

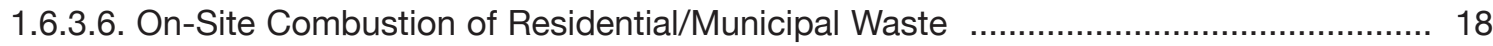

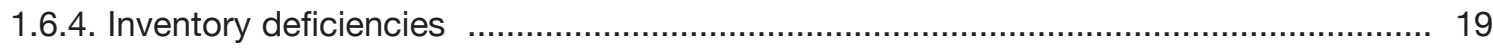

\section{CHAPTER TWO}

2. ELISA

\section{CHAPTER THREE}

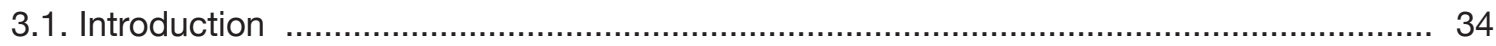

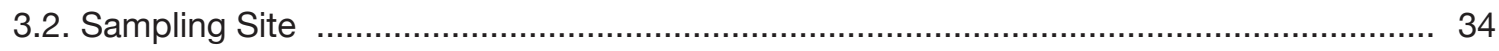

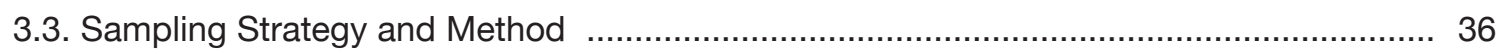

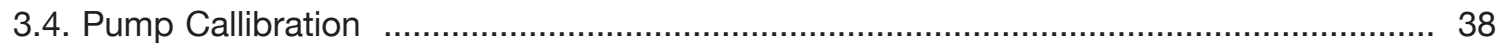

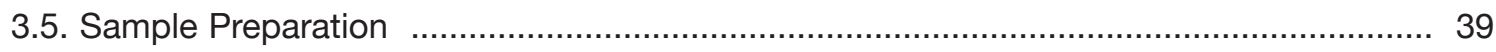

3.5.1. Comparison between Manual and Automated ..................................................... 39

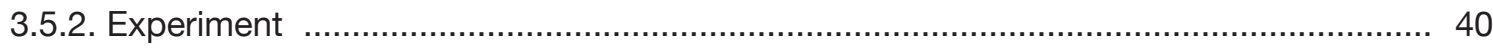

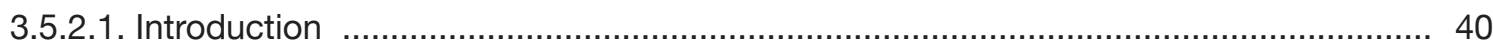

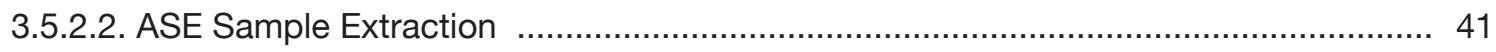

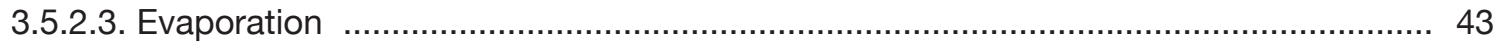

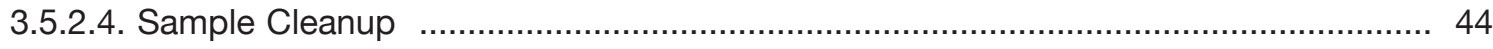

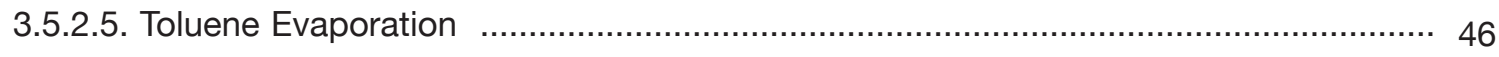

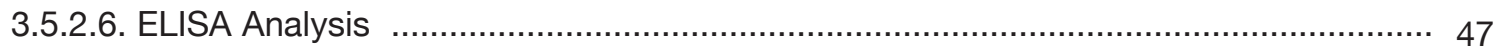

CHAPTER FOUR

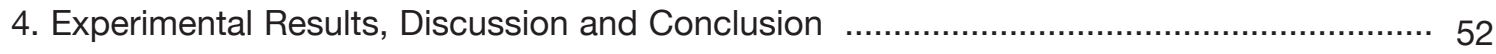

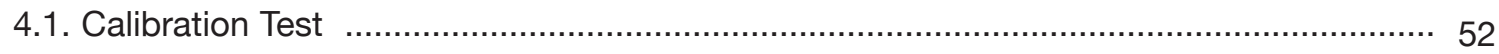

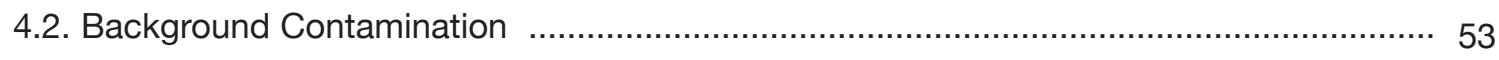

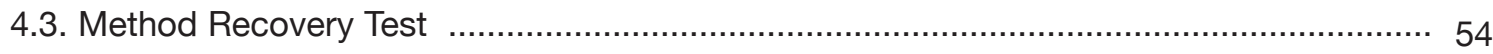

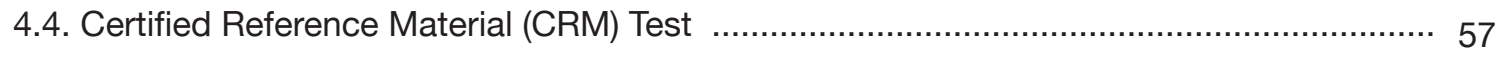

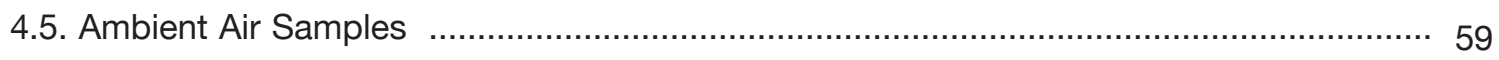




\section{CHAPTER FIVE}

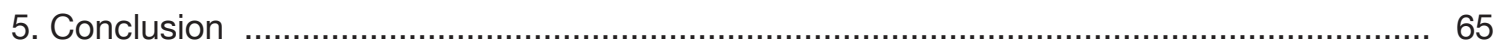

\section{CHAPTER SIX}

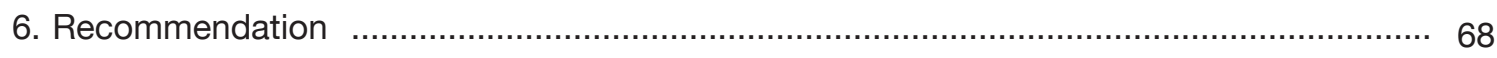

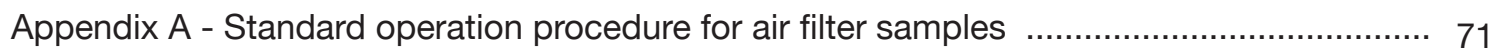

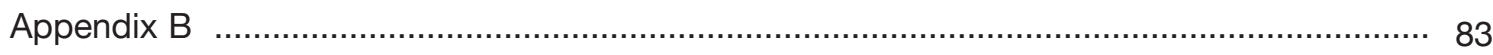

Table B1. TEQ \& expected BEQ calculation for CRM …............................................. 83

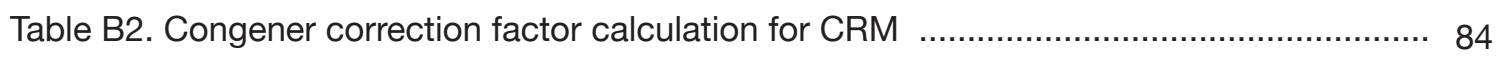

Table B3. Congener profile for $n=5$ air samples and W9 congener contribution in BEQ $\ldots . \ldots . . . \quad 85$

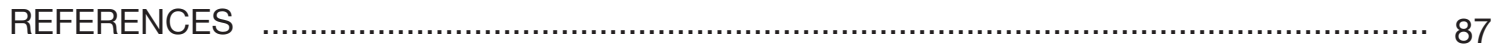




\section{LIST OF TABLES}

Table 1. The 1989 NATO derived I-TEF values

Table 2. WHO94, WHO98 and WHO05 TEF values

Table 3. Cross reactivity for 27 dioxin and furan congeners and 5 dioxin-like PCBs

Table 4. Dioxin source-Specific Correction Factor

Table 5. ELISA results for background contamination test with $n=7$ samples

Table 6. ASE method recovery results for twelve spike samples

Table 7. ASE method recovery results for seven spike samples after extended toluene evaporation

Table 8. Ambient air samples analysis results of ELISA and GC-HRMS 


\section{LIST OF FIGURES}

Figure 1. General chemical structure of dioxins (left) and furans (right)

Figure 2. PCDD/PCDF annual fluxes into air (g-ITEQ); reference year 1995.

Figure 3. Dioxin releases profile by media

Figure 4. Downward trend in dioxin releases from pulp \& paper boilers

Figure 5. Downward trend in dioxin releases from incineration

Figure 6. Downward trend in dioxin releases from electric arc furnaces

Figure 7. Dioxin releases to air from priority sources comparison for years 1990 and 2013

Figure 8. Dioxin-antibody key and lock concept

Figure 9. Schematic Diagram of DF1 Dioxin/Furan Immunoassay Protocol

Figure 10. Canadian Centre for Inland Waters

Figure 11. Air samplers Ocean King (left) PS1 (right)

Figure 12. Ambient air sampling procedure flow chart

Figure 13. Calibration schematic for high volume samplers (Ocean King \& Queen)

Figure 14. Pump calibration curve for Ocean King

Figure 15. ASE extraction flow chart

Figure 16. Acetone evaporation flow chart

Figure 17. Acid silica carbon-mini-column kit

Figure 18. Acid silica carbon column cleanup flow chart

Figure 10. Toluene evaporation flow chart 
Figure 20. ELISA analysis flow chart part 1

Figure 21. ELISA analysis flow chart part 2

Figure 22. Correlation between expected and observed values for calibration standards

Figure 23. ELISA results for the seven blank samples and average with error bar

Figure 24. ELISA results for the twelve spike recovery test samples and average with error bar

Figure 25. ELISA results for the seven spike recovery test with extended toluene evaporation and average with error bar

Figure 26. Comparison between ELISA results for duplicate CRM samples and GC-HRMS calculated TEQ without correcting for congener profile

Figure 27. Comparison between ELISA results for duplicate CRM samples and GC-HRMS calculated TEQ after correcting for congener profile

Figure 28. Correlation between ELISA and GC-HRMS results for $n=7$ sample set

Figure 29. Bagplot (Bivariate Boxplot) for outlier testing

Figure 30. Dioxins and furans mass distribution in five field samples

Figure 31. Comparison of ELISA results with temperature fluctuations

Figure 32. Bland \& Altman ELISA GC-HRMS mean-difference chart 
CHAPTER ONE 


\section{DIOXINS AND FURANS: PROPERTIES, TOXICITIES, AND INVENTORIES}

\subsection{Overview}

Polychlorinated dibenzo-p-dioxins (PCDDs) and Polychlorinated dibenzofurans (PCDFs) are a group of more than 200 similarly structured chemical compounds, often known collectively as dioxins (CEC, 2014). They are persistent, toxicologically significant trace organic contaminants that enter the environment in ultra-trace amounts from various combustion sources and as chemical impurities in a range of manufactured organochlorine products (Hutzinger et al., 1985; Rappe, 1992; Hagenmaier et al., 1994; Ballschmiter and Bacher, 1996 as cited in Lohman et al., 1998). Dioxins are persistent, bioaccumulative and toxic to both humans and wildlife (Mandal, 2005; Pesatori et al., 2002; Pelclova et al., 2002; Environment Canada, 1990). They exhibit biological effects commonly associated with chlorinated organic chemicals. Dioxins exposures are associated with an increased risk of severe skin lesions, altered liver function and lipid metabolism, general weakness associated with drastic weight loss, changes in activity of various liver enzymes, depression of the immune system, and endocrine and nervous system abnormalities (UNEP, 1999). Many of these effects have been observed in fish, bird and mammal studies at body burdens that approach levels present in the background human population (Martinez et al., 2003; Birnbuan and Tuomisto, 2000). Due to the toxicity effect and potential for long-range transport their creation and emission into environment are subject to monitoring and control. In May 2001, over 100 countries signed the Stockholm Convention on persistent organic pollutants (POPs), in which PCDDs, PCDFs and polychlorinated biphenyl ether (PCBs) are designated as three of the "dirty dozen" POPs singled out for global action and virtual elimination (CEC, 2014). 


\subsection{Physical and Chemical Properties}

PCDDs and PCDFs are a group of planar, tricyclic ethers, which have up to eight chlorine atoms attached at carbon atoms 1 to 4 and 6 to 9 (Fiedler, 2003)

Figure 1. General chemical structure of dioxins (left) and furans (right)

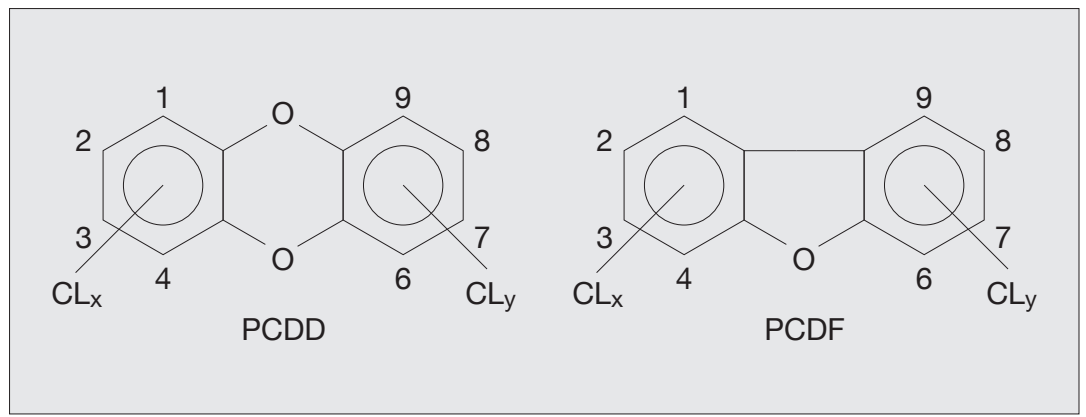

Depending on the number of chlorine atoms and where they are attached to carbon they can form 75 dioxin congeners and 135 furan congeners. Only 7 of the PCDDs and 10 of PCDFs exhibit toxicity. Among these 17 toxic congeners 2,3,7,8-TCDD has the highest toxicity. The physico-chemical properties differ widely between homologue groups and congeners and are still quite uncertain (Mackay et al., 1991) due to the difficulties in their determination (Lohman et al., 1998). In general they have extremely low solubility in water ranging from $419 \mathrm{ngL}^{-1}$ for 2,3,7,8 TCDF and $19.3 \mathrm{ngL}^{-1}$ for 2,3,7,8 TCDD to $0.074 \mathrm{ngL}^{-1}$. They tend to dissolve into oils, fats, non-polar organic solvents and organic carbon in soil. Octanol-water coefficient (Kow) is a predictor for the partitioning between lipid phases in the environment and water. It is the ratio of the solubility of a compound in octanol (a non-polar solvent) to its solubility in water (a polar solvent). Chemicals with high Kow are lipophilic and have tendency to accumulate in the food chain. Organic carbon-water partitioning coefficient $(\mathrm{Koc})$ is an indicator for the partitioning between organic carbon and water. Koc is the ratio of the mass of a chemical that is adsorbed in the soil per unit mass of organic carbon in the soil per the equilibrium chemical concentration in solution. Koc indicates the mobility of chemical in soil and shows where a chemical is likely to end up. Kow, Koc and octanol-air partitioning coefficient are used to predict the distribution of a chemical between water, soil and sediment, air and living organisms ("Partitioning coefficients and distribution models", no date; "Notes on chemical", no date). Dioxins have high Kow and they have high octanol-water coefficients (Kow) and therefore have high affinity to absorb to organic/fatty matrices, log Kow ranges from 5.6 for CI4DF and 6.1/7.1 for CI4DD to 8.2 for Cl8DD (Fiedler, 2003). They have large organic carbon water partition coefficient (Koc). Log Koc 
for 2,3,7,8 TCDD varies between 6.4 and 7.6 and consequently in environmental systems will partition strongly to soil and sediments as opposed to readily entering the aqueous phase (Lohman et al., 1998). Their octanol-air partition coefficients (Koa) vary over several orders of magnitude from the mono-CDD/ Fs (Koa 7-8) to octa-CDD/Fs (Koa 11-12), which influences the gas- particle partitioning of dioxins in the atmosphere under ambient conditions (Lohman et al., 1998). Combination of these properties plays an important role in dioxins transport and fate in the environment and toxicological effects on living organisms.

\subsection{Release, Transport and Fate}

Dioxins are ubiquitous pollutants and once released to the environment become distributed between different environmental compartments. According to the earth pollutant terminology, they are next to the nuclear catastrophes (Kulkarni et al., 2007). The largest release of dioxins is open burning of household waste, municipal waste, medical waste, landfill fires, agricultural and forest fires (Dyke et al., 1997). They can also form as by-products from the manufacture of chlorinated compounds such as chlorinated phenols, PCBs, phenoxy herbicides, chlorinated benzene, chlorinated aliphatic compounds, chlorinated catalysts and halogenated phenolic ethers (Oberg et al., 1992, 1993; Sidhu and Edwards, 2002). National Pollution Release Inventory has categorized smelting of aluminum and lead, the operation of electric arc furnaces, the combustion of fuel in the pulp and paper as some specific industries that release dioxins as a by-product (NPRI, 2003).

Dioxins released into atmosphere quickly partition into gas and particle phase. Half-lives in atmosphere vary from hours to days. Tysklind et al., 1993 states that tetra or higher chlorinated congeners, which are extremely stable, can undergo photodegradation if only they are not adsorbed on particulate matters. However, due to their high octanol-air coefficient and plane chemical structure they exhibit higher tendency to adsorb to particles. Kaupp et al., 1994 and Kurokawa et al., 1996 report that approximately $90 \%$ of dioxins adsorb onto the particles with aerodynamic diameters less than $1.35 \mu \mathrm{m}$. Fieldler, 2003 notes that particle phase dioxins are subject to long range transport over $100 \mathrm{~km}$. A study conducted by Kaupp \& McLanchlan, 2000 reports the typical moving speed of dioxins to be $480 \mathrm{~km} /$ day. Depending 
on ambient condition and particle size, dioxins will ultimately deposit on soil and water bodies in varying distances from the source. A study commissioned by the North American Commission for Environmental Cooperation (NACEC) and conducted by the Center for the Biology of Natural Systems (CBNS) in September 2000 reports that the elevated concentration of dioxin in Nunavut is due to deposition of dioxins transported from distant sources and are estimated to be $2-20 \%$ of the total dioxin deposition in Nunavut. Dioxins on soil strongly attach to soil particles and exhibit a low potential for leaching (McLachlan et al., 1996) or volatilization (US EPA 1994). Dioxins in soil-air interface may undergo photodegradation. The half-life for 2,3,7,8-TCDD on surface soil is estimated to range from 9-15 years (ATSDR, 1998). However, extremely gradual degradation may occur into less toxic congener in the soil (Watterson, 1999). The half-life for 2,3,7,8-TCDD in subsurface soil may range from 25-100 years (ATSDR, 1998). Miller et al. 1989 and Tysklind et al. 1992 note that dechlorination in soil results in an increase in the concentration of 2,3,7,8-substituted congeners, which may result in increased toxicity. Dioxins from soil may transport into water through soil run-off and quickly partition into organic matter and so accumulate in sediments (Watterson, 1999). As such the ultimate destination and sink for dioxins are soil and sediments (Environment Canada, 1999) with half-lives reported of greater than 10 years (CCME, 2007; Mukerjee, 1998).

\subsection{Human Exposure}

Dioxins and similar compounds are usually released in relatively low concentrations such as parts per trillion (ppt) or parts per quadrillion (ppq), but because they are very persistent they remain in the environment and can accumulate in the tissues of animals (ATSDR, 1998). Kulkarni et al., 2007 reports humans primary exposure through foods that are contaminated with dioxins as a result of the accumulation of these substances in the food chain and in high-fat foods, such as, dairy products, eggs, animal fats, and some fish. US EPA report (1994) indicates that consumption of meat, fish, and dairy is the primary pathway of human exposure. Commoner et al., 2000 report dioxins are taken up by animal food crops and hence appear in milk and meat, which in US account for two thirds of the diet-mediated exposure. The authors also note that dioxins enter the major terrestrial food chain, caribou, chiefly through lichen, mosses and shrubs; and in marine food chain, seal and walrus, through algea. A few studies confirm the bioac- 
cumulation and bioconcentration of dioxins in terrestrial organisms by measuring of bioaccumulation and bioconcentration factors (BAFs, BCFs respectively). Bioconcentration is the intake and retention of a substance in an organism entirely by respiration from water in aquatic ecosystems or from air in terrestrial ones, whereas bioaccumulation is the intake of a chemical and its concentration in the organism by all possible means, including contact, respiration and ingestion (Alexander, 1999). Scroll and Scheunert, 1993 report BCFs for carrots to be 0.07 to 0.99 . Other studies report the BAFs of $65-80$ for TCDD in earthworms (Nash et al., 1980). A few studies report BAFs of less than 0.1 to 12 for rats, cattle and monkeys (Kobica et al., 1978; Kenaga, 1980; Jensen et al., 1981; Bowman et al., 1985; Geyer et al., 1986; Parker et al., 1980; Fierstone et al., 1979 as cited in CCME 2002). Fiedler, 2003 notes that 30-40\% of 2,3,7,8 TCDD, 1,2,3,7,8 PeCIDD and 2,3,4,7,8 PeCIDF are transferred from feed to cow's milk. MacConnel and Healy, 2008 report bioconcentration of dioxins in pigs to 80-200 times safe level through consumption of contaminated pig feed. A study performed in Japan by Suzuki et al., 2005 reports that dioxins do transfer to fetuses and infants through maternal blood and breast milk. The authors link the accumulation of dioxins in maternal blood to seafood; the congener profiles of seafood were similar to those of maternal blood. Baccarelli et al., 2002 includes some industrial accidents as human exposure pathway. The first case of dioxins exposure in humans was reported in 1949 after a Monsanto Company plant manufacturing trichlorophenol (TCP) reactor exploded in Nitro, West Virginia, USA (Sweeney and Mocarelli, 2000). In 1979 another explosion occurred in a chemical plant producing 2,4,5-tricholorophenol in Seveso, Italy (Bertazzi et al., 1997). One hundred and twenty-one workers developed chlorance immediately after the incident (Lee, 2007). In early 1970s dioxin contaminated oil was sprayed on soil for dust control in Times beach. Studies on individual residents showed a significant depression in cell-mediated immunity (Kimbrough et al., 1977). Between 1962 and 1971 nearly 19 million gallons of Agent Orange, defoliant contaminated with dioxins, was sprayed across southern Vietnam (Schecter et al., 2006); in 1971, three scientists from Harvard University tested fish from Dong Nai and Sigon Rivers and Can Gio coastal waters and found elevated levels of dioxins ranging from 18-184 ppt. The same study on human breast milk revealed levels of dioxins as high as 1850 ppt (Agent Orange Record, 2010).

Hatfield report (2009) indicates that dioxins move from soil into Sen Lake, and ultimately into humans via ingestion of contaminated fish, direct dermal contact with soils and sediments, and likely via inhalation 
of dust, and is directly linked to historical Agent Orange use on the Da Nang Airport. The same study reports the maximum toxic equivalency in Tilapia fat from Sen Lake in 2009 is more than 400 times the acceptable level established by Health Canada.

\subsection{Mode of Mechanism and Toxicological Effects}

\subsubsection{Toxicological effects}

Dioxins provoke an extraordinary broad spectrum of toxic effects in vertebrate laboratory animals. Exposure to a few micrograms per kg body weight of the most potent congener, 2,3,7,8-TCDD, leads to (among numerous effects) loss of body weight, liver necrosis, immune impairment, reproductive toxicity, teratogenesis and cancer in many laboratory species (Poland \& Knutson,1982; Pohjanvirta \& tuomisto, 1994; Okey et al., 1994; Birnbaum \& Tuomisto, 2000). The liver is a dioxin target organ in many species

(McConnet \& Moore, 1979). Turner et al., 1984 report that an increase in liver size can occur at relatively low doses, reflecting not only enzyme induction but also changes in lipid content. Couture et al., 1990 state that TCDD is a developmental toxin in all species examined and induces major structural abnormalities only in the mouse. Dioxins also affect the immune system, Holsapple et al., 1991 report that dioxin is highly immunotoxic in the mouse and one of the most sensitive responses is the suppression of the primary antibody response. Huff et al., report that dioxin is positive carcinogen in the rat, mouse, and hamster.

Human exposure to dioxins can cause sever skin disorder known as chlorance, reproductive disorders, developmental toxicity, insulin insensitivity and cancer (Geusau, 2001, Yu et al., 2000; Rogan et al., 1988; Kern et al., 2004; Fiedler, 2003). There is a controversy and uncertainty regarding dioxins carcinogenicity, however, there is an agreement that specifically 2,3,7,8-TCDD congener is a human carcinogen (ATSDR, 1998; US EPA, 2000c).

\subsubsection{Mechanism}

There has always been a question that how dioxin causes its biological effect. There is a general agreement that all the effects of TCDD are mediated through the action of a cellular protein known as 
the aryl hydrocarbon receptor (AhR) (Birnbuam, 1994). The precise chain of molecular events by which the ligand-activated receptor elicits these effects is not yet fully understood. However, alteration in key biochemical and cellular functions are expected to form the basis for dioxin toxicity (WHO, 1998). AhR is a transcription factor, which is involved in expression of many genes. TCDD binds to Ah and produces ligand-complex, which interacts with dioxin-response elements (Whitlock, 1990) and induces a class of xenobiotic metabolizing enzymes (Heiden et al., 2012) that can metabolize aromatic hydrocarbons (Qin, 2006). Enzymes include cytochrome P450 CYP1A1, CYP1A2, and CYP1B1, and phase II enzymes GST-A1 and UGT-06 (Schmidt and Bradfield, 1996; Whitlock. 1999). Stansbury et al., 1994 report that adaptation response to aromatic hydrocarbons could be damaging, because the intermediate metabolites can mutate DNA and therefore are carcinogenic. Hahn and Stegeman, 1994 state that specifically induction of cytochrome P450 1A1 (CYP1A1) responses to Ah activation play an important role in TCDD toxicity. Heiden et al, 2012 note that since dioxins are poorly metabolized, the induction of CYP1A1 might result in toxicity through the generation of reactive oxygen species or modulation of normal signaling cascades. Briefly, the inappropriate modulation of gene expression represents the initial steps in a series of biochemical, cellular and tissue changes that result in the toxicity observed (Mandal, 2005).

Dioxin congeners exhibit different magnitude of affinity to bind to Ah receptor hence, induce different magnitude of toxicity. Since dioxins are found in the environment in mixtures. Thus organisms respond to the cumulative exposure of Ah receptor-mediated chemicals, rather than exposure to any single dioxinlike compound (CCME. 2002). Therefore, to express the overall toxicity the concept of toxic equivalence has been developed.

\subsubsection{Toxic Equivalency (TEQ) and Toxic Equivalency Factors (TEFs)}

The toxicity of mixture dioxins is expressed as toxicity equivalent quantities, which is the cumulative toxicity exhibited by constituent congeners. TEQ has been built based on the assumption that all congeners mediate the aryl hydrocarbon through a common mechanism to cause toxicity and that the effects are additive (Boening, 1998; Kerkvliet, 2002). There is experimental evidence to support the assumption of additivity (Viluksela et al., 1998; Walker et al., 2005). However, principles of receptor 
pharmacology predict that compounds competing for the same receptor site may antagonize each other and thus the overall toxicity exhibited is less than that predicted by additive model. In other hand, it is possible that congeners might synergize and exhibit overall toxicity that is greater than that predicted by additive model (Reiner et al., 2006). Several studies has found antagonism between chemicals that act at the Ah receptor sites (Safe, 1998; Van Birgelen et al., 1994; Haag-Gronlunde et al., 1998), but evidence for dioxin-like chemicals are limited (Toyoshiba et al., 2004).

Development of the TEF concept was based on the results of structure activity relationships and bioassays, which suggested that the effects of congeners in the mixture were related to the potency and concentrations of the individual congeners in the mixture (Safe, 1990). In this approach, 2,3,7,8-TCDD, the most potent congener, has been assigned a TEF of 1.0, and all other congeners are assigned TEFs that reflect their potency relative to that of TCDD. This model is applied only to agents that are dioxinlike, meaning that they mediate the AhR through the same mechanisms (Reiner et al., 2006). Only 7 of PCDDs, 10 of PCDFs (all chlorinated in at least the 2,3,7,8 position) and 12 coplanar-polychlorinated biphenyls (PCBs) exhibit dioxin-like toxicity. PCBs are less potent than TCDD but they are usually found in higher concentrations in the environment, as such their relative contribution to the total TEQ is considerable. The toxicity of the mixture is calculated by summing up the concentration of individual congeners multiplied by their potencies (TEF) (Safe, 1997):

$\mathrm{TEQ}=\Sigma[\mathrm{PCDDi} \times \mathrm{TEFi}]+\Sigma[\mathrm{PCDFi} \times \mathrm{TEFi}]+\Sigma[\mathrm{PCBi} \times \mathrm{TEFi}] \quad$ (Eq. 1)

TEF approach was first proposed by Ontario Ministry of the Environment in 1984 (Haws et al., 2006), and later developed by North Atlantic Treaty Organization (NATO) , adapted internationally and termed InternationalTEFs (I-TEFs) (Kulkarni et al., 2007). The I-TEF unified at least ten slightly different schemes throughout the world to simplify the communication among scientists and regulatory agencies concerning toxicological significance of complex mixtures of dioxins, furans and PCBs. TEF values are developed primarily based on long-term whole animal studies and when insufficient, whole animal short-term studies, subchronic effects data and acute toxicity studies were considered. Data from in vivo and in vitro enzyme induction were also used to confirm the values determined by the in vivo toxicological data (Kutz, et al., 1990). The I-TEF values developed by NATO are given in the Table 1. 
Table 1. The 1989 NATO derived I-TEF values

\begin{tabular}{|l|l|l|l|}
\hline PCDD Congener & I-TEF value & PCDF Congener & I-TEF value \\
\hline $2,3,7,8-$ TCDD & 1 & $2,3,7,8-$ TCDF & 0.1 \\
\hline $1,2,3,7,8-\mathrm{PeCDD}$ & 0.5 & $2,3,4,7,8-\mathrm{PeCDF}$ & 0.5 \\
\hline & & $1,2,3,7,8-\mathrm{PeCDF}$ & 0.05 \\
\hline $1,2,3,4,7,8-\mathrm{HxCDD}$ & 0.1 & $1,2,3,4,7,8-\mathrm{HxCDF}$ & 0.1 \\
\hline $1,2,3,7,8,9-\mathrm{HxCDD}$ & 0.1 & $1,2,3,7,8,9-\mathrm{HxCDF}$ & 0.1 \\
\hline $1,2,3,6,7,8-\mathrm{HxCDD}$ & 0.1 & $1,2,3,6,7,8-\mathrm{HxCDF}$ & 0.1 \\
\hline & & $2,3,4,6,7,8-\mathrm{HxCDF}$ & 0.1 \\
\hline $1,2,3,4,6,7,8-\mathrm{HpCDD}$ & 0.01 & $1,2,3,4,6,7,8-\mathrm{HpCDF}$ & 0.01 \\
\hline & & $1,2,3,4,7,8,9-\mathrm{HpCDF}$ & 0.01 \\
\hline OCDD & 0.001 & OCDF & 0.001 \\
\hline
\end{tabular}

Source: Kutz et al., 1990

In 1994, World Health Organization (WHO) completed I-TEFs values by introducing TEFs for dioxinlike PCBs and reviewed and revised TEFs values twice in 1998 and 2005. The modified TEFs were recommended for use with mammals and humans, and separate TEFs were developed for birds and fish. Health Canada has adapted revised WHO TEF scheme for managing human health risks posed by dioxins in food, water, air and consumer products (Van den Berg, 1998). The TEF values revised by WHO are given in the Table 2.

Table 2. WHO94, WHO98 and WHO05 TEF values

\begin{tabular}{|c|c|c|c|}
\hline \multicolumn{1}{|c|}{ Congener } & WHO94 TEF & WHO98 TEF \\
\hline \multicolumn{2}{|c|}{ Dioxins } \\
\hline $2,3,7,8-$ TCDD & 1 & 1 & 1 \\
\hline $1,2,3,7,8-P e C D D$ & 0.5 & 0.1 & 0.1 \\
\hline $1,2,3,4,7,8-H x C D D$ & 0.1 & 0.1 & 0.1 \\
\hline $1,2,3,6,7,8-H x C D D$ & 0.1 & 0.1 & 0.1 \\
\hline $1,2,3,7,8,9-H x C D D$ & 0.1 & 0.01 & 0.01 \\
\hline $1,2,3,4,6,7,8-H p C D D$ & 0.01 & 0.0001 & 0.0001 \\
\hline OCDD & 0.001 & & 1 \\
\hline
\end{tabular}




\begin{tabular}{|c|c|c|c|}
\hline \multicolumn{4}{|c|}{ Furans } \\
\hline $2,3,7,8-T C D F$ & 0.1 & 0.1 & 0.1 \\
\hline 1,2,3,7,8-PeCDF & 0.05 & 0.05 & 0.03 \\
\hline $2,3,4,7,8-\mathrm{PeCDF}$ & 0.5 & 0.5 & 0.3 \\
\hline $1,2,3,4,7,8-\mathrm{HxCDF}$ & 0.1 & 0.1 & 0.1 \\
\hline $1,2,3,6,7,8-\mathrm{HxCDF}$ & 0.1 & 0.1 & 0.1 \\
\hline $1,2,3,7,8,9-\mathrm{HxCDF}$ & 0.1 & 0.1 & 0.1 \\
\hline $2,3,4,6,7,8-\mathrm{HxCDF}$ & 0.1 & 0.1 & 0.1 \\
\hline 1,2,3,4,6,7,8-HpCDF & 0.01 & 0.01 & 0.01 \\
\hline 1,2,3,4,7,8,9-HpCDF & 0.01 & 0.01 & 0.01 \\
\hline OCDF & 0.001 & 0.0001 & 0.0003 \\
\hline \multicolumn{4}{|c|}{ Dioxin-like PCBs } \\
\hline 3,3',4,4'-ТeCB & 0.0005 & 0.0001 & 0.0001 \\
\hline $3,4,4^{\prime}, 5$-ТCВ & & 0.0001 & 0.0003 \\
\hline $2,3,3^{\prime}, 4,4^{\prime}-\mathrm{PeCB}$ & 0.0001 & 0.0001 & 0.00003 \\
\hline $2,3,4,4^{\prime}, 5-\mathrm{PeCB}$ & 0.0005 & 0.0005 & 0.00003 \\
\hline $2,3^{\prime}, 4,4^{\prime}, 5-\mathrm{PeCB}$ & 0.0001 & 0.0001 & 0.00003 \\
\hline $2^{\prime}, 3,4,4^{\prime}, 5-\mathrm{PeCB}$ & 0.0001 & 0.0001 & 0.00003 \\
\hline 3,3',4,4',5-PeCB & 0.1 & 0.1 & 0.1 \\
\hline $2,3,3^{\prime}, 4,4^{\prime}, 5-\mathrm{HxCB}$ & 0.0005 & 0.0005 & 0.00003 \\
\hline $2,3,3^{\prime}, 4,4^{\prime}, 5^{\prime}-\mathrm{H} \times \mathrm{CB}$ & 0.0005 & 0.0005 & 0.00003 \\
\hline $2,3^{\prime}, 4,4^{\prime}, 5,5^{\prime}-\mathrm{H} \times \mathrm{CB}$ & 0.00001 & 0.00001 & 0.00003 \\
\hline $3,3^{\prime}, 4,4^{\prime}, 5,5^{\prime}-\mathrm{H} \times \mathrm{CB}$ & 0.01 & 0.01 & 0.03 \\
\hline $2,2^{\prime}, 3,3^{\prime}, 4,4^{\prime}, 5-\mathrm{HpCB}$ & 0.0001 & --- & --- \\
\hline $2,2^{\prime}, 3,4,4^{\prime}, 5,5^{\prime}-\mathrm{HpCB}$ & 0.00001 & --- & --- \\
\hline 2,3,3',4,4',5,5'-НрСВ & 0.0001 & 0.0001 & 0.00003 \\
\hline
\end{tabular}

Source: Chandler, 2006

Van den Berget al., 2005

\subsection{Dioxins Emission Inventories and Approaches for Elimination}

\subsubsection{Overview}

Dioxins are toxic, persistent, bioaccumulative, and result predominantly from human activities.

Due to their extraordinary environmental persistence and capacity to accumulate in biological tissues, dioxins have been designated as Track 1 substances, and are targeted for virtual elimination under 
the Stockholm Convention on Persistent Organic Pollutants (POPs). Virtual elimination means to reduce the emission of toxin down to the lowest level of quantification (LLOQ) (CEPA 1999). LLOQ is the lowest level that can be measured by routine analysis, which is $32 \mathrm{pgTEQ} / \mathrm{m}^{3}$ for air and 9pgTEQ/g for soil (CCME, 2004). The Stockholm legally binding treaty requests Parties to reduce and where feasible eliminate the releases of dioxins (UNEP, 2005). This task is feasible only if the sources of dioxins are identified and quantified. Therefore starting early 1990 s a few countries, mostly industrialized, initiated national emission inventories and subsequently enforced measures of pollution controls.

\subsubsection{Dioxin Global Inventories}

The global releases of dioxins into the atmosphere are approximated based on insufficient data provided by a few countries' national inventories. In 1999, UNEP issued a report on dioxins global releases into the air based on available data from some European countries, Canada, US and Japan from known sources. The report estimated an average dioxin releases to be $10500 \mathrm{~g} \mathrm{I-TEQ/a} \mathrm{for} \mathrm{the} \mathrm{year} 1995$ with the lower and upper estimates of 8300 and $36000 \mathrm{~g}$ I-TEQ respectively. In 1993, The European Commission initiated a project on dioxins and furans called "The European Dioxin Project". The objective of the project was to identify dioxins' relevant industrial sources and to evaluate abatement technologies. Stage one of the project provided emissions inventory from 17 European countries. European Commission estimated $5800 \mathrm{~g} \mathrm{I-TEQ/a} \mathrm{dioxins} \mathrm{to} \mathrm{be} \mathrm{emitted} \mathrm{into} \mathrm{the} \mathrm{air} \mathrm{from} 17$ European countries. However, The Netherlands Organization for Applied Scientific Research (TNO) reported a lower value of $1300 \mathrm{~g}$ I-TEQ. Another study conducted by Brzuzy and Hites, 1996 estimated the global dioxins releases to be $50000 \mathrm{~g} \mathrm{I-TEQ.} \mathrm{The}$ estimation of global releases of dioxins has remained uncertain mainly because 1) the first estimation was based on very limited source testing that may not be a true representative of untested sources 2) in many cases, estimation was based on extrapolation of data for the same category from another country 3) many industries potential for dioxin releases have never been tested and accounted for release 4) only a few countries have collaborated to provide their national inventory release. Figure 2 illustrates the dioxin global releases from available national inventory data. 


$\begin{array}{rr}\text { A } & \text { Austria } \\ \text { AUS } & \text { Australia } \\ \text { B } & \text { Belgium } \\ \text { CH } & \text { Switzerland } \\ \text { CAN } & \text { Canada } \\ \text { D } & \text { Germany } \\ \text { DK } & \text { Denmark } \\ \text { F } & \text { France } \\ \text { HUN } & \text { Hungary } \\ \text { JPN } & \text { Japan } \\ \text { NL } & \text { The Netherlands } \\ \text { S } & \text { Sweden } \\ \text { SR } & \text { Slovak Republic } \\ \text { UK } & \text { United Kingdom } \\ \text { USA } & \text { United States }\end{array}$

Figure 2. PCDD/PCDF annual fluxes into air (g I-TEQ/a); reference year 1995. Total emissions from known sources $=10,500 \mathrm{~g} \mathrm{I}-$ TEQ/a (Source: UNEP

(1999

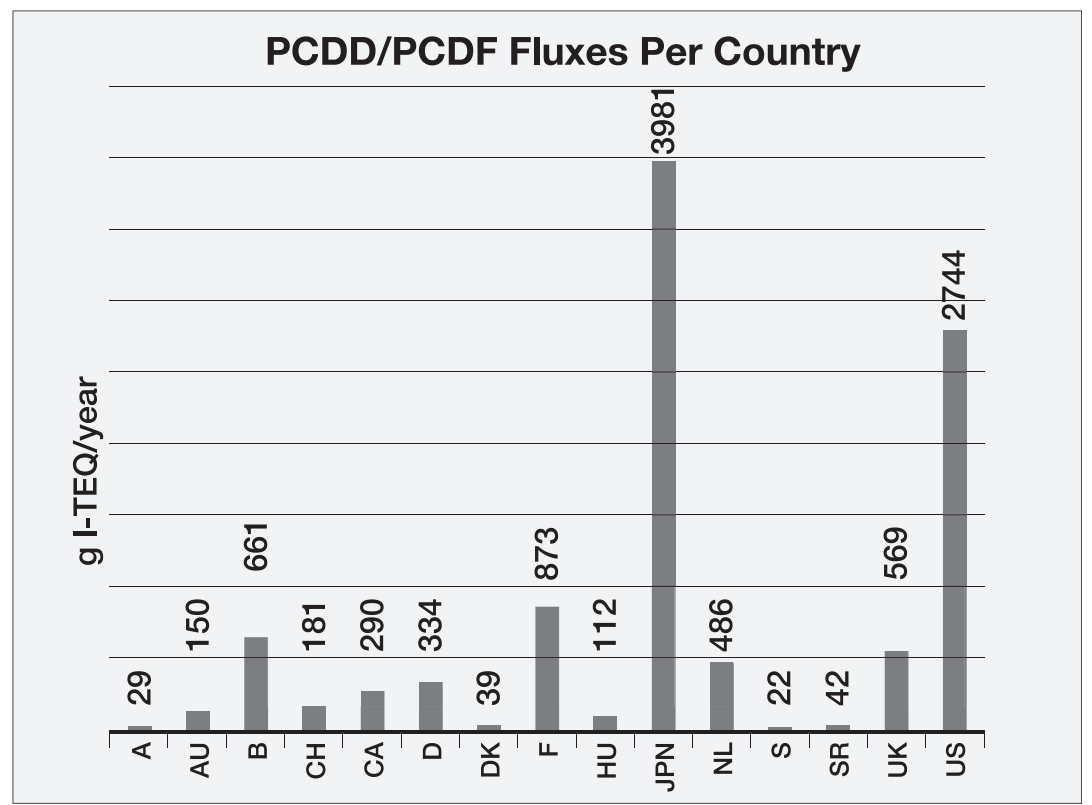

\subsubsection{Canadian Inventory}

Canada was the very first country that attempted to estimate the overall emissions of dioxins from known sources (Sheffield, 1985). A mandate was given to Federal/Provincial Task Force on Dioxins and Furans to develop an inventory of sources releasing dioxins and furans listed emissions from over 20 sectors by province and territory with focus on atmospheric releases (CCME, 2001). Attention was paid mostly to atmospheric releases mainly because atmosphere is the predominant dioxins entry to environment and also because the major concentration of dioxins is distributed in air. Figure 3 illustrates the dioxins distribution in three main environmental vectors.

Figure 3. Dioxins releases profile by media

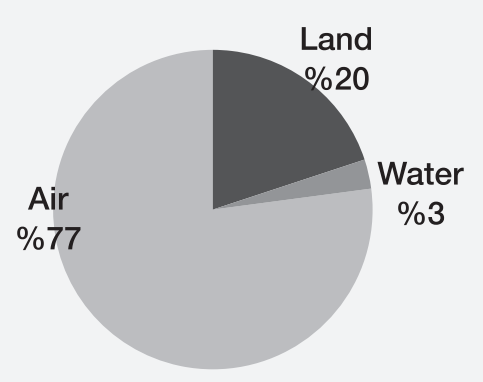

-2007Total Release 96glTEQ/yr 
Following the mandate, facilities releasing dioxins to environment are required under the Canadian Environmental Protection Act, 1999 to estimate and report their atmospheric dioxins release to Environment Canada's National Pollutant Release Inventory (NPRI) annually. The purpose of the inventory report was to identify priority sectors for the development of prevention or reduction measures with the final goal of "virtual elimination" of dioxins. Canada Wide Standards (CWS) were then developed under Canadian Council of Ministers of the Environment (CCME) in order to assist industries with pollution prevention and control strategies and to set the technologically and economically achievable targets for reduction and the ultimate goal of virtual elimination.

Based on NPRI inventory data, CWS has identified and reported six priority sectors, accounting for about $80 \%$ of national emissions including coastal pulp and paper mill boilers burning salt laden wood in British Columbia, waste incineration (municipal solid waste, hazardous waste, sewage sludge and medical waste), electric arc furnace steel manufacturing, iron sintering plants, conical municipal waste combustion in Newfoundland, and residential wood combustions.

The CWS has set out numerical target for priority sources to reduce dioxins releases in a specific timeframe with the final goal of elimination. The focus was first on primary measures, steps that prevent dioxins from formation. However, due to the nature of some processes and industries dioxin formation is inevitable. Therefore, secondary measures are required to remove dioxins from entering the environment to comply with regulatory requirements.

\subsubsection{Pulp and paper boilers burning salt laden wood}

Dioxins from this sector are emitted through the burning of salt contaminated hogged fuel. Logs stored in salt water absorb the chlorine into the bark; the bark is then stripped from the log and grounded to produce hogged fuel. This chlorine contaminated fuel is used in boilers to produce heat and electricity and results in dioxins formation.

British Colombia pulp and paper boilers contributed to annual release of $8.6 \mathrm{gTEQ} / \mathrm{yr}$ (4.3\% of total annual national release as of 2001) into atmosphere. Releases to water were reduced by $99 \%$ to below 
the measurable concentration level by 1997 and no additional work was recommended (UNEP, 1999). The target for atmospheric release was to reduce emission to less than $100 \mathrm{pg} / \mathrm{m}^{3}$ for new boilers and to less than 500pg $/ \mathrm{m}^{3}$ for existing boilers by 2006. In 2008 all facilities demonstrated test results that were in compliance with the CWS target. However, due to the large variations of individual test results many of the mills had difficulties in ensuring compliance with the CWS. Total emissions from this sector have declined to $1.5 \mathrm{gTEQ} / \mathrm{yr}$ as of 2013 (CCME, 2001; CCME, 2009)

Figure 4. Downward trend in dioxin releases from pulp \& paper boilers

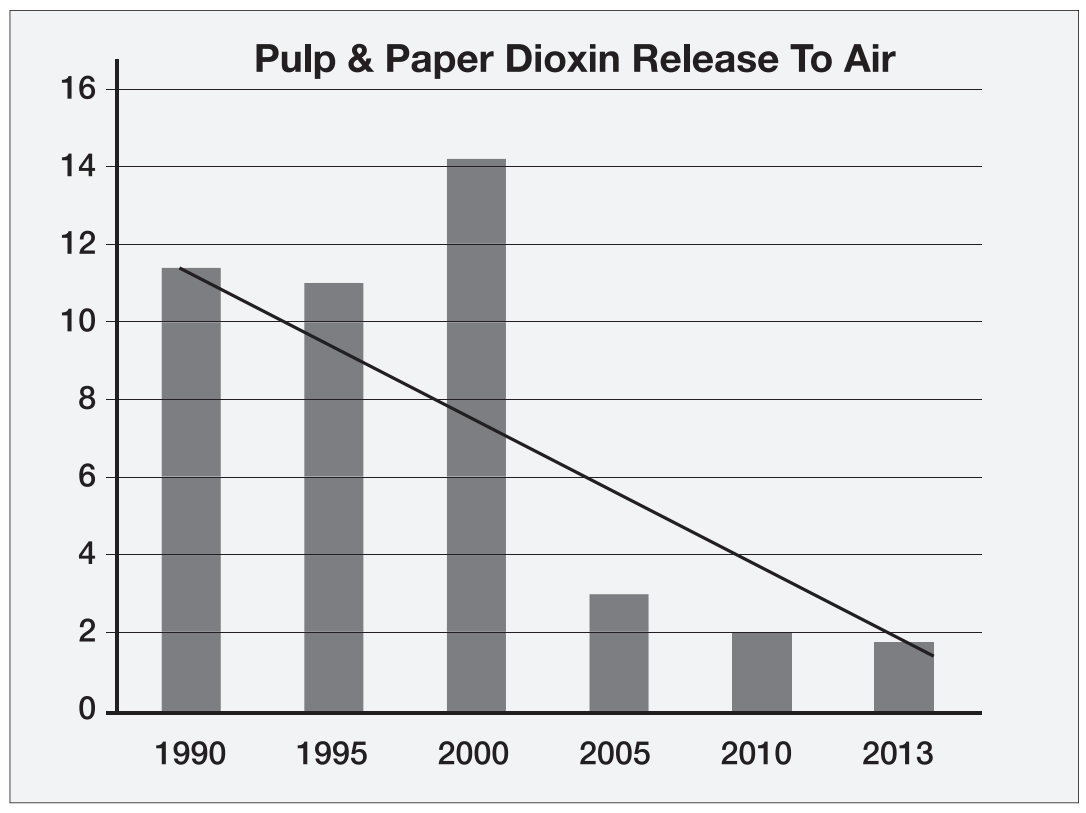

\subsubsection{Waste Incinerations}

Waste incinerator consists of municipal solid waste, medical waste, hazardous waste, and sewage sludge incinerators. Waste incinerators are defined by CWS as facilities used to thermally treat a waste for the purpose of reducing its volume, destroying a hazardous chemical present in the waste, or destroying pathogens present in the waste. This sector has historically been responsible for a significant portion of dioxins worldwide. Emissions from incinerators are the flue gases, the fly ash and the slag (McKay, 2002). Technology advances was successful in reducing the dioxin concentrations in fly ash and slag to LLOQ. The secondary measures were proposed to remove dioxins from the flue gases including adsorption of dioxins on active carbon or coke, the application of selective catalytic reduction using a TiO2-DENOX catalyst, and 
using dry scrubbers with lime and active carbon followed by fabric filters. These technologies are capable

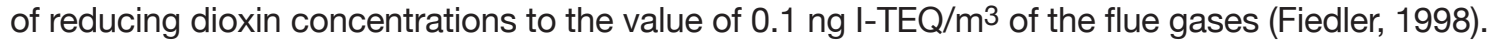

This sector had significant contribution in dioxins releases into atmosphere. The total release was reported $44.9 \mathrm{gTEQ} / \mathrm{yr}$. (22.5\% of total annual national release as of 2001). All incinerators were required to reduce stack emissions to lower than $80 \mathrm{pgTEQ} / \mathrm{m}^{3}$ by 2006 except for sewage sludge incinerator; the target was $100 \mathrm{pgTEQ} / \mathrm{m}^{3}$ to be met by 2005 . All types of incinerators met the target by 2008 except for a single sewage sludge incinerator in Ontario. The facility has collaborated with the Ministry of Environment to develop and implement reduction strategy by 2013 (CCME, 2001; CCME, 2009). No data was found whether the facility has implemented reduction strategy by far. As shown in Figure 5, measures and strategies were successful in reducing dioxins emissions from this source to 3.838gTEQ for the year 2013.

Figure 5. Downward trend in dioxin releases from from incineration

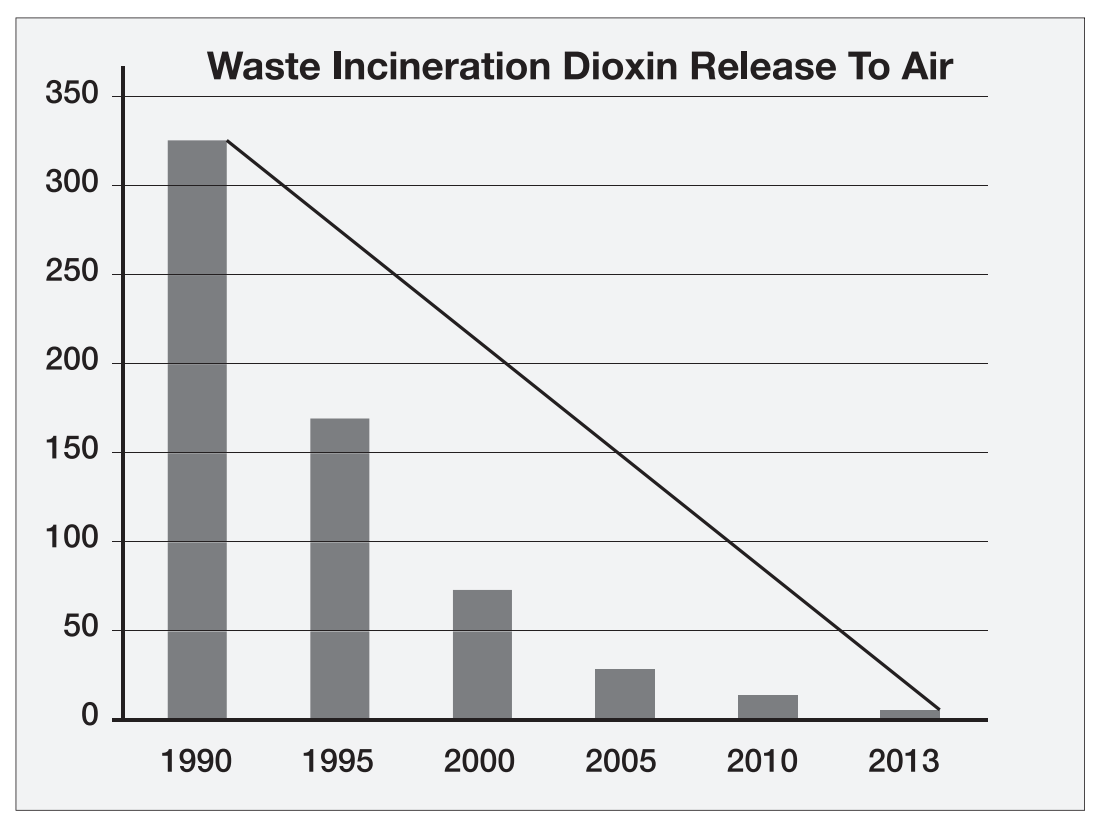

\subsubsection{Conical Waste Combustion}

These facilities are unique to Newfoundland and Labrador and contributed to $44.0 \mathrm{gTEQ} / \mathrm{yr}$ ( $27 \%$ of total annual national emission as of 2001). Due to the design of conical combustors, emission reduction was not feasible. As such, it was proposed to close all existing facilities within Newfoundland and Labrador and impede the operation of new facilities anywhere in Canada (CCME, 2006). In total 58 conical waste 
combustors were identified and as of fall 2009,42 facilities have been shut down resulting in $76.3 \%$ reduction in emission. The remaining 16 facilities were proposed to phase out by 2010 (CCME, 2009).

\subsubsection{Iron Sintering Plants}

Iron sintering plants are associated with the manufacture of iron and steel, often in integrated steel mills. The sintering process is a pre-treatment step in the production of iron, where fine particles of iron ores and in some plants, also secondary iron oxide wastes (collected dusts, mill scale), are agglomerated by combustion. Agglomeration of the fines is necessary to enable the passage of hot gases during the subsequent blast furnace operation (UNEP, 2003). PCDD/PCDF appears to be formed in the iron sintering process via de novo synthesis. The PCDD/PCDF formation mechanism appears to start in the upper regions of the sinter bed shortly after ignition, and then the dioxins/furans and other compounds condense on cooler burden beneath as the sinter layer advances along the sinter strand towards the burn through point. The process of volatilization and condensation continues until the temperature of the cooler burden beneath rises sufficiently to prevent condensation and the PCDD/PCDF exit with the flue gas (Stockholm Convention on POPs draft, 2004).

Iron sintering plants are unique to Ontario and release $6.0 \mathrm{gTEQ} / \mathrm{yr}$ ( $4 \%$ of total national release as of 2001). The target was to reduce emission to less than $1350 \mathrm{pgTEQ} / \mathrm{m}^{3}$ by $2002,500 \mathrm{pgTEQ} / \mathrm{m}^{3}$ by 2005 , and $200 \mathrm{pg} T E Q / \mathrm{m}^{3}$ by 2010 (CCME, 2003). The only sintering plant, Stelco Hamilton, was shut down in 2007 and as of 2009 no plan to restart has been indicated (CCME, 2009).

\subsubsection{Electric Arc Furnaces}

Electric arc furnaces are used for recycling and recovery of steel from contaminated metallic scrap. These scrap are usually contaminated with paints, oils or other organic substances. During the thermal treatment, dioxins are released or produced during waste gas treatment (Werner, 2005). Gas handling systems differ from one facility to another, therefore, resulting in different concentrations of dioxins. The off-gas processing in Canadian facilities produced approximately 44 to $254 \mathrm{pg}$ I-TEQ/ $\mathrm{Nm}^{3}$ (CCME, 
2003). CCME developed CWS for these facilities to apply best available technologies to prevent, capture or control the dioxins emissions in two phases.

The phase I goal was to reduce the dioxins emissions to less than $150 \mathrm{pgl-TEQ} / \mathrm{m}^{3}$ by 2006 and the phase II was to reduce dioxins emissions for all existing and new facilities to $100 \mathrm{pgl-TEQ} / \mathrm{m}^{3}$ by 2010 (CCME, 2004). Application of pollution prevention control technologies resulted compliance with the CWS targets in 2008 for all facilities except for one facility in Ontario, which has been required to consider changes in operation and meet the target by 2010 (CCME, 2009).

Figure 6. Downward trend in dioxin releases from electric arc furnaces

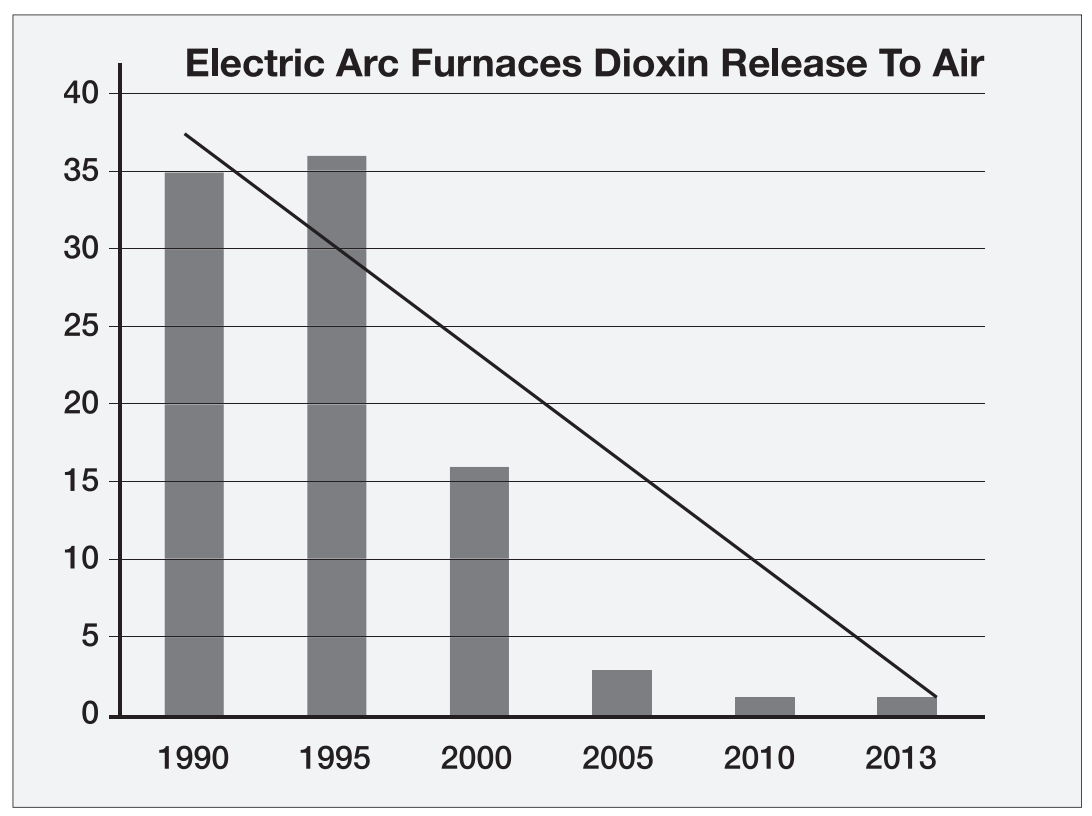

\subsubsection{On-Site Combustion of Residential/Municipal Waste}

On-site combustion is a non-point source that its distribution and volume is not accurately known. It has been estimated that $20-40 \mathrm{gTEQ} / \mathrm{yr}$ are released into atmosphere, which accounts for $12-22 \%$ of total annual national release. No numerical target has been set out for this sector. Instead, it has been suggested that increasing public awareness about dioxins release and linkage with human health would be the most practical and effective practice. Some regulatory approaches have been in effect in many Canadian jurisdictions, open burning is either banned or is required pre-approval (CCME, 2004). 
To summarize, regulatory limits and technological advances were successful in reducing dioxin formation and releases significantly. Among six priority sources two sectors, conical waste combustion and iron sintering were successful in eliminating dioxins; except for the open burning sources, whose contribution still remains under shadow, other sectors are cooperating by employing new technologies to prevent dioxin formation and/or to remove it from entering into environment. Figure 7 illustrates the comparison of dioxin releases from six dioxin targeted sources between 1990 and 2013.

Figure 7. Dioxin releases to air from priority sources comparison for years 1990 and 2013

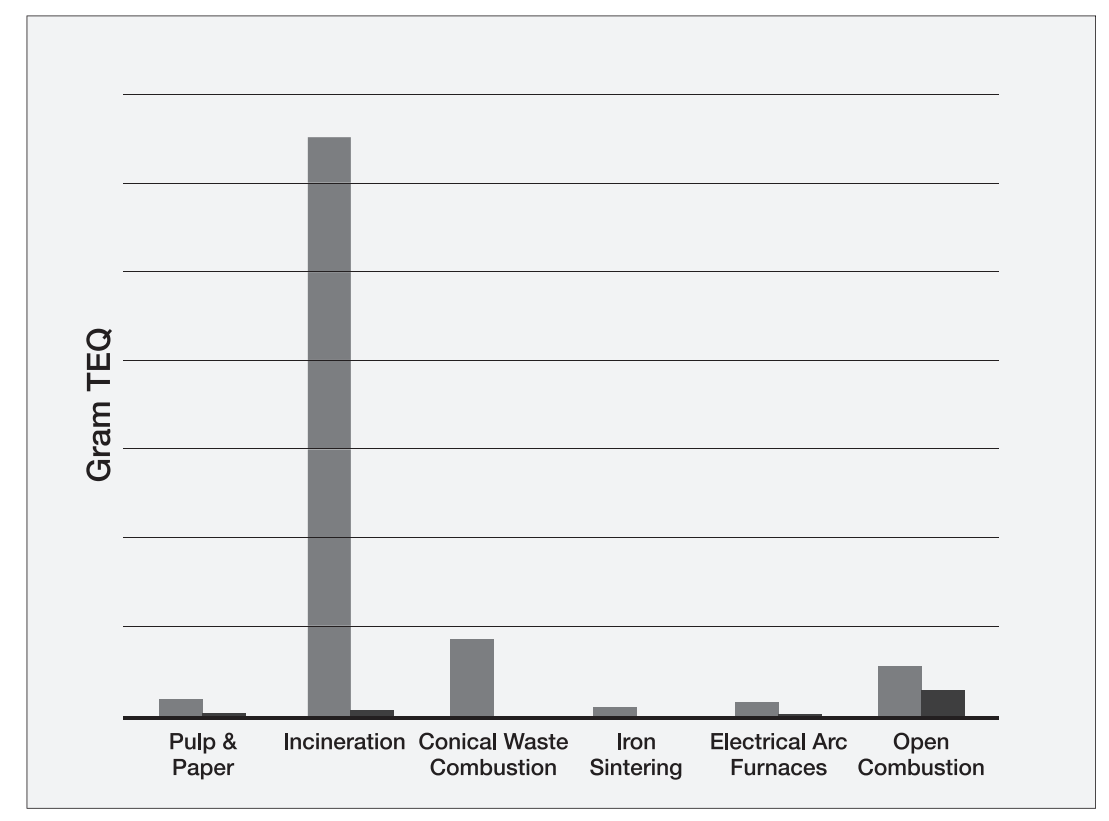

\subsubsection{Inventory deficiencies}

Despite of the fact that regulatory limits and technological advances have been successful in reducing dioxin formation and releases into environment, the ultimate goal of virtual elimination has not been met by far perhaps due to some deficiencies in NPRI guidelines for source identification and source quantification. These deficiencies may result in underestimating the true fluxes of dioxins into environment, which in turn demand inadequate regulatory tracking and control measures. Some deficiencies are identified as below:

- Facilities may use different methods to determine how much dioxins they release. This fact was addressed by UNEP, and a standardized Toolkit was introduced to unify dioxins estimation in 2001 . 
The Toolkit suggested calculating and reporting dioxins releases based on gram of TEQ per year using equation 2:

Source Strength $=$ Emission Factor $x$ Activity Rate (Eq. 2)

Or

Emission of source $=$ Concentration in emission $\times$ Operational hours (Eq. 3 )

Activity rate is defined as tons or liters of material processed or product produced per year.

Emission factor is defined as the amount of dioxins in $\mu \mathrm{g}$ I-TEQ that is released to each vector per unit of material processed or produced.

The Toolkit could not solve the uncertainty of reports because there is no harmonized numerical value for emission factor for a specific activity. Emission factor estimations differ from one study to another. The uncertainty in the emission factor estimate depends primarily on how well the tested facilities represent the untested facilities. The increase of variability in physical design and operating conditions within a class of facility increases the uncertainty of emission factor estimation (EPA draft, 1998).

For example, municipal waste combustion emission factor from Switzerland was reported $3230 \mu \mathrm{g}$ I-TEQ/t, while for the same industry the value of $5000 \mu \mathrm{g}$ I-TEQ/t was reported from The Netherlands (UNEP, 2005). Therefore, the dioxin estimation report for an activity within a same category may vary considerably depending on which range (lower, upper, central) of emission factor is employed.

- The national dioxin inventory does not account for dioxins originating from outside sources and no data exists to quantify the dioxins re-entering to atmosphere from secondary sources (dioxin reservoirs). For example, 2-20\% of dioxins deposited in Nunavut are originating from outside sources. Since no air monitoring program exists to quantify the dioxin concentration in air, the overall dioxin concentration has been underestimated.

- Many activities are potential sources of dioxin releases. These activities have been listed in Air Pollution Emission Inventory website, however they have not been required to estimate or report the dioxin releases by far. The potential sources include but are not limited to petrochemical industries, upstream and downstream petroleum industries, steel recycling, mineral product industries, fertilizer 
production, primary aluminum smelting and refining.

- NPRI applies employee threshold as a requirement for industries to report their emission. Dioxin release known facilities, which operate with less than 20,000 employee hours are exempted from reporting to NPRI. Employee threshold in fact disregards the cumulative impact of small facilities.

- The feed threshold for reporting the dioxin emission is another requirement for reporting dioxin emission. Biomedical or hospital waste incinerator and non-hazardous waste incinerators that incinerate less than 26 tonnes per year are not required to conduct annual stack testing and are exempted from reporting to NPRI. In a study by Chandler on effectiveness of CWS on incinerators, it was suggested that many small incinerators in Canada have the potential to exceed the "small" incinerator designation in the CWS (Chandler, 2006). It means that they must all be tested annually, however, testing is highly unlikely to happen due to high cost of analysis.

The deficiencies in NPRI can be adjusted by increasing source testing capacity on a regular basis. This will help to better identify and quantify sources. However, source testing is limited by the capacity of testing facilities and the high cost of current analytical method. The high cost of analysis not only prevents to identify new sources of dioxin but will also avert to verify the effectiveness of new pollution prevention technologies.

Currently, gas chromatography -high resolution mass spectrometry (GC-HRMS) is the only legally accepted method for dioxin analysis. It was found over 40 years ago that GC-HRMS was the instrumental method for dioxin determination because it is highly accurate and can provide concentrations for all most toxic congeners in only one analysis (Buan, 2009). The concept of GCHRMS is described in Reiner et al., 2006. In essence, samples are extracted three times through classical extraction techniques such as, Soxhlet, liquid/liquid extraction, solid-phase extraction or the most recent pressurized liquid extraction. Extracts are then run through a series of cleanup column such as a three stages silica, alumina and carbon. After cleanup and removing interfering chemicals, extract is introduced to gas chromatogram and dioxin congeners isolate sequentially based on their mass starting with tetrachlorinated congeners followed by penta, hexa, hepta and octachlorinated congeners. In the final stage the molecular fragment of each congener is measured 
and recorded by a mass spectrometer.

Although GC-HRMS is very accurate in determining the dioxin congeners concentration, it is very expensive and time consuming to use. For environmental screening and monitoring, where high throughput of samples are required, the cost of analysis limits the scope and thoroughness of sampling effort. Therefore, there is a need to introduce a method that can substitute GC-HRMS and offset burdens on frequent environmental monitoring.

Enzyme-linked immunosorbent assay (ELISA) has been successful in detecting dioxins in soil and sediments and was approved by US EPA as method 4025. ELISA was compared against methods 1613B and 1668A, using GC-HRMS, and demonstrated $85 \%$ reduction in cost and $91 \%$ reduction in time for analysis (US EPA 2005a).

Many studies have validated that ELISA can detect dioxins in soil, milk, and fish (Sugawara et al., 2002; Okuyama, 2004; Saito et al., 2003; Buan, 2010; Nording et al., 2006; Li et al., 2010). However, no research was found in open literature on testing air samples using ELISA. To author's best knowledge only one research has been carried out in Ryerson University using ELISA for detecting dioxin in ambient air (Zi, 2013). Thus, the author was encouraged to build on this preliminary success at Ryerson and validate ELISA in conjunction with an automated sample preparation at a test site.

Dioxins analysis consists of two parts: 1) sample preparation 2) dioxins quantification with ELISA. Determination with ELISA is the same for different sample matrices. Sample preparation is the most crucial part because trace analysis of dioxins requires a method that can extract part per trillion and part per quadrillion of dioxins from sampling media and a cleanup method that can separate dioxins from interfering co-extracts.

Zi (2013) utilized dimethylformamide (DMF) for extraction and fuming sulphuric acid for cleanup.

Zi combined this manual sample preparation with ELISA for measuring dioxins in ambient air samples collected from downtown Toronto between 2012 and 2013. The author found the dioxins concentration in Toronto varying between $3.95 \pm 0.83 \mathrm{fgBEQ} / \mathrm{m}^{3}$ in summer and $10.26 \pm 0.36 \mathrm{fgBEQ} / \mathrm{m}^{3}$ in winter.

DMF is a promising extraction solvent and fuming sulphuric acid is very strong oxidizing agent. 
However, DMF is carcinogenic and fuming sulphuric acid needs high precaution to use. Therefore, there was a need to seek for alternative methods that can eliminate the use of hazardous chemicals.

\section{The research objective of this study}

The primary objective is to validate an automated method for sample preparation combining with ELISA that eliminates the use of highly hazardous chemicals for screening dioxins in ambient air. The ELISA analysis was the same method utilized by $\mathrm{Zi}$ (2013) for measuring dioxins in ambient air samples from Toronto. The sample preparation method tested was pressurized liquid extraction (PLE) commercially known as accelerated solvent extraction (ASE). Sample preparation consists of extraction, volume reduction, and cleanup. Extraction and volume reduction procedures were the same procedure performed in Environment Canada's Air Quality Division for extracting polyaromatic hydrocarbons, polychlorinated biphenyls, and polybrominated diphenyl ethers. The cleanup method was based on Cape Technologies protocol for cleaning dioxin contaminated soil samples. The automated extraction method has been proven to be successful in extracting dioxins from soil samples (Chuang et al., 2009; Nording et al., 2006). However, it has not been tested on ambient air samples. This method has the advantage that reduces time, cost, human error and labour.

\section{Scope of the study}

In total, 20 samples were collected from a site in Burlington on weekly basis using two high volume samplers from November 2014 to February 2015.

Since $90 \%$ of dioxins adsorb to particulate matters, air samples were collected from particle-phase using glass fiber filters (GFF). Dioxins in gas-phase were collected using polyurethane foam (PUF). ELISA test results on dioxins concentration in particle-phase revealed that dioxin concentrations collected on PUFs were below the method detection limit and therefore were not tested. 


\section{Research methodology}

This study approach comprised a series of laboratory experiments and field sampling of air at a site in Burlington, Ontario, Canada. The methodology is listed below:

Samples were prepared using ASE machine with hexane and acetone.

To determine ELISA performance in our lab, a series of dioxin standards purchased from Cape Technologies were tested prior to sample analysis. A series of tests were conducted on blanks to determine the background dioxin carry over from method, lab equipment, and from travelling to sampling site. A series of quality control tests (spikes) were carried out on different stages of sample preparation to determine the recovery of method and potential dioxin losses in each stage. A series of tests were performed on certified reference material (CRM) to determine the ability of method on detecting and quantifying known concentration of dioxins in CRM. Once the performance of ELISA was proven and background carryover and method recovery were determined, field samples were prepared and tested with ELISA. Finally, in order to evaluate ASE/ELISA performance 5 parallel samples were sent for GC-HRMS analysis. The result of ELISA and GC-HRMS on 5 parallel field samples and 2 urban dust samples with known GC-HRMS results was compared using statistical analysis.

\section{Thesis organization}

Chapter 1 introduces the research problems and needs, states the objectives and scope, and outlines the methodology. A review of previous works related to the research is prescribed in chapter 2. Chapter 3 introduces sampling site, sampling scope and methodology; and briefly compares previous manual method and current automated method. A description on steps of sample preparation and ELISA analysis are also provided in this chapter. Chapter 4 describes in detail the experiment including calibration test, background test, method recovery test and certified reference material test. Field sample tests and statistical analysis of results are included in this chapter. Obsrvations from this research study are concluded in chapter 5 and finally some recommendations are provided in Chapter 6. 
CHAPTER TWO 


\section{ELISA}

ELISA has been used as a diagnostic tool in medicine and plant pathology and has wide application including the food industries for detecting potential food allergens, in toxicology for testing for certain classes of drugs such as cocaine and opiates and testing for HIV, blood, tissue, pregnancy, hepatitis, and anabolic steroid (Kimball, 2008). The basis of ELISA method is antibody. Antibody or immunoglobulin is a large protein with antigen-combining sites that identifies foreign objects such as bacteria and viruses based on their shape. Antibody is designed in a way that specifically recognizes dioxin because its shape is complementary to antibody. The shape of antibody and TCDD is like key and lock; dioxin attaches to antibody and completes its shape. Other congeners that have slightly different shape can attach to antibody but not as tight as TCDD, and other congeners, which have very different shapes, cannot bind to antibody. The schematic key and lock concept is well depicted in Cape Technologies website (Fig 8).

Fig 8.Dioxin- antibody key and lock concept (Source: Cape Technologies website. http://www.capetech. com/)

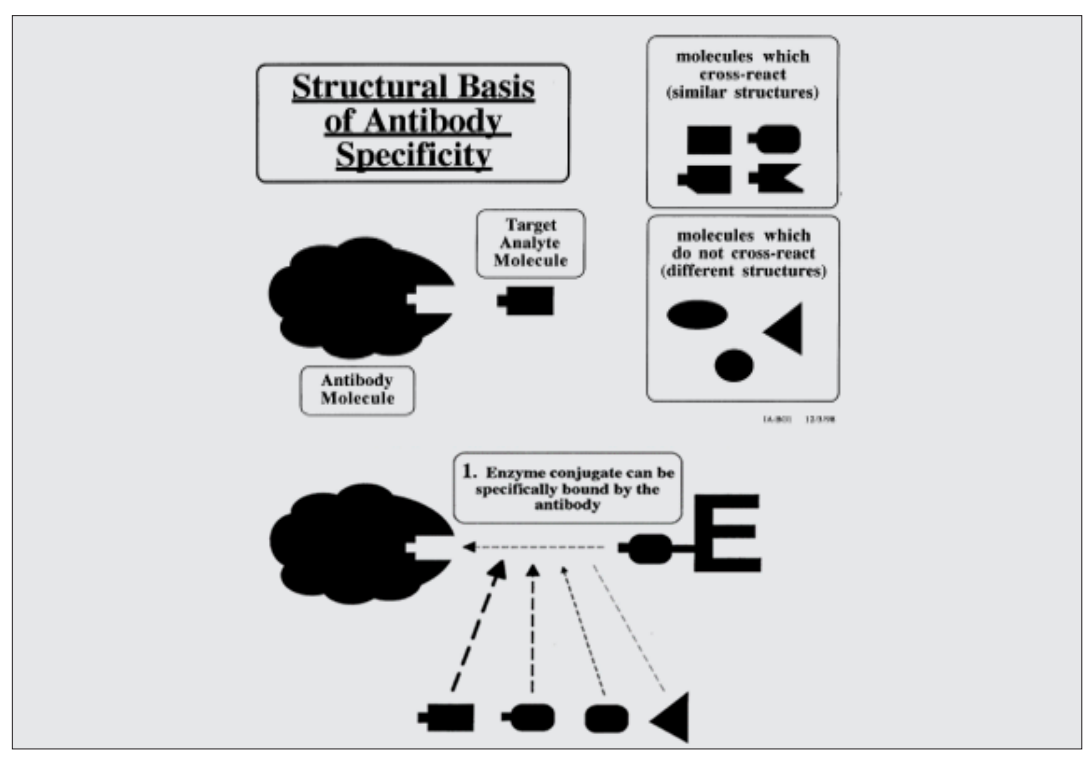


ELISA takes place in a heterogeneous format in which antibody is coated on a polypropylene tube that facilitates the isolation of the bound analyte-antibody. These antibodies specifically target 2,3,7,8-TCDD because this molecule best fits to their shape. Other congeners are also binding to antibodies but to differing degrees. In this study horseradish peroxidase (HRP) conjugate, a dioxin like molecule chemically attached to an enzyme competes with dioxin to bind to antibodies. These two reactions form the basis of ELISA.

This research was performed using ELISA kit (DF1 Dioxin/Furan Immunoassay Kit) purchased from Cape Technologies. Extracted dioxins are introduced to ELISA tube and binds to antibodies. After unbound and unwanted compounds are removed by washing with deionized distilled water (DDW) conjugate of dioxin-like competitor coupled to the horseradish peroxidase is added to solution and competes to bind to any antibodies that remain available. The competitor occupies the antibody sites that are not bound to dioxins. Another wash step is applied to remove unbound HRP. The amount of HRP-competitor conjugate bound by anti-dioxin antibody is inversely proportional to the dioxins concentration in the sample incubation step. No detection can be made until a solution of chromogenic HRP substrate and hydrogen peroxide is added to the tube. Conjugate enzyme cleaves the peroxide and produces oxygen radical. The oxygen radicals attack chromogens and convert them to their coloured form. Stop solution is added to stop colour development. The light absorbance or optical density (OD) of each sample and standard calibrators are measured by a spectrometer and interpreted. The stronger the colour, the more HRP conjugate was bound and thus the lower is the concentration of dioxins in sample. The complete ELISA schematic diagram is shown in Fig 9. 
Figure 9. Schematic Diagram of DF1 Dioxin/ Furan Immunoassay Protocol (Source: Cape Technologies)

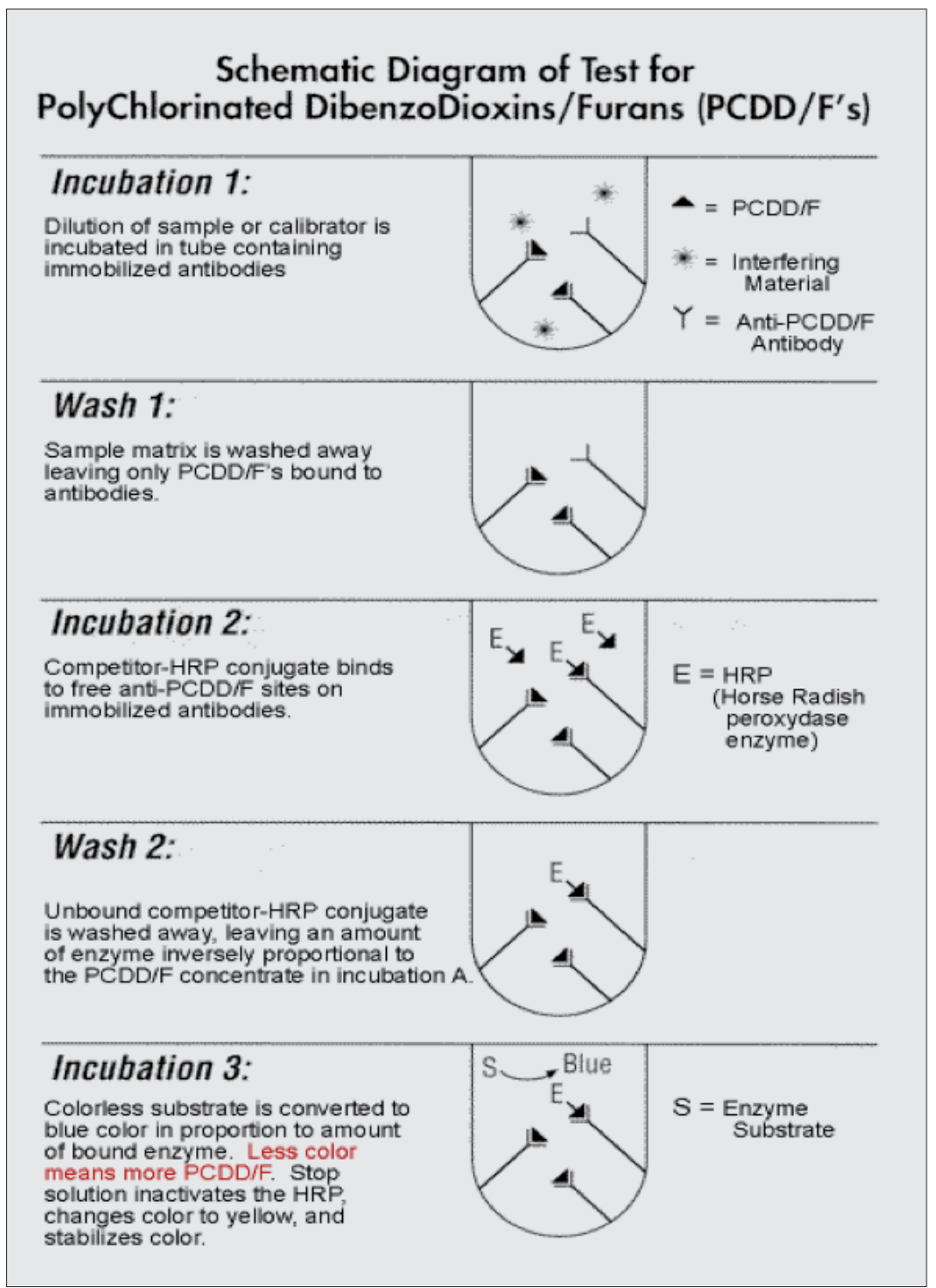

The OD readings are converted to the overall toxic equivalency by developing a standard curve, which relates the absorbance to TEQ. Standard curve is plotted by inserting the OD readings of a series of standards to an Excel sheet available in Cape Technologies website (Cape Technologies, 2004) with known concentration of 2,3,7,8- TCDD in a four-parameter equation using Excel solver function; solver automatically finds four parameters and then plots a curve that best fits to the OD readings. The fourparameter equation is as follow:

$Y=\frac{A-D}{1+\left(\frac{X}{C}\right)^{B}}+D$ 
Where

$\mathrm{Y}=\mathrm{OD}$ as percentage of $\mathrm{OD}$ in negative control (NC)

$\mathrm{X}=\mathrm{pg}$ per ELISA tube

$A=Y$ value of upper asymptote

$\mathrm{B}=$ degree of curvature

$\mathrm{C}=\mathrm{X}$ value at $50 \%$ point of curve

$D=Y$ value of lower asymptote

The TEQ of a sample is obtained by comparison made between sample OD and standard OD. The final outcome of ELISA is the overall biological reaction between antibodies and dioxin congeners, which depends on congeners cross-reactivity. Cross-reactivity is defined as the affinity of each congener to bind to antibody. The percent cross-reactivity of each congener is developed by Cape Technologies (Cape-Tech, 2003b) by dividing the result of an ELISA analysis of a pure sample of 2,3,7,8-TCDD by the result of an ELISA analysis of a pure sample of each congener at the same concentration (Buan, 2009). Cross-reactivity for dioxins, furans and dioxin-like PCBs are provided in Table 3. 
Table 3. Cross reactivity for 27 dioxin and furan congeners and 5 dioxin-like PCBs

\begin{tabular}{|c|c|c|c|}
\hline Toxic Dioxin Congeners & $\begin{array}{l}\text { Percent } \\
\text { Crossreactivity }\end{array}$ & Other PCDD/F Congeners & $\begin{array}{l}\text { Percent } \\
\text { Crossreactivity }\end{array}$ \\
\hline 2,3,7,8-TCOD & 100 & 2,3-dichlorodibenzo-p-dioxin & 0.13 \\
\hline 1,2,3,7,8-PeCDD & 105 & 2,7-dichlorodibenzo-p-dioxin & 0.003 \\
\hline $1,2,3,4,7,8-\mathrm{HxCOO}$ & 1.6 & dichlorodibenzofuran & 0.02 \\
\hline $1,2,3,6,7,8-\mathrm{HxCDD}$ & 7.9 & 2,7-dichlorodibenzofuran & $<0.002$ \\
\hline 1,2,3,7,8,9-HxCDO & 39 & 2,3,7-trichlorodibenzo-p-dioxin & 24 \\
\hline 1,2,3,4,6,7,8-HpCDD & 0.7 & 2,3,8-trichlorodibenzofuran & 0.26 \\
\hline OCDD & $<0.001$ & 1,2,3,4-TCDD & $<0.001$ \\
\hline Toxin Furan Congeners & & 1,2,3,4-TCOF & $<0.001$ \\
\hline 2,3,7,8-TCDF & 20 & 1,3,6,8-TCDD & 0.05 \\
\hline 1,2,3,7,8-PeCDF & 4.6 & 1,3,6,8-TCDF & 0.007 \\
\hline 2,3,4,7,8-PeCDF & 17 & PolyChlorinated Biphenyls & 0.4 \\
\hline 1,2,3,7,8-HxCDF & 0.4 & 3,3',4,4' (PCB 77) & 0.5 \\
\hline $1,2,3,6,7,8-\mathrm{HxCDF}$ & 1.0 & 3,3’,4,4’,5 (PCB ‘126\} & $<0.1$ \\
\hline $1,2,3,7,8,9-\mathrm{HxCDF}$ & 3.3 & $2,2^{\prime}, 4,4^{\prime}, 5$ (PCB 153\} & $<0.1$ \\
\hline $2,3,4,6,7,8-\mathrm{H} \times \mathrm{CDF}$ & 4.9 & $3,3^{\prime}, 4,4^{\prime}, 5,5^{\prime}$ (PCB 169) & $<0.1$ \\
\hline 1,2,3,4,6,7,8-HpCDF & 0.02 & Aroclor 1254 & $<0.1$ \\
\hline 1,2,3,4,7,8,9-HpCDF & 0.9 & & \\
\hline OCDF & $<0.001$ & & \\
\hline
\end{tabular}

\section{Source: Cape \\ Technologies, High \\ Performance Dioxin/ \\ Furan Immnuoassay \\ IN-DF1}

ELISA result is presented as BEQ (biological equivalency) to differentiate with the results obtained by GC-HRMS. Since BEQ and TEQ are produced with two different measurement techniques they cannot be compared directly. To overcome this obstacle Buan, 2009 presented congener correction factor concept. Correction factor for a congener is calculated by dividing TEF of each congener by its cross-reactivity. The concept was examined with both WHO and NATO derived TEFs. Both schemes correlated equally to GC-HRMS showing that BEQ corrected ELISA can be easily compared to both schemes. Buan expanded this concept and calculated site-specific correction factor for some industries with known congener profiles. Theoretically, application of correction factor improves the 
correlation between ELISA and GC-HRMS results. The author showed that how congener profiles cause ELISA BEQ to be different from TEQ. Source-specific correction factors are presented in Table 4.

Table 4. Dioxin source-Specific Correction Factor

\begin{tabular}{|l|c|}
\hline Source & Source-specific Correction Factor \\
\hline Soil and Sediment Samples at Study Sit & 1.01 \\
\hline Secondary Copper Refinery & 2.68 \\
\hline Incinerator-Hazardous Waste & 1.93 \\
\hline Medical Waste Incineration & 1.84 \\
\hline Barrel Burning for House Waste & 1.71 \\
\hline Secondary Aluminum Smelters & 1.7 \\
\hline Coal Fired Plants & 1.49 \\
\hline Municipal Solid Waste Incinerators & 1.31 \\
\hline Secondary Lead Smelters & 1.26 \\
\hline Cement Kilns & 1.07 \\
\hline Tire Combustion & 1.07 \\
\hline Diesel Fuelled Trucks & 1.05 \\
\hline Primary Ferrous Metal Smeltering & 1.02 \\
\hline
\end{tabular}

Source: Buan, 2009

However, the soil samples of the dioxin contaminated site studied by Buan et al., 2009 happened to have a site-specific congener profile that produced a correction factor close to unity ( 0.9 by NATO TEF and 1.1 by WHO98 TEF). Multiplying the BEQ by a value close to 1.0 did not present a convincing case to demonstrate the beneficial effect of a correction. Therefore, the present study pays special attention to whether the ambient air correction factor improves BEQ / TEQ agreement.

ELISA has many advantages as screening tool. ELISA is faster and has lower cost in comparison with GC-HRMS. The US EPA, under its Superfund Innovative Technology Evaluation Program, tested ELISA for screening 209 soil samples. The test demonstrated that ELISA could reduce the cost by $91 \%$ and the time of analysis by $85 \%$. 
ELISA has been successful in samples with high concentration of dioxins such as soil (Harrison and Carlson, 1998, 1999), fly ash (Zennegg et al., 1998), and chimney soot (Zennegg and Shmid, 1999). Later it was improved by developing a polyclonal antibody for screening PCDDs and PCDFs (Sugawara et al., 1998) for detecting dioxins in samples with low concentration such as milk and blood.

This thesis is employing the same polyclonal antibody-based immunoassay to test ambient air samples, which have much lower concentration of dioxins in comparison with soil and fly ash. The experiment has been described in subsequent chapter. 


\section{CHAPTER THREE}




\subsection{Introduction}

A sampling strategy was planned and samples were collected based on the Environment Canada's protocol for collecting other POPs such as PCBs, PBDEs and PAHs. Extraction conducted using accelerated solvent extraction machine (ASE-200) with the mixed hexane and acetone. Sample cleanup was based on protocol developed for soil samples by Cape Technologies, this process utilizes acid silica carbon mini-column purchased from Cape Technologies. ELISA analysis was the same protocol previously coupled with manual extraction at Ryerson and Ontario Ministry of the Environment (OMOE) for dioxin contaminated soil samples (Buan, 2009; Lee, 2007) and for air samples (Zi, 2013).

\section{2. Sampling Site}

Since dioxins are found in environment in ultra-trace amount, it was primarily planned to collect samples from a congested industrial area that higher concentration of dioxins are expected. The sampling time was planned to be fall and winter. Zi (2013) found that dioxins concentration in Toronto area in winter were noticeably higher than summer. His finding was in agreement with many studies that reported dioxins concentration in fall or winter months higher than spring or summer months (Christmann et al, 1989; Hippelein et al. 1996; Lee et al, 1999; Lee et al, 2008; Li, et al., 2008; Lorber et al., 2013 as cited in $\mathrm{Zi}, 2013)$. Therefore, sampling was planned to be conducted in fall and winter from McMaster University campus in Hamilton. Since permission was not granted by November 2014, samples were collected from Burlington. Permission was granted from Canadian Center for Inland Waters (CCIW) to mount the 
samplers in their facility. CCIW is located at Hamilton Harbour, Ontario $43.29^{\circ} \mathrm{N}$ and $79.80^{\circ} \mathrm{W}$. Since many industries are operating in Burlington and Hamilton area, it deemed that dioxins and furans concentration are higher than Toronto area. Therefore, sufficient amount of dioxins could be collected to cover the method detection limit of the test.

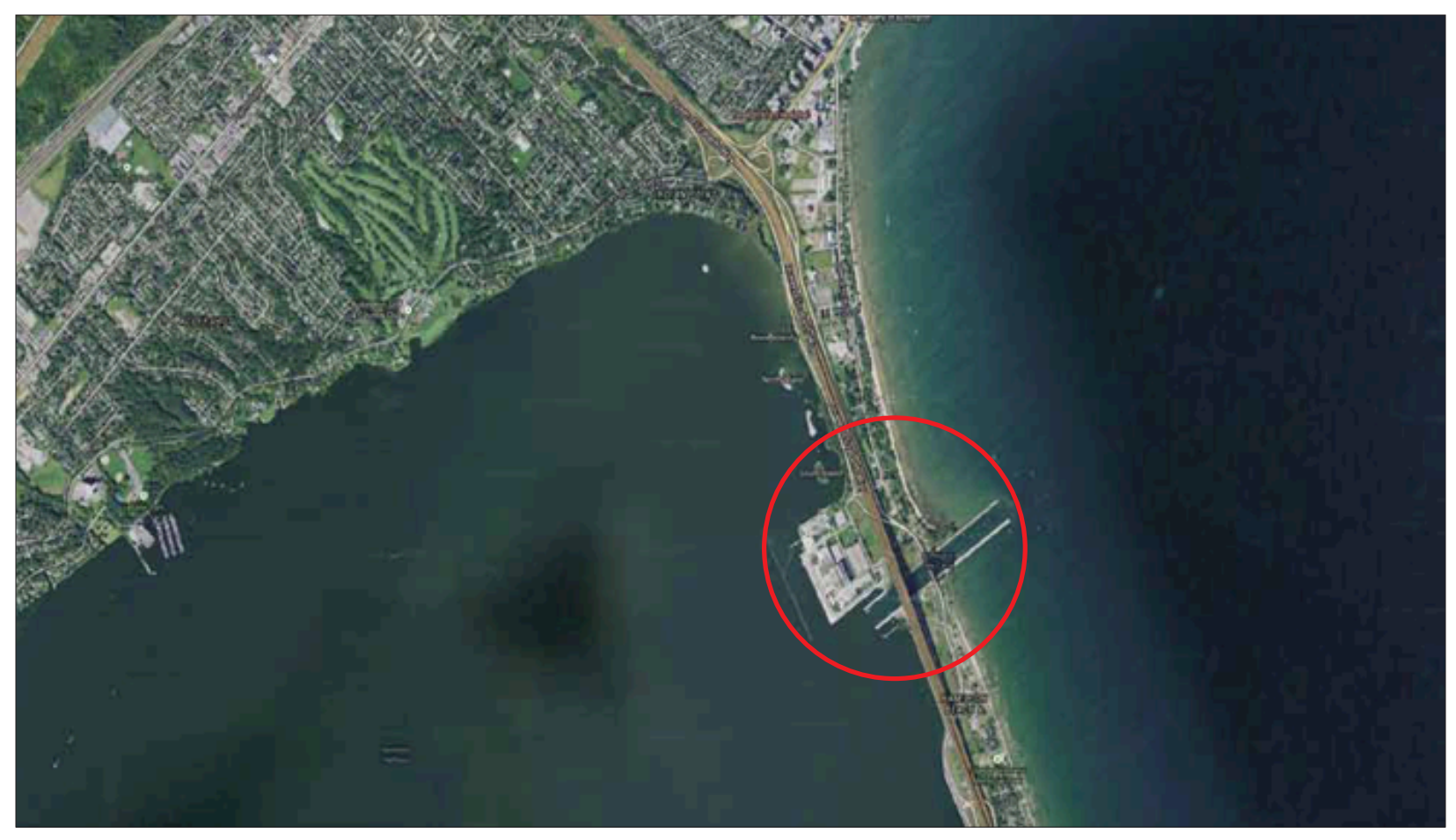

\section{Figure 10. Canadian \\ Center for Inland \\ Waters (Source: \\ google map) (up) \\ CCIW facility, installing \\ samplers (down)}

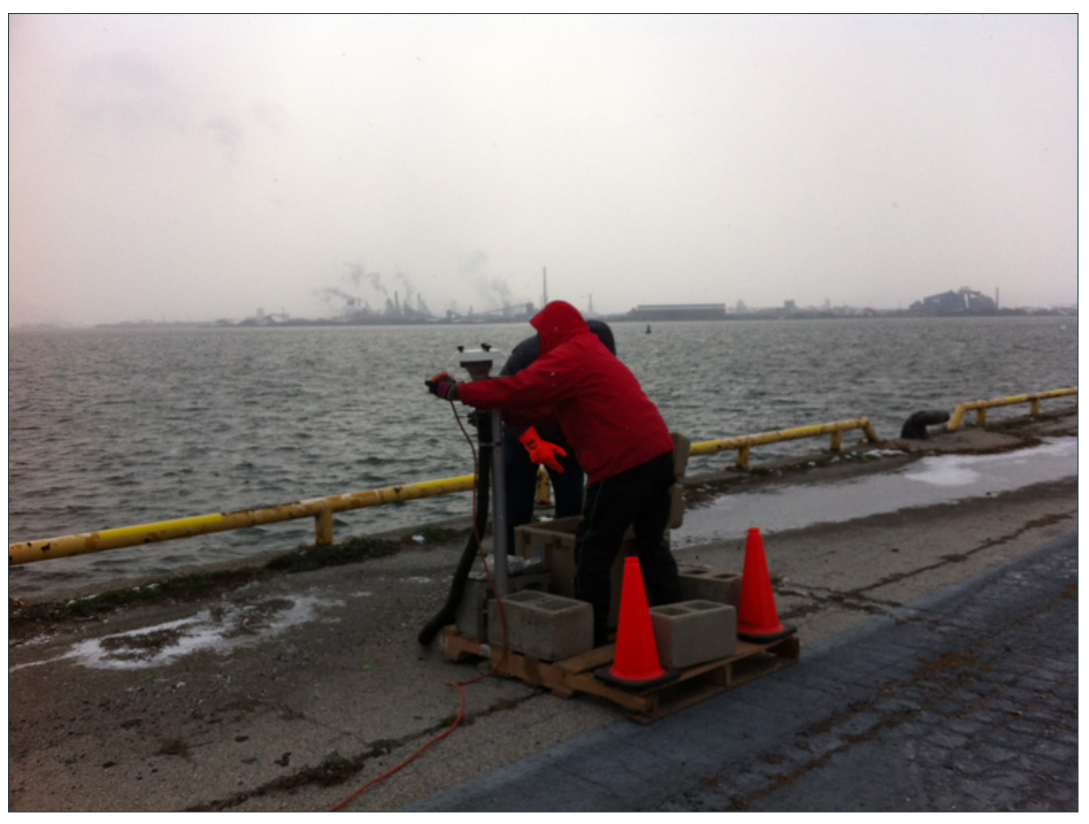




\section{3. Sampling Strategy and Method}

Samples were collected over weekly sampling periods in duplicate from November 2014 to January 2015 with a typical sampling volume of $3000-6000 \mathrm{~m}^{3}$. In total 10 duplicate samples were collected. Glass fiber filter (GFF) and polyurethane foam (PUF) were used to collect particle phase and gas phase dioxins respectively. The sampling system was based on two high volume samplers borrowed from Environment Canada (Ocean Queen \& PS1). The PS1 was later exchanged with another pump (Ocean King) having similar power of vacuuming air to Ocean Queen (Fig 11).
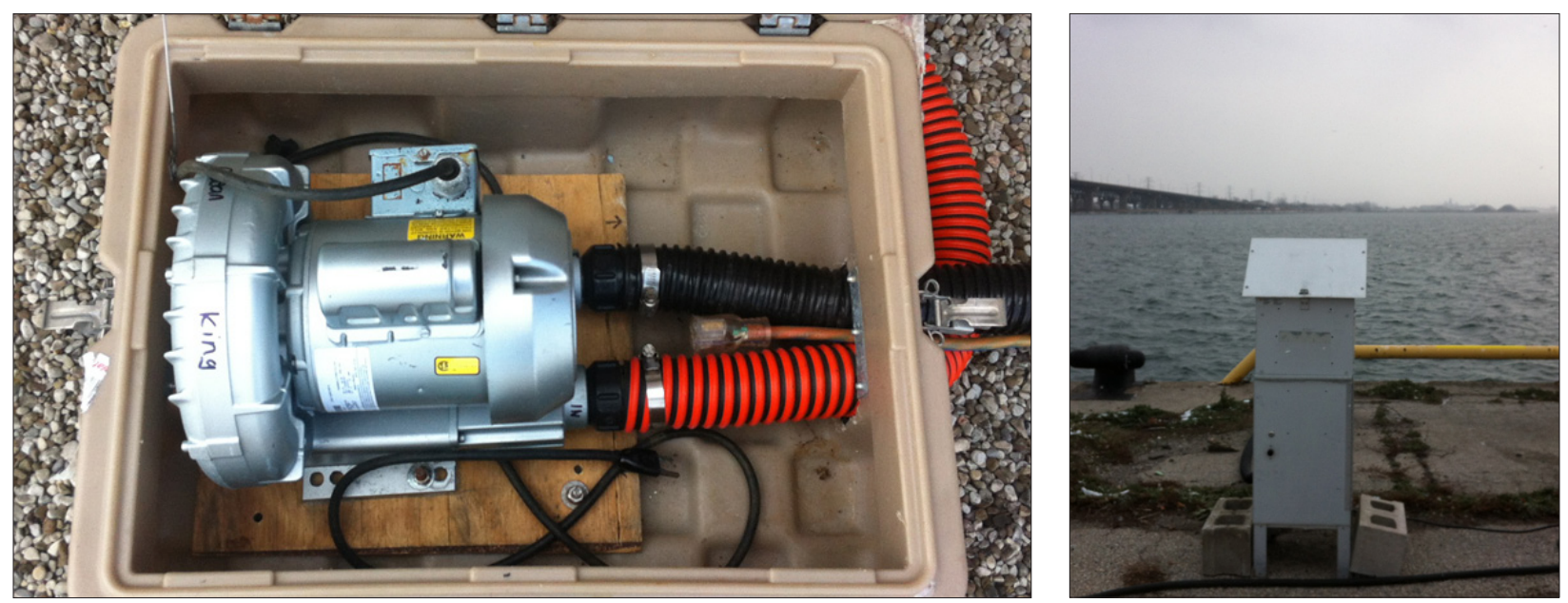

Figure 11. Air samplers Ocean King (left) PS1 (right)

The air volume collected was calculated from pump calibration curve by inserting sampling period (hours) and pump pressure drop (inch- $\mathrm{H}_{2} \mathrm{O}$ ). Samplers were equipped with GFF and PUF placed in a cartridge. Filters were $10.2 \mathrm{~cm}$ diameter purchased from Gelman (VWR, P/N 28150-214). They were oven baked at $400^{\circ} \mathrm{C}$ overnight to bake off any contaminants from the GFF preceding shipment to sampling site. PUFs were Soxhlet extracted for 18-24 hours using hexane then they were dried in a vacuum oven before installation in cartridge. After installation in the cartridge the whole sampling head was placed in a clean plastic bag and transported to sampling site. The head was installed and pump was turned on. Time was recorded and pressure drop was measured. At the end of sampling period pressure drop was recorded, pump was turned off, and time was recorded. Sampling head was detached and placed back in a clean 
plastic bag and returned to Environment Canada Organic Analytical Lab. GFF was removed using a clean forceps and placed on a piece of baked aluminum foil, folded, labeled and stored in freezer for future analysis. PUF was removed using a clean forceps, placed in a glass jar, labeled and stored in freezer for future analysis.

Recommended sampling period is 24 -hr (midnight to midnight) to a maximum of 48 hours $(C E C, 2014)$ because continuous air stream moving through the PUF may take off loosely attached dioxin molecules. In case of GFF, high concentration of particle may clog the filter. Clogged filter will no longer absorb dioxin molecules and estimation of dioxin concentration in unit volume of air is invalid. To determine whether GFF is clogged, pressure drop was measured by plugging a Magnehelic meter into the nozzle at the inlet hose of the sampler in the beginning and at the end of each sampling period. Pressure drop lower than $5 \%$ means no clogging has occurred. Pressure drop for all sampling periods in this study were within the acceptable level.

National Air Pollution Surveillance Program (NAPS) has reported the average air born dioxin concentration in Toronto to be $105 \mathrm{fgTEQ} / \mathrm{m}^{3}$ from samples collected between 1994 and 1997 (Environment Canada, 1998).The research study by Zi, 2013 on ambient air samples from downtown Toronto collected in 2013 found the dioxin concentration to be $7.64 \pm 2.001 \mathrm{fgTEQ} / \mathrm{m}^{3}$. The later value was chosen as a reference for dioxin concentration estimation in Burlington. The method detection limit (MDL) for ELISA analysis is 4pg per tube; considering the extraction percent recovery for half a filter (other half is stored for GCMS analysis), in best case scenario a minimum of $1000 \mathrm{~m}^{3}$ air is required to meet the method detection limit. However, ELISA kit manufacturer recommends that best results can be obtained when dioxins concentration is between 15 to $85 \mathrm{pg} /$ tube. Therefore, sampling period was extended to a maximum of seven days. Sampling procedure is depicted in Figure 12. 

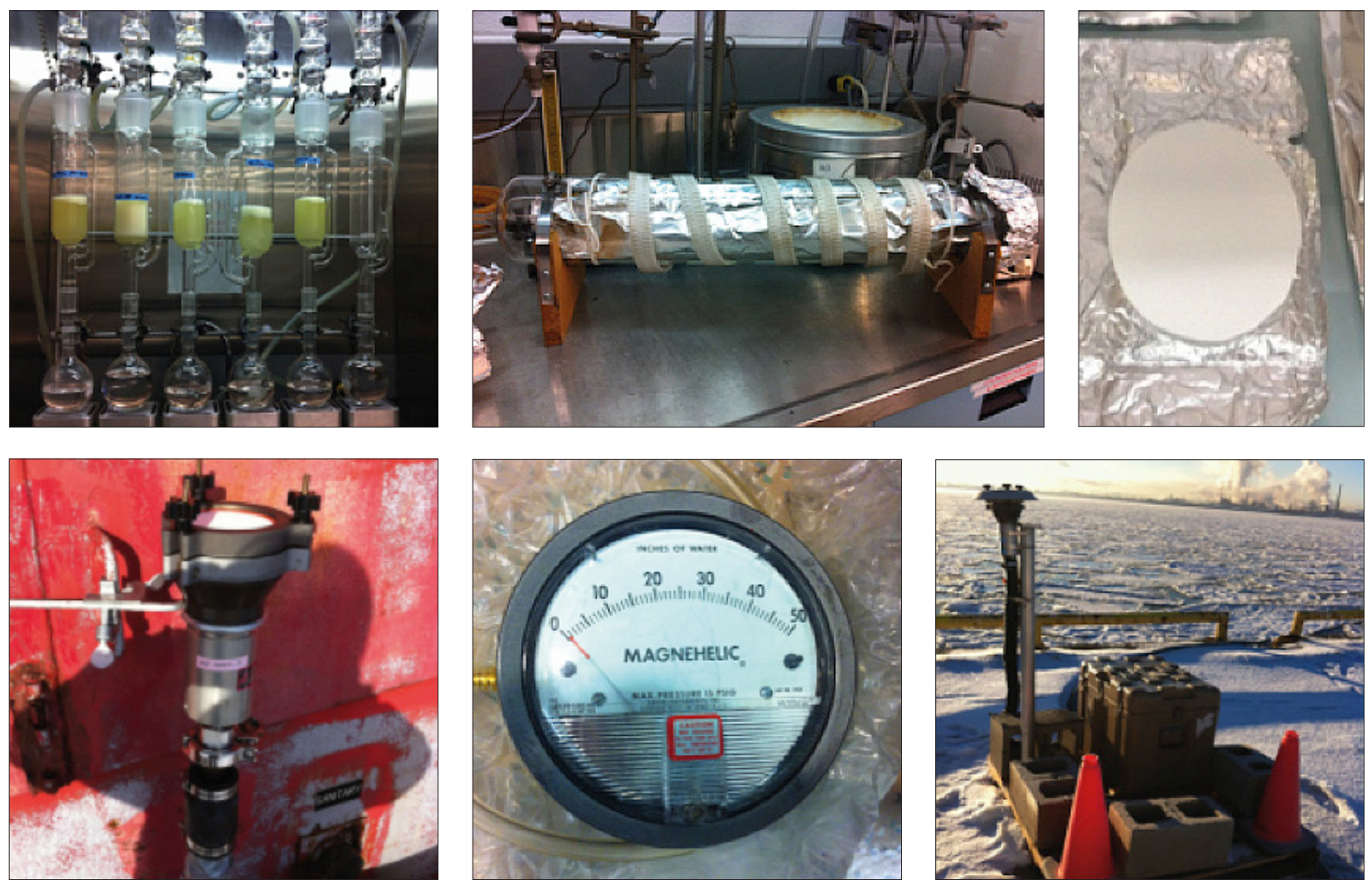

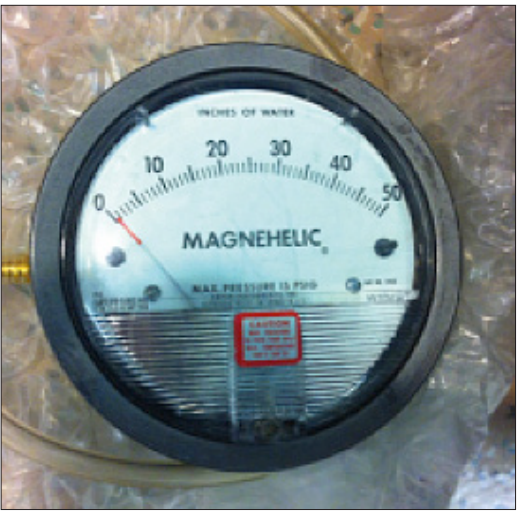

2. Dry in Vacuum Oven

3. Bake GFF

4. Assemble and Install

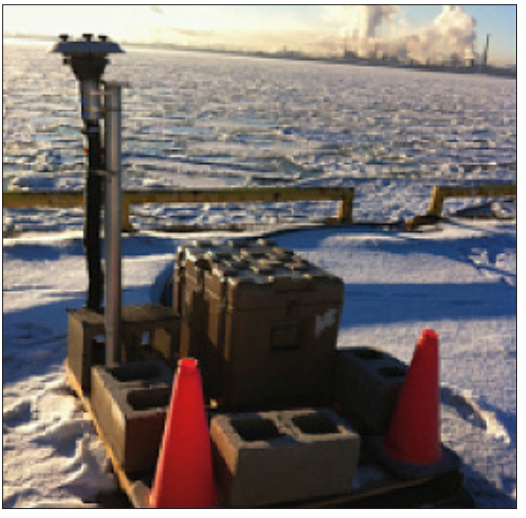

5. Measure Flow Rate

6. Deploy for 5-7 days flow chart

1. Soxhelt clean PUFs

\section{4. Pump Calibration}

The flow rate of pump was measured using a Magnehelic flow meter. The flow meter was attached to the end of the hose and the other end of the hose was attached to the pump. A three feet long ABS/ PVC pipe was attached to the other end of flow meter to create a laminar flow before the air hits the flow meter (Figure 13). To the end of the hose an empty sampler canister was attached. Pump turned on and the top of canister was totally blocked by a plate. Plate was moved slowly to let a bit of air flow. The Magnehelic gauge and flow meter reading was recorded. The flow meter shows the volume of air vaccumed by pump in $\mathrm{m}^{3 / h}$ and Magnehelic shows pressure drop in inch- $\mathrm{H}_{2} \mathrm{O}$. By gradually moving the plate a set of data is produced. Using the data set, pressure drop curve was plotted against flow rate. By inserting average pressure drop and time period the total volume in $\mathrm{m}^{3}$ is calculated (Figure 14). 
Figure 13. Calibration schematic for highvolume samplers (Ocean King \& Queen)
Figure 14. Pump calibration curve for Ocean Queen

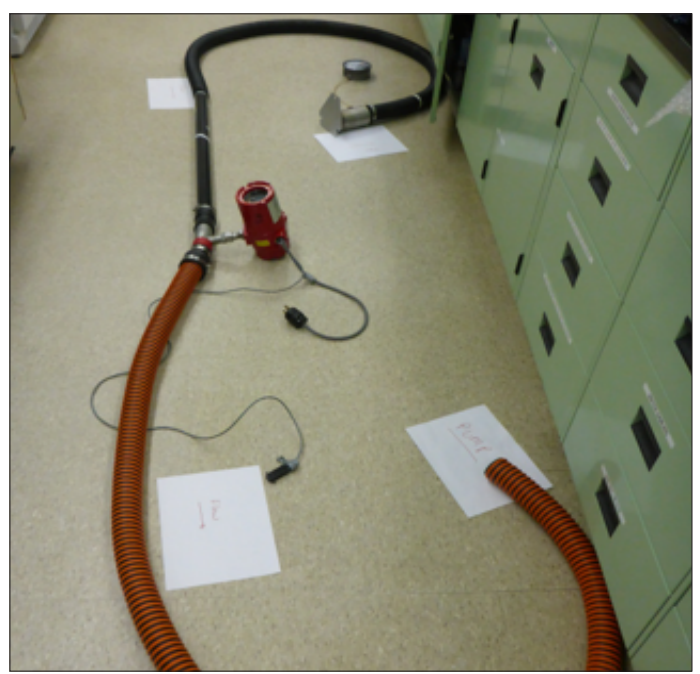

P drop ("H2O)

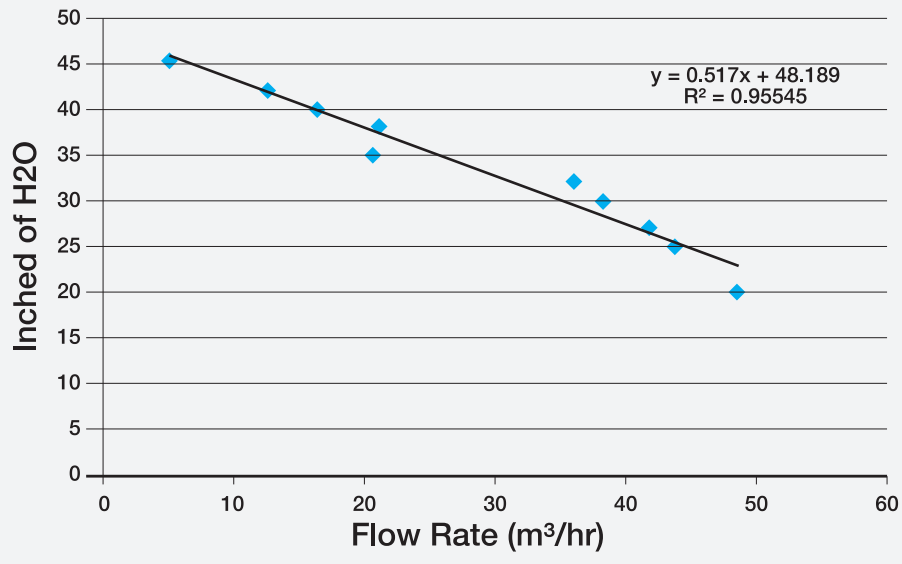

\section{5. Sample preparation}

\section{5. 1. Comparison between Manual and Automated Method}

Previous method for dioxins extraction utilized dimethylformamide (DMF) followed by fuming sulfuric acid for cleanup (detailed method is available in Zi, 2013). DMF is a polar (hydrophilic) aprotic solvent, which facilitates reactions that follow polar mechanisms. The advantage of this method is that fuming sulfuric acid is a strong oxidizing agent that breaks down oil and grease. The broken down lipids can no longer form micelles to sequester dioxins. Therefore, sulphuric acid eliminates lipid interference from the sample. (C. Lo, personal communication, November 2014). This method is promising for dioxins extraction, however it has some disadvantages. DMF is carcinogenic and fuming sulphuric acid is highly corrosive; both require 
extra precaution and proficiency to use. Aside from the safety issues each sample is prepared individually, which increases the inconsistency between sample extracts and increases the time for preparing a series of samples to be analyzed in one run ELISA analysis.

Current study intends to replace the above manual method with an automated pressurized liquid extraction (PLE) method commercially known as accelerated solvent extraction (ASE). ASE has many advantages; ASE is unique in that extractions are performed rapidly with reduced solvent use (approximately $35 \mathrm{ml}$ / sample), compared with traditional extraction techniques. ASE reduces the extraction time down to 25 minutes per sample versus hours in manual method. ASE-200 specifically used for this study can accommodate 25 samples and spikes in one run extraction and can operate unattended overnight. Therefore, it reduces the time, cost, and human error and increases consistency between sample extracts. Another advantage of this method is that in one rune sample extraction both PCBs and dioxins can be fractionated separately, and finally this method is more in line with the method currently used for other air pollutant analysis such as PCBs, PAHs and PBDEs.

\section{5. 2. Experiment}

\section{5. 2. 1. Introduction}

ASE is a technique performed to extract samples using organic solvents. Elevated temperatures up to $200^{\circ} \mathrm{C}$ is applied to increase the kinetics of the extraction process while applying high pressure about 2000 psi to keep the organic solvents in liquid state. Higher temperature reduces solvent viscosity and increases solvent migration; it also increases the solubility of solute in solvent and therefore increases

extraction efficiency. This method has the capability to perform in-line clean up through use of adsorbents to the extraction cell and two steps can be combined into one workflow. However two steps were performed separately in this study. Chaung et al., 2009 and Nording et al., 2006, have already validated ASE method for dioxins extraction from soil samples for ELISA analysis. Based on the results exerted from both studies simultaneous ASE and purification combining with ELISA analysis is a promising approach for high-throughput screening of PCDD/F contaminated soil as shown by the satisfactory correlation between the ELISA and GC-HRMS results. The success of ASE in dioxin extraction from soil 
samples encouraged the author to examine this method for extracting dioxins from air samples.

\section{5. 2. 2. ASE Sample Extraction}

This experiment was performed in Organics Analysis Laboratory, Air Quality Processes Research Section, Science and Technology Branch, Environment Canada. Samples were extracted using ASE-200 machine. A complete description of sample preparation and reagents used can be found in Appendix A. A brief description is provided below (Fig 15). Prior to extraction care must be taken to ensure that all equipment used in analysis are free of dioxins contamination. Therefore, baked glassware and equipment were rinsed with hexane: acetone (70:30) and air-dried prior to use. To reduce the chance of dioxin losses, routine baking of test tubes was avoided because baking may activate sites on glassware that will irreversibly adsorb dioxins (US EPA, 1994) instead they were soaked in hexane, sonicated for $30 \mathrm{~min}$ and rinsed with acetone. ASE stainless cells were washed with soup water, rinsed with distilled deionized water, soaked in acetone, sonicated and air-dried. They were then baked overnight at $125^{\circ} \mathrm{C}$.

GFF samples were cut into halves. One half was folded in aluminum foil and stored in freezer for future analysis. Second half was weighed, using forceps folded and placed into ASE cell. Cells were capped tightly and placed in ASE-200. Collection vials were capped with ultra clean septa and clean caps, labeled accordingly and placed in corresponding positions. Solvent reservoirs were filled with fresh acetone and hexane and placed in corresponding positions. Nitrogen and compressed air cylinders were attached to machine. Extraction method and schedule were loaded; temperature and pressure were set out $\left(100^{\circ} \mathrm{C}\right.$ and $\left.2000 \mathrm{psi}\right)$. Extraction time for each cell is about 25 minutes. For each extraction run, one blank cell is placed in machine to determine dioxins background in solvents and machine (method blank). Field blank analysis is also required. Field blank is a clean GFF that has been transported to sampling site, placed on sampling head and left for at least 10 minutes without turning on the pump. Field blank analysis will show how much dioxins can adsorb to sampling media during travel to sampling site. Filter blanks are also required to determine the concentration of dioxins in clean baked filters. 
ASE machine can be left unattended overnight to complete extraction schedule. Extraction solvents are hexane and acetone. Since acetone interferes with the oxidative part of acid silica cleanup column, it should be evaporated completely prior to cleanup. Sample extraction procedure is depicted in Figure 15.
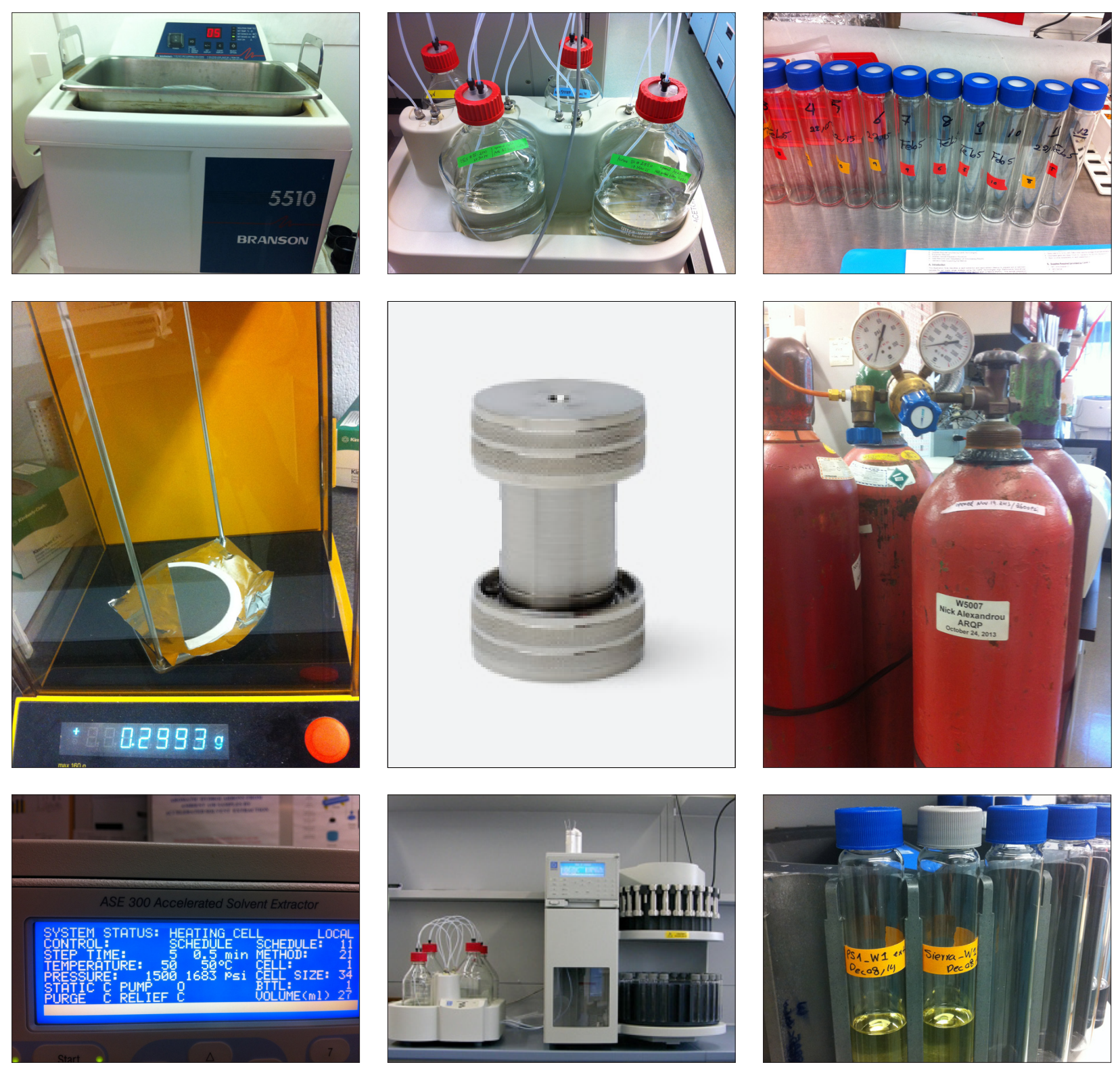

Figure 15. GFF extraction with ASE machine

1. solvent wash and sonicate
2. Fill with fresh solvent

3. Number collection tubes

4. Weigh sample

5. Put in the cell
6. Attach air and nitrogen

7. Program the ASE

8. Run the machine

9. Collect extracts 


\subsubsection{Evaporation}

Acetone interferes with the oxidative part of acid silica cleanup column and can lead to false positive results if not completely removed. Therefore, acetone must be evaporated completely prior to introduction to column cleanup. Turbovap-200 machine was used for solvent evaporation. Prior to evaporation system was purged for 10 minutes with clean air to prevent samples from any potential contamination. All turbovap funnels were hexane: acetone rinsed. Sample extracts were transferred from collecting vials to turbovap funnels using clean pasture pipettes. $0.5 \mathrm{ml}$ isooctane was added to each funnel as keeper to prevent dioxins losses during evaporation. Temperature was set out at $55^{\circ} \mathrm{C}$ and a stream of clean nitrogen with 6 psi pressure was applied to prevent evaporated solvent condensing down into sample tubes. Funnels were placed in turbovap bath and machine was programmed to reduce down the volume to $0.5 \mathrm{ml}$. Evaporated extracts were then transferred into clean vials and made up to $1 \mathrm{ml}$ by isooctane, labeled and stored in freezer (Figure 16).
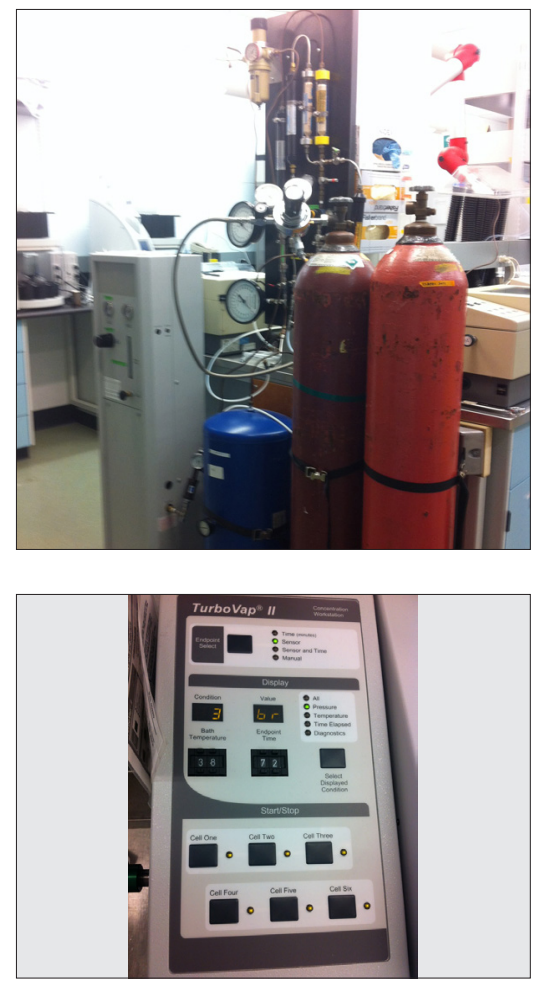

Figure 16. Acetone evaporation flow chart 1. Purge the system 2. Transfer extract to funnel 3.Add isooctane with
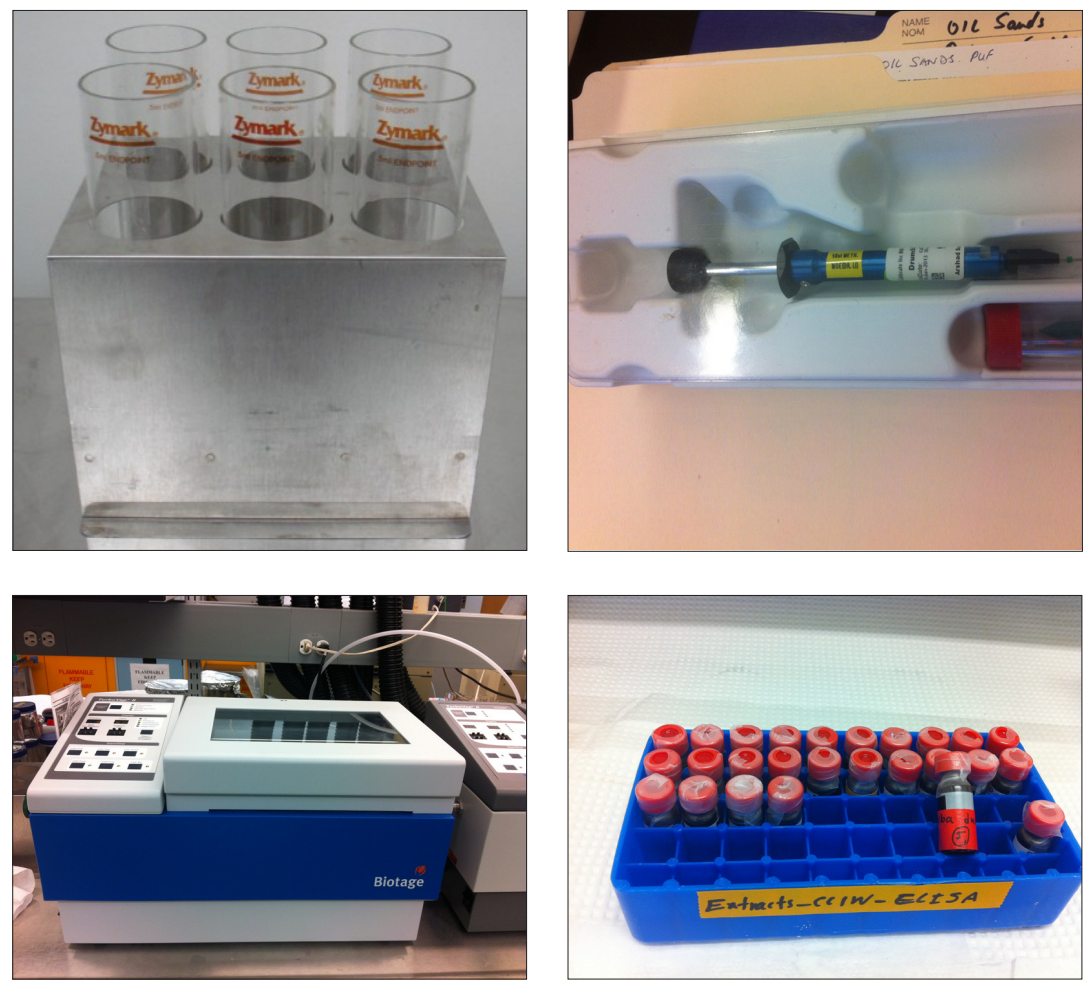

microdispenser

4. Set Temp \& pressure

5. Evaporate to $0.5 \mathrm{ml}$

6. Transfer to vial made up to $1 \mathrm{ml}$ with isoocctane 


\subsubsection{Sample Cleanup}

Particulate matters have very high affinity to adsorb almost to everything from the atmosphere. Hence, air samples contain many unwanted chemicals that are co-extracted with dioxins. These chemicals, specifically long chain molecules and lipids, sequester dioxins and prevent them from actively interacting with antibodies and bind to them (R. Harrison, personal communication, November 2014). Therefore, it is crucial to remove interfering molecules before the sample extracts are introduced to ELISA tubes. Cleanup was performed using acid silica carbon mini-column (SP4-12, SP2/3-ST and SP2-RK kits) purchased from Cape Technologies. This cleanup method was originally designed for screening method for bioassay kits. A dozen of samples can be cleaned up simultaneously with this kit. Acid silica column has $27 \mathrm{~cm}$ length with $15 \mathrm{~mm}$ diameter. Each column contains 5 gram acidic silica gel and the bottom of it is directly coupled onto a little carbon column. Carbon column is packed with $150 \mathrm{mg}$ of $2 \%$ activated carbon (Hope, 2014).

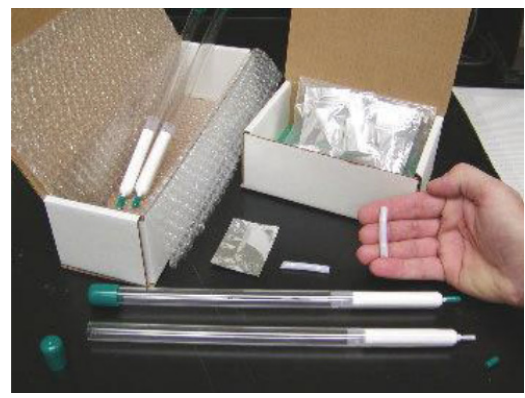

Figure 17.Acid silica carbon-mini-column kit
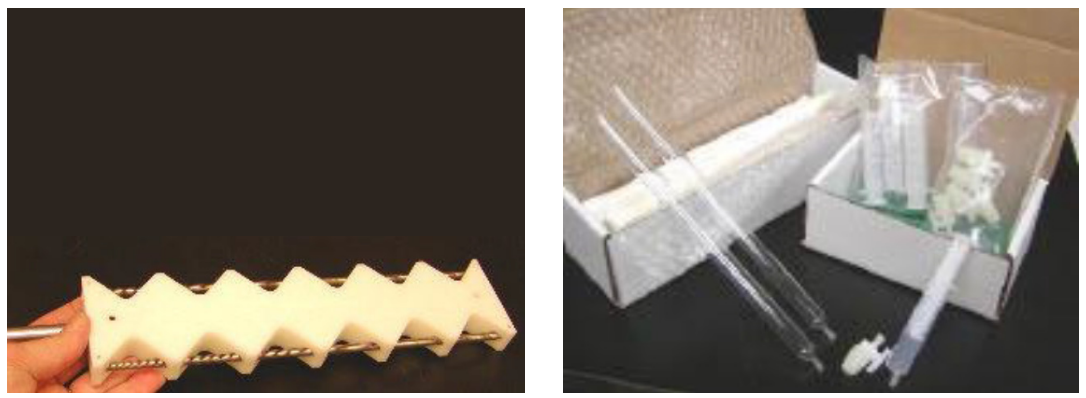

SP4-12 (left), SP2-RK (middle), SP2/3-ST (right)

Source: Cape Technologies website www.cape-tech.com

Each rack can accommodate up to 12 columns, therefore 12 sample extracts can be cleaned up simultaneously. Acid silica column was placed in cleanup rack. $10 \mathrm{ml}$ of hexane was added to top of column and was left to flow by gravity. Solvent was caught in a plastic waste bucket. When hexane started dripping from tip, outside of tip was rinsed with 1-2 ml hexane. The square tip of carbon column was firmly twisted onto tip. To ensure that no air bubble blocks the hexane stream from acid silica column to carbon column, top of mini-column was filled with hexane using a pasture pipette. After carbon column was attached, flow was almost stopped. Thus, a stream of clean nitrogen with approximately 10 psi pressure was applied to increase the flow to approximately $2 \mathrm{ml}$ per minutes. When hexane level reached $1-2 \mathrm{~cm}$ above bed of acid silica column, pressure was removed and diluted extract (extract in $6 \mathrm{ml}$ hexane) was added to top of acid 
silica column and pressure was applied. In total $30 \mathrm{ml}$ hexane was added to complete sample loading onto carbon mini-column. After hexane flowed completely through the acid silica column to the neutral silica layer, pressure was removed and carbon column was detached. In this step all interfering molecules and $80 \%$ of PCBs were removed (fraction 1) (Hope, 2014). Carbon column was removed and was attached from square end to a clean and empty reservoir and was placed in the rack. Clean and marked test tube was placed on a tube holder for dioxin-like PCBs collection. Carbon mini-column was washed with $6 \mathrm{ml}$ 1:1 toluene/hexane and pressure was applied to increase the dripping to 0.5-2 $\mathrm{ml} / \mathrm{min}$. Fractionated PCBs (fraction 2) consisted of all dioxin-like PCBs plus a few other PCBs (Hope, 2014). Fraction 2 collected, capped and stored in freezer. Carbon mini-column was removed, reversed, and attached to the same reservoir from slant cut end. Clean hexane washed test tube was marked and placed on tube holder for dioxins collection. $12 \mathrm{ml}$ of toluene was added to reservoir, pressure was applied and all dioxins eluted from carbon column into test tube (fraction 3). $62.5 \mu \mathrm{L}$ of Triton X-100 keeper (100 ppm Triton X-100 in 80:20 methanol PEG) was added to test tube. The top of tube was covered with aluminum foil, wrapped in parafilm and stored in freezer for next day for toluene evaporation.

- Place acid silica column on rack and pre-wash with $10 \mathrm{ml}$ hexane
- After hexane started dripping attach carbon column from the square cut end to the tip of acid silica column
- load sample (sample extract diluted in $6 \mathrm{ml}$ hexane)
- Add $30 \mathrm{ml}$ hexane and collect solvent (containing all co-extracts and PCBs) in a waste basin (Fraction 1)
- Remove carbon column and attach to an empty reservoir from square cut end
- Add $6 \mathrm{ml} 1$ :1 toluene/hexane
- Collect all dioxin-like PCBs and some other PCBs in test tubes (Fraction 2)
- Remove carbon column and attach to the same reservoir from slant cut end
- Add $12 \mathrm{ml}$ toluene
- Collect all dioxins in test tubes (Fraction 3)
- Add 62.5 microliter keeper and cover the mouth and keep in freezer for the next day for solvent exchange and
analysis with ELISA



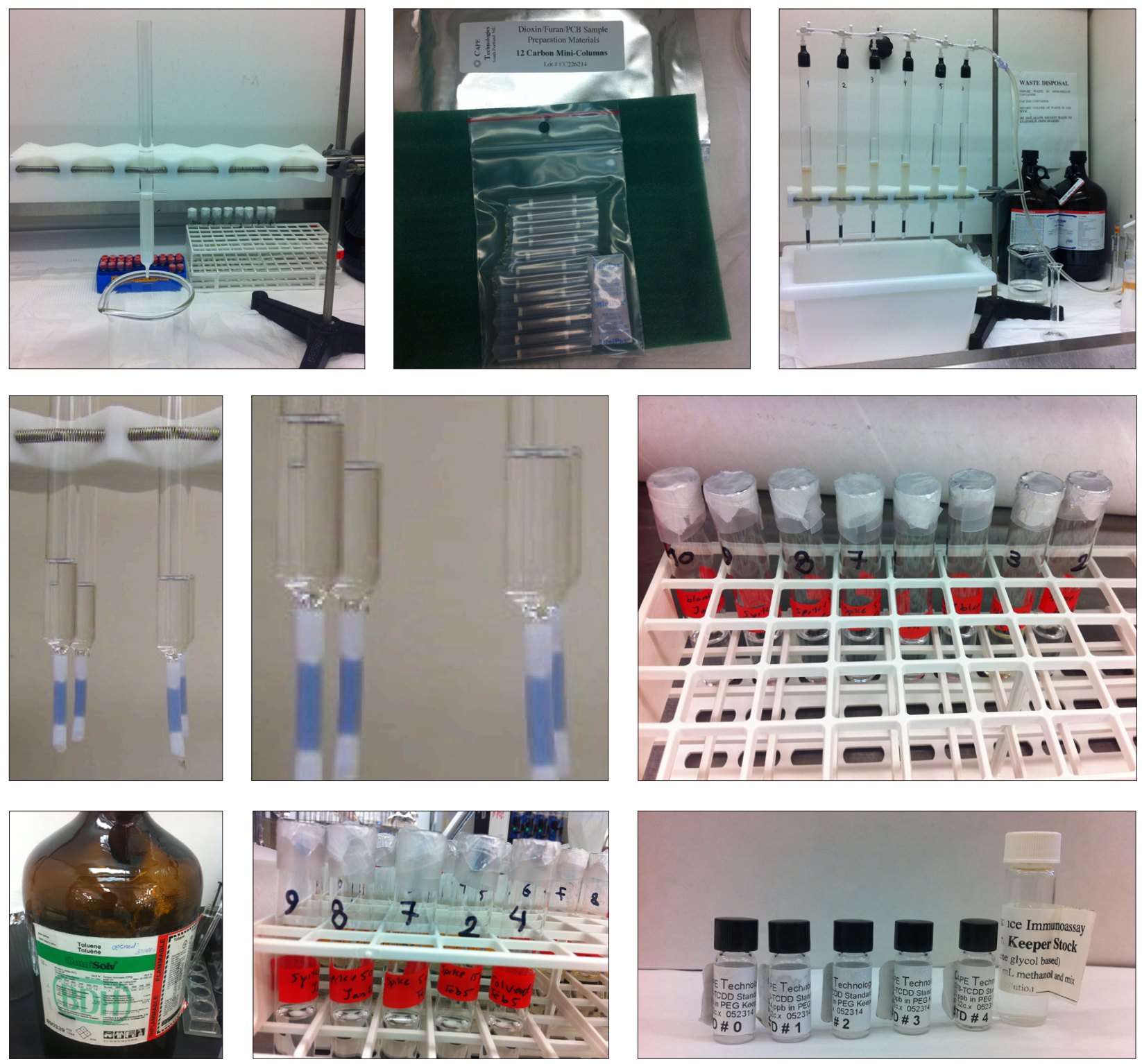

Figure 18. Acid silica carbon column 1. Pre-wash acid silica column with Hexane 2. Attach carbon minicolumn

3.Add sample extractWash with $30 \mathrm{ml}$ hexane
4. Attach carbon column to clean reservoirwash with Hex:Ace

5. Collect PCBs

6. Reverse carbon column attach to same reservoir

7. Wash with $12 \mathrm{ml}$ toluene
8. Collect Dioxins

9. Add keeper \& store

\subsubsection{Toluene Evaporation}

Since toluene is not compatible with ELISA, it has to be removed completely from sample extract prior to introduction to ELISA tubes. This task was done using a dry bath and application of nitrogen 
gas. Application of heat is required because the boiling point of toluene is very high $\left(111^{\circ} \mathrm{C}\right)$ but the temperature has to be well below the boiling point of toluene, therefore, dry bath temperature was set out at $80^{\circ} \mathrm{C}$. Gentle stream of nitrogen is required to increase circulation and sweep away evaporated solvent. It is important that the nitrogen flow rate be kept low enough to prevent aerosol formation. Aerosol formation carries away dioxins from sample extract and leads to dioxins losses.

Clean pasture pipettes were attached to tubes delivering nitrogen. Nitrogen was turned on for 10 minutes to purge the system from dust. Test tubes containing sample extracts were placed in dry bath and evaporation was continued until complete removal of toluene. Sample tubes were centifuged for 30 minuets at $2000 \mathrm{rpm}$ to collect any microscopic droplets inside the tubes wall.
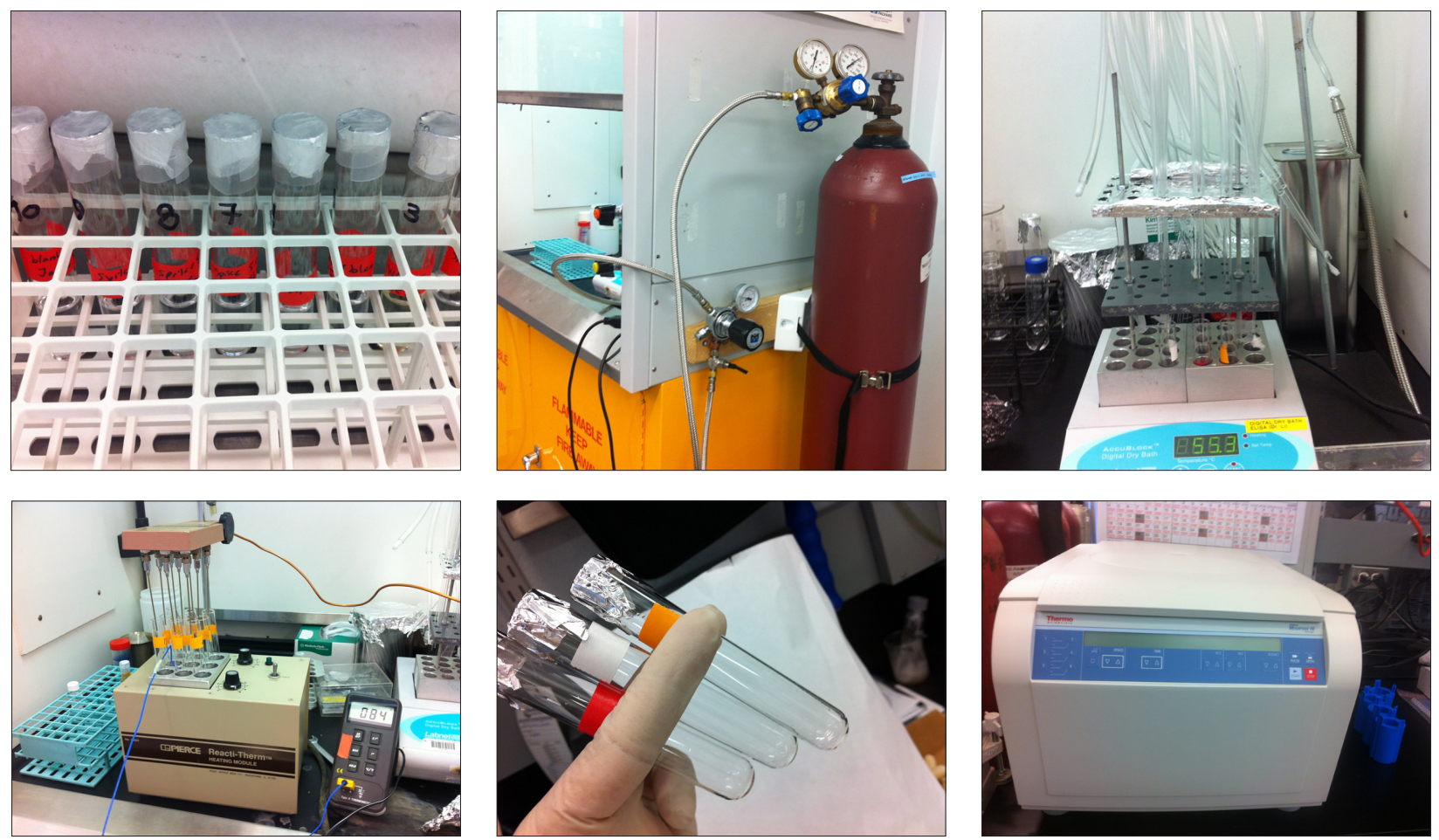

Figure 19. toluene evaporation flow chart

2. Purge the system 3. Insert clean pasture pipettes

\section{Set Temp at $80^{\circ} \mathrm{C}$ and evapo-} rate

5. Check samples 6. Centrifuge

\subsubsection{ELISA Analysis}

The ELISA kit DF1-ST-B purchased from Cape Technologies was used for this analysis. The method is the same method previously used for dioxins analysis with manual extraction. The detailed procedure is available 
in Appendix A. Prior to analysis working tables and vacuum fuming hood were dusted and cleaned with Kimwipe and soup water. Latex poly gloves purchased from Fisher Scientific were used for both protections from accidental exposure and to prevent sample from contamination. Calibration standards were purchased from Cape Technologies. 5 bottles of standards were diluted with $1 \mathrm{ml}$ high purity methanol and mixed for at least 1 minute prior to use. It is recommended by manufacturer that a maximum of 20 tubes be tested in one run to reduce the time to add competitor-HRP conjugate for incubation.

To begin, 20 ELISA tubes were place on magnetic rack, labeled and filled with $5 \mathrm{ml}$ distilled deionized water for antibody rehydration. After at least 5 minutes water was dumped and $0.5 \mathrm{ml}$ of sample diluent was added to each tube. Evaporated samples were reconstituted with $50 \mu \mathrm{L}$ methanol and using microdispenser was added to each ELISA tube. After all samples transferred, $50 \mu \mathrm{L}$ of each standard was added to 6 ELISA tubes, NC was made in duplicate. The whole rack was covered with aluminum foil and placed on a shaker plate to increase the chance of effective contact of dioxins and antibodies for 3 hours at room temperature. The procedure is depicted in Figure 20.
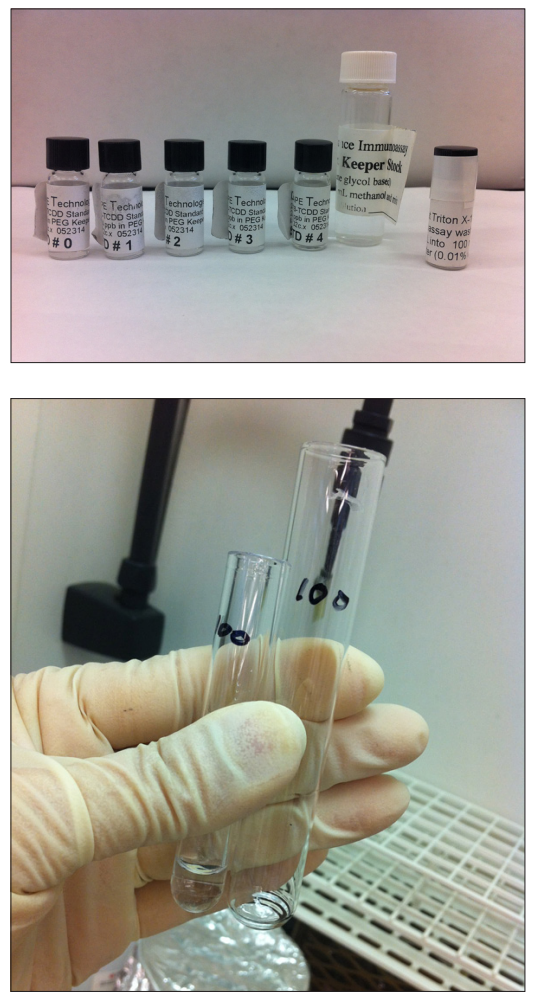

Figure 20. ELISA anlysis flow chart part 1 1. Dilute standards
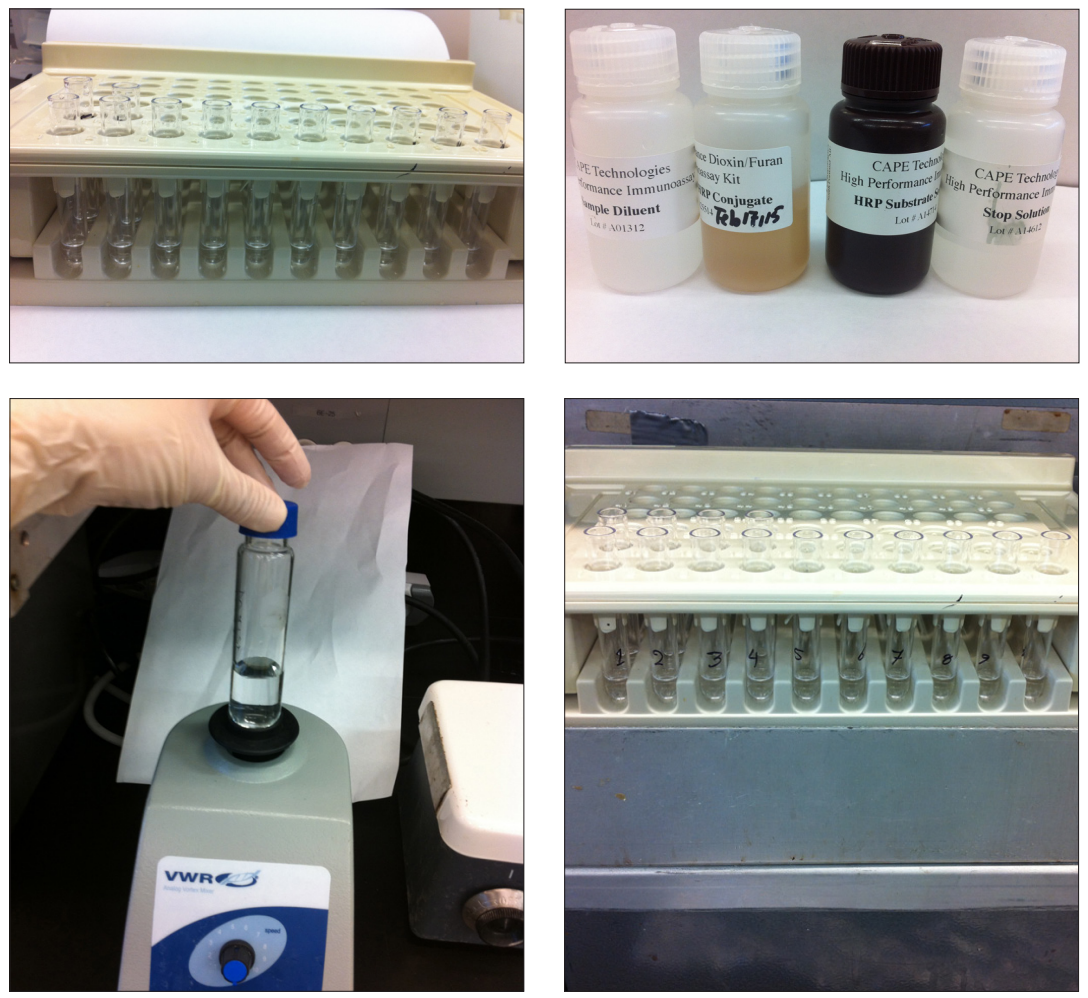

2. Rehydrate antibodies

3. Add sample diluent

4. Reconstitute sample

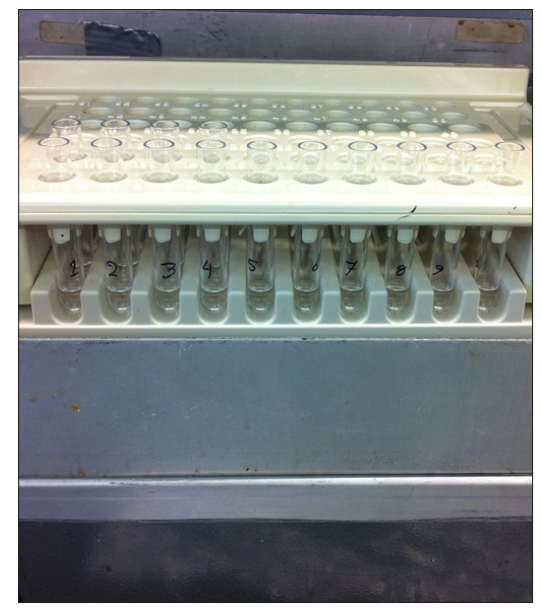

5. vortex \& add to tubes 6. Incubate on Shaker 
After the first incubation, the tubes content were dumped and tubes were washed four times with 1 $\mathrm{ml}$ wash solution for each wash. Then $500 \mu \mathrm{L}$ competitor-HRP conjugate was added to each tube and incubated at room temperature for 20 minutes. The content of tubes were dumped and they were then washed with $2 \mathrm{ml}$ distilled deionized water 4 times and they were filled with $500 \mu \mathrm{L}$ substrate. Tubes were allowed to incubate at darkness for 40 minutes to develop blue colour. After incubation, 500 $\mathrm{L}$ stop solution was added to each tube to stop colour development. The contents were transferred using clean pasture pipettes to cuvettes. The colour intensity (OD) of each cuvette was measured by spectrophotometer at $450 \mathrm{~nm}$ wavelengths.

The standards and samples absorbance intensity inserted to Module $C$ spreadsheet provided by Cape technologies, modified for this study. The original Module has been designed for soil samples and calculates the dioxins concentration per gram of soil. The modified version only calculates the dioxins concentration in each tube. The subsequent step for calculating dioxins concentration in cubic meter of air samples was performed separately. Spreadsheet automatically calculates raw ELISA BEQ. The results were then processed by applying some correction factors, and converted to TEQ. The ELISA TEQ was then directly compared to those of GC analysis. 

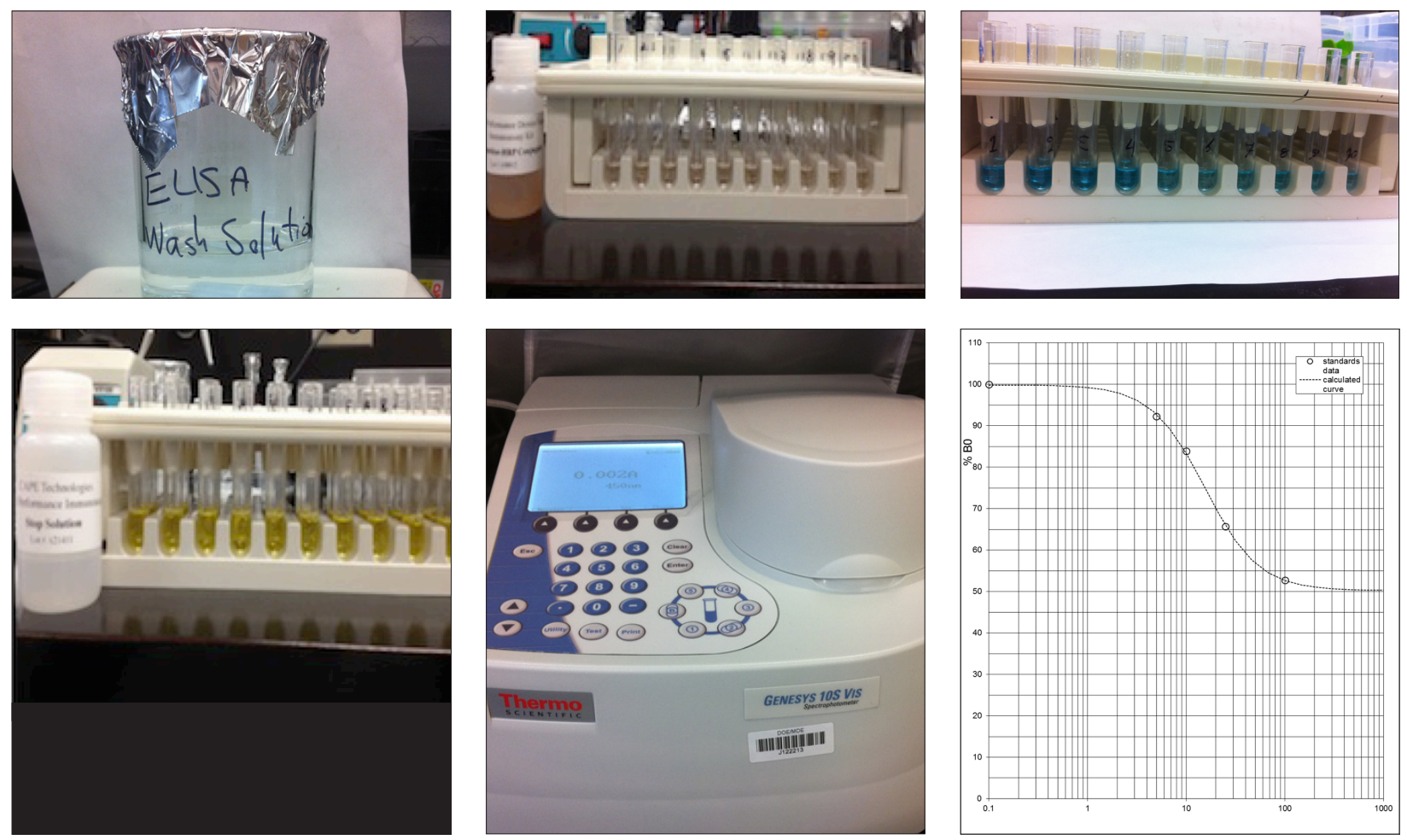

Figure 21. ELISA analysis flow chart part 2

1. Wash with wash solution
2. Add conjugate \& incubate $20 \mathrm{~min}$

3. Wash with DDW Add substrate \& incubate
4. Add stop solution
5. Read absorbance
6. Develop Module C 
CHAPTER FOUR 


\section{Experiment Results, Discussion and Conclusion}

\subsection{Calibration Test}

Preceding testing samples, it is necessary to develop calibration curve to determine if ELISA kit performance in our lab is acceptable. To do so a series of standards purchased from Cape Technologies were tested. The standard kit contains 5 bottle of pure 2,3,7,8-TCDD with concentrations of $0,3.2,10,32$, and $100 \mathrm{pg}$. Standard with 0 concentration is referred to as negative control (NC). Each bottle was diluted with $1 \mathrm{ml}$ high purity methanol and mixed vigorously to distribute dioxin evenly in solvent. ELISA tubes were prepared as defined in Chapter 2 and test was performed in duplicate. $50 \mu \mathrm{L}$ of standard solution was added into each ELISA standard tube and incubated for 3 hours on shaker plate. Subsequent steps proceeded according to procedure. The OD readings were inserted in excel sheet and excel solver automatically solved 4-parameter equation and plotted the calibration curve. The acceptable range of \% NC of standards is given by the manufacturer. The result from this test fell within one standard deviation of the mean concentrations and therefore ELISA was able to accurately report dioxin concentrations. The $r$-squared value of the $n=5$ regression line is 0.994 with a slope of 0.944 .

Figure 22. Correlation between expected and observed values for calibration standards

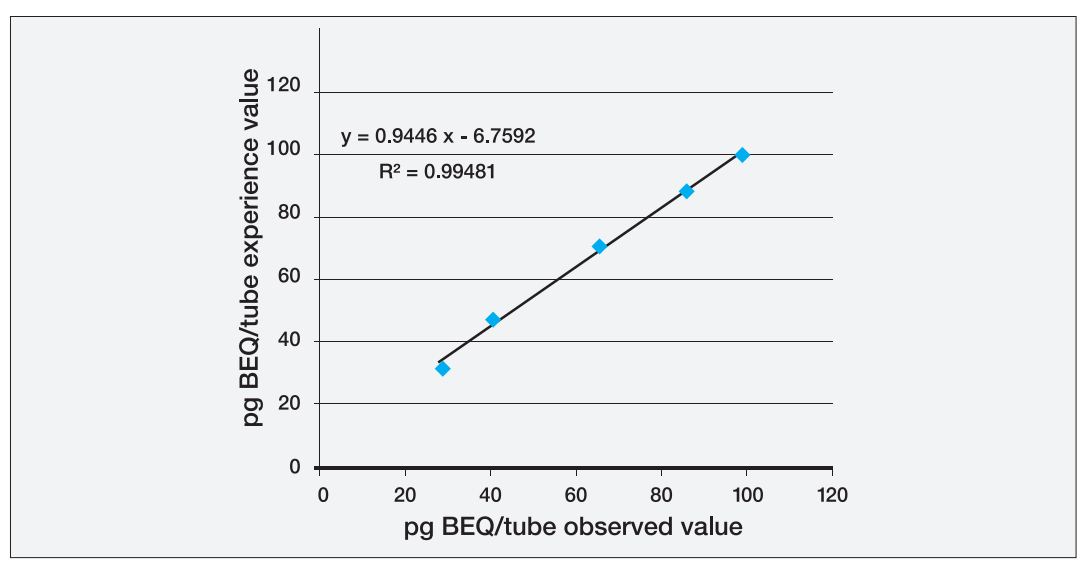




\subsection{Background Contamination}

Since dioxins are found in ultra trace amount in environment it is crucial to identify sources of artificially introduced dioxins that may alter the true result of real sample analysis. Therefore, the carry over from method, filter, and travel were tested.

Filter blank is the dioxins carry over from blank filter used for sample collection. Since filters are baked prior to use, dioxins may form due to oven high temperature and the presence of chlorinated vapour.

Field blank or travel blank refers to dioxins carry over during sample collection and sample shipment. A field blank was prepared by taking a clean filter to the sampling site, installing on sampler without turning on the pump; filter remains on sampler for about 10 minutes and is then taken back to laboratory for analysis.

Method blank indicates the carry over originated from solvents and equipment used for sample preparation. The method blank was tested by placing one empty extraction cell (for each extraction run) in ASE machine; the extract was then prepared and analyzed exactly like the field samples.

For this study 2 method blanks, 3 field blanks, and 7 filter blanks were analyzed in three different runs of ELISA. Since the observed optical density of standards in one of the ELISA analysis were not within the acceptable range recommended by kit manufacturer, no standard curve could be plotted and therefore background concentration of 6 blanks remained undetermined. The remaining 7 blanks were extracted and treated exactly like field samples. The results from background test are tabulated in Table 5.

Table 5. ELISA results for background contamination test with $n=7$ samples

\begin{tabular}{|l|l|l|}
\hline Blank & Filter Proportion & Dioxin Concentration pg BEQ \\
\hline Filter Blank A & Whole Filter & 4.66 \\
\hline Filter Blank B & Whole Filter & 2.64 \\
\hline Method Blank A & No Filter & 3.1 \\
\hline Method Blank B & No Filter & 3.6 \\
\hline Field Blank A & Whole Filter & 4.07 \\
\hline Field Blank B & Whole Filter & 3.67 \\
\hline Field Blank C & Whole Filter & 3.65 \\
\hline Average & & $3.6 \pm 0.65$ \\
\hline
\end{tabular}


The method detection limit (MDL) recommended by the manufacture is $4 \mathrm{pgBEQ}$ per tube; this is the lowest analyte concentration that can be detected and identified with a certain degree of certainty. The average background concentration for this study was found $3.6 \mathrm{pg} / \mathrm{tube}$ with the standard deviation of 0.65 which is below the MDL. When background concentration is below the detection limit there are many ways to report it. In statistical analyses, these values are often censored and substituted with a constant value, such as half the MDL, the MDL divided by the square root of 2 , or

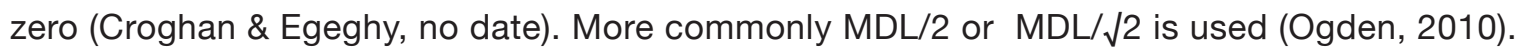

Environment Canada has used both one-half the detection limit and zero for values below MDL in estimating dioxins concentration in ambient air between 1989 and 1997 (Environment Canada, 1998). In this study background concentration was reported zero because the result of a low concentration spike of $3.2 \mathrm{pg} /$ tube (2.8 pg/tube) verified that anything below $4 \mathrm{pg} / \mathrm{tube}$ was unreliable.

Figure 23. ELISA results for the seven blank samples and average with error bar

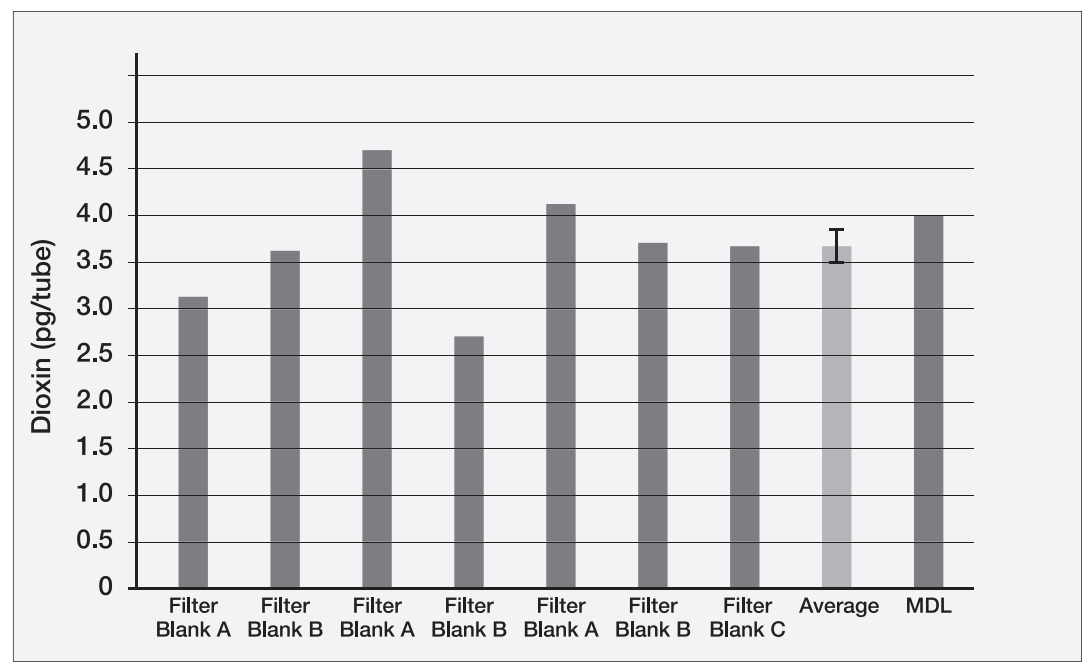

\subsection{Method Recovery Test}

Method recovery is essential for testing and validating a new analytical method. The recovery test is usually performed at three levels of concentration: low, medium and high. The ELISA kit used for this study detects dioxins with concentrations between 4 and $100 \mathrm{pg}$ per tube. Therefore, a series of spike recovery tests conducted at $6.4,32$ and 100 pg per tube.

The firs test was designed and performed to determine percent recovery of each step of sample 
preparation by running triplicate spike of pure 2,3,7,8-TCDD before each step.

12 blank GFF were weighed and numbered from 1 to 12 . The first three filters were spiked with $100 \mathrm{pg}$ dioxin. All filters were then ASE extracted with hexane: acetone (70:30). The extracts were collected and were transferred to conical funnels for acetone evaporation. $0.5 \mathrm{ml}$ of keeper isooctane was added to each tube. $100 \mathrm{pg}$ dioxin was spiked to funnels 4,5 , and 6 each. Funnels were placed into turbovap machine and evaporated down to $0.5 \mathrm{ml}$. Evaporates were transferred to test tubes and reconstituted with $6 \mathrm{ml}$ hexane. $100 \mathrm{pg}$ dioxin was added to test tubes 7 to 9 each. The content of 12 tubes were cleaned up using acid silica followed by carbon mini-column and eluates were captured in new test tubes. Once cleanup completed $100 \mathrm{pg}$ dioxin was added to eluates 10 to 12 each. The final step was evaporation. Prior to evaporation $62.5 \mu \mathrm{L}$ of PEG-Tritonmethanol keeper solution was added to each tube containing toluene eluate. 12 toluene eluates were evaporated at $80^{\circ} \mathrm{C}$ under a gentle stream of nitrogen. Once evaporation completed, tubes were centrifuged, diluted with $50 \mu \mathrm{L}$ methanol and analyzed with ELISA.

Table 6. ASE method recovery results for twelve spike samples

\begin{tabular}{|l|l|l|l|l|l|}
\hline Spike Step & $\begin{array}{l}\text { Number } \\
\text { of Samples }\end{array}$ & $\begin{array}{l}\text { Expected Value } \\
\text { (pg/tube) }\end{array}$ & $\begin{array}{l}\text { Mean Actual } \\
\text { Recovery }\end{array}$ & $\begin{array}{l}\text { Standard } \\
\text { Deviation }\end{array}$ & $\begin{array}{l}\text { Recovery } \\
\text { Rate }\end{array}$ \\
\hline Extraction & 3 & 100 & 39.3 & 14.1 & $39.3 \%$ \\
\hline Acetone Evaporation & 3 & 100 & 56.1 & 12.5 & $56.1 \%$ \\
\hline Cleanup & 3 & 100 & 43.1 & 13.0 & $43.1 \%$ \\
\hline Toluene Evaporation & 3 & 100 & 44.0 & 21.5 & $44 \%$ \\
\hline
\end{tabular}

It was expected that dioxin losses may occur in each step of sample preparation and therefore spike recovery result would show an increasing trend from extraction to toluene evaporation. However, the observation from this test rejected the increasing trend hypothesis. No explanation was found to justify the higher observation from acetone evaporation except that samples might have been contaminated during the analysis. Except for acetone evaporation, approximately the same recovery was observed from all steps (42\%). Since the toluene evaporation was the only commonality between spike samples, the link between dioxin losses and toluene evaporation was made and investigated. 
Figure 24. ELISA

results for the twelve

recovery test samples

and average with error

bar

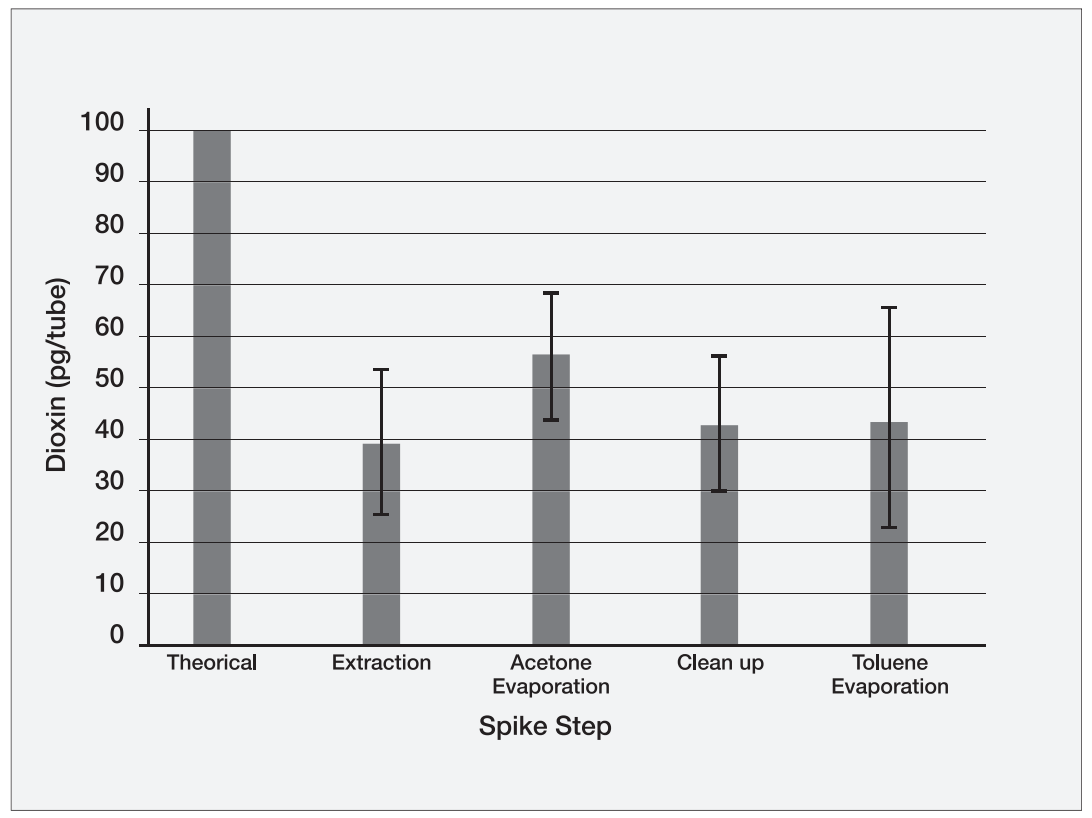

The first possibility may stem from incomplete toluene evaporation. Toluene has very high boiling point $\left(111^{\circ} \mathrm{C}\right)$ and it may remain in the tube even after the tube appears to be dry. The presence of toluene in incubation tube does not allow dioxin to interact to antibody and therefore, reduces the recovery.

The second possibility stems from possible residue in toluene. Even in the production of purest toluene it is possible that residue is carried through distillation along with the toluene. If this is the case, residue in incubation tube can reduce the recovery by 20 to $30 \%$.

Because the testing for residue was not possible, a recovery test was designed to test only completeness of evaporation on a duplicate of low concentration (6.4 pg/tube), a duplicate of medium concentration (32pg/tube), and a triplicate of high (100 pg/tube) concentration of standard spikes. Dioxin standards were added to $12 \mathrm{ml}$ toluene and $62.5 \mu \mathrm{L}$ of PEG-Triton-methanol keeper solution was added to each tube. Tubes evaporated at $80^{\circ} \mathrm{C}$ and under a gentle stream of nitrogen and checked periodically. Once tubes appeared to be completely dry, evaporation was continued 30 more minutes. After evaporation was completed tubes were tested by ELISA analysis. Numerical value of ELISA on spikes is tabulated in Table 7. 
Table 7. ASE method recovery results for seven spike samples after extended toluene evaporation

\begin{tabular}{|l|l|l|l|l|}
\hline Spike Level & $\begin{array}{l}\text { Expected value } \\
\text { (pg/tube) }\end{array}$ & $\begin{array}{l}\text { Mean Actual } \\
\text { Recovery }\end{array}$ & Standard Deviation & Recovery Rate \\
\hline Low & 6.4 & 3.6 & 0.5 & $56.2 \%$ \\
\hline Medium & 32 & 28.5 & 2.7 & $89 \%$ \\
\hline High & 100 & 82.4 & 3.6 & $82.4 \%$ \\
\hline
\end{tabular}

The findings from this test indicate that extending the toluene evaporation significantly improves the recovery. Increased evaporation enhanced the recovery rate at high concentrations to a mean of $82.4 \%$ and at medium concentrations to a mean of $89 \%$. The recovery for low concentrations did not improve significantly. From the result of this test two evaporation correction factors for medium and high concentrations were developed and were applied for the correction of the field samples. Since no sample was detected with low concentration, correction factor for low concentration samples was not applicable.

Figure 25. ELISA results for the seven spike recovery test with extended toluene evaporation and average with error bar

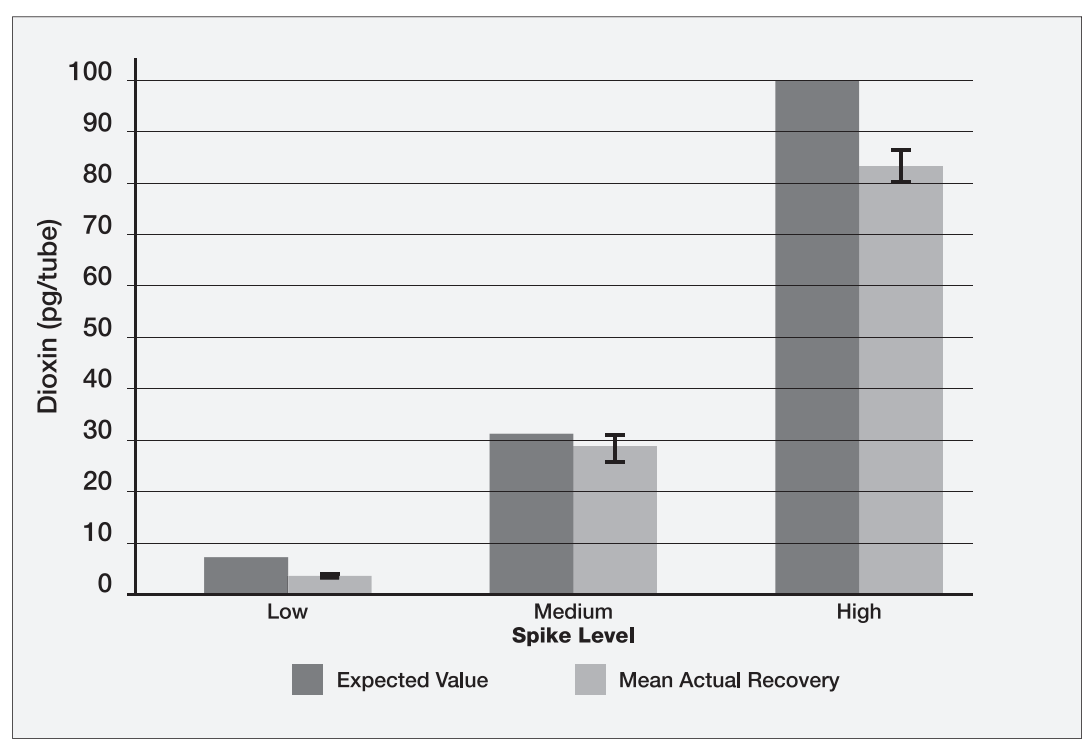

\subsection{Certified Reference Material (CRM) Test}

CRM test was performed as one of the requirements for method validation to measure how accurately ELISA can estimate the dioxins concentration. CRM used for this study was Urban Dust-1649b provided by Environment Canada. The mean mass fraction of dioxins and furans were reported on dry mass basis. Material as received contained approximately $1 \%$ moisture. The ELISA kit used for this study is 
sensitive to dioxin concentrations between 4 to $100 \mathrm{pgTEQ} /$ tube, therefore first the TEQ of CRM was calculated using WHO TEF 2005 and Eq. 1 (introduced in Chapter One) to calculate the sample size. The Expected BEQ was also calculated using Eq. 4 to determine the correlation between expected and observed ELISA values. (TEQ and expected BRQ calculations are provided in Appendix B, Table B1) Expected $\mathrm{BEQ}=\sum_{i=1}^{17}$ (cross reactivity $i \times$ mass fraction $\left.i\right)($ Eq. 4$)$

Since the congener profile was provided, the congener correction factor was calculated based on procedure developed by Buan, 2009. The author previously proved that congener correction factor converts ELISA BEQ to ELISA TEQ and can increase the correlation between ELISA and GC-HRMS in soil samples; and ELISA TEQ results can be directly compered to those of GC-HRMS. Congener correction factor calculation is provided in Appendix B, Table B2.

Test was performed by first adding anhydrous sodium sulfate to extraction cell in order to remove moisture from CRM. A few droplet of acetone was added to filter; this will increase the absorbance of dust to filter. CRM was shaken properly to ensure that dioxins were evenly distributed. Filter was placed on a piece of clean baked aluminum foil and placed into Sartorius balance with precision of $0.0001 \mathrm{gram}$. Balance was then normalized; and with a clean scoopula approximately $0.1 \mathrm{~g}$ dust was added on filter. The exact weight recorded, filter was folded and placed into ASE cell for extraction.

The total of 6 CRM were extracted and undergone the complete sample preparation processes. 4 extract were lost during ELISA analysis. The result from 2 remaining CRM is as below:

Figure 26. Comparison between ELISA results for duplicate CRM samples and GCHRMS calculated TEQ without correcting for congener profile

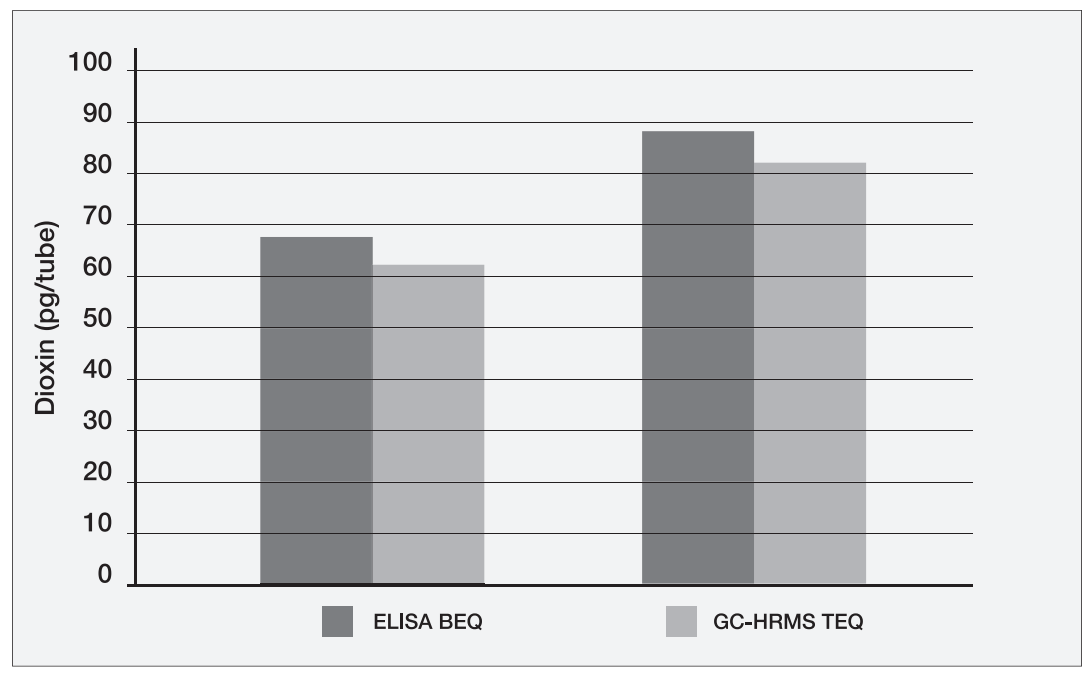


Finding from this test demonstrate that ELISA results corrected for method recovery, very well correlated to the result obtained from GC-HRMS analysis. ELISA overestimates the result by approximately $7 \%$. However, when sample specific congener correction factor was applied, a significant disagreement between ELISA and GC-HRMS results was observed. Sample specific correction factor increased the ELISA results to an average of $48 \%$ higher than GC-HRMS values.

Figure 27. Comparison between ELISA results for duplicate CRM samples and GCHRMS calculated TEQ after correcting for congener profile

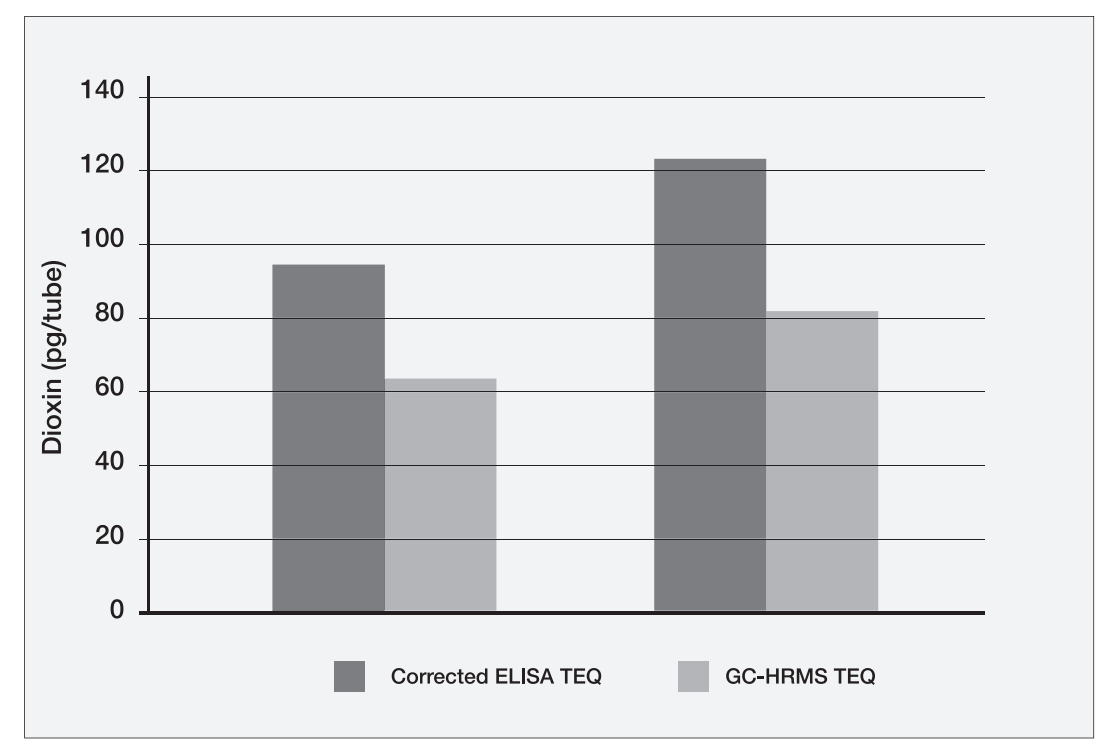

\subsection{Ambient Air Samples}

The findings form calibration, recovery, and CRM tests showed that the ELISA method is able to detect dioxins extracted with ASE automated method. Therefore, it was predicted that the similar result could be obtained for the analysis of real field samples. Thus, a total of 15 out of total 20 air samples collected from November 2014 to February 2015 were extracted and analyzed with ELISA. Five parallel samples were sent to Wellington Laboratories for testing with GC-HRMS for verification of ELISA results. Two urban dust samples with known congener profile were also tested with ELISA. Therefore, there were a total of 7 samples that had both ELISA and GC-HRMS results for comparison. A series of sample specific congener correction factors was calculated for each sample with known congener profile. The site-specific congener correction factor was then calculated for CCIW sampling site by taking an average from sample specific correction factors (0.85). ELISA BEQ results were corrected for evaporation losses and congener profile differences. The corrected ELISA TEQ results where then compared to those of GC-HRMS. 
Based on the literature only $10 \%$ of dioxins are partitioning in gas -phase. The ELISA result on particle-phase dioxins (GFF analysis) showed that the gas-phase dioxins concentrations fell below the method detection limit and therefore no PUFs were analyzed with ELISA.

\section{Table 8. Ambient air samples analysis results of ELISA and GC-HRMS}

\begin{tabular}{|l|l|l|l|}
\hline Sample Number & $\begin{array}{l}\text { ELISA corrected for } \\
\text { recovery (pg/tube) }\end{array}$ & $\begin{array}{l}\text { ELISA corrected for } \\
\text { congener (pg/tube) }\end{array}$ & GC-HRMS (pg/tube) \\
\hline 1 & 53.5 & 45.5 & 37.4 \\
\hline 2 & 85.9 & 73.0 & 43.5 \\
\hline 3 & 23.4 & 19.9 & 37.8 \\
\hline 4 & 37.3 & 31.7 & 62.2 \\
\hline 5 & 38.0 & 32.3 & 30.70 \\
\hline 6 & 55.3 & 77.5 & 63.3 \\
\hline 7 & 72.2 & 101.0 & 82.2 \\
\hline
\end{tabular}

The result from statistical analysis indicated that concentration of dioxins detected by ELISA and by GC-HRMS correlates significantly at $95 \%$ confidence level $(0.01<p<0.05)$ although the correlation coefficient $r^{2}$ is 0.59 $(n=7)$. A distribution test was performed on data from both methods. Since number of data was very limited no conclusion could be made whether data were distributed normally and f-test on variances of two methods failed to prove that two methods were correlating $(F=2.46)$. Therefore, due to limited number of data points, the correlation between ELISA and GC-HRMS is inconclusive.

Figure 28. Correlation between ELISA and GC-HRMS results for $\mathrm{n}=7$ sample set

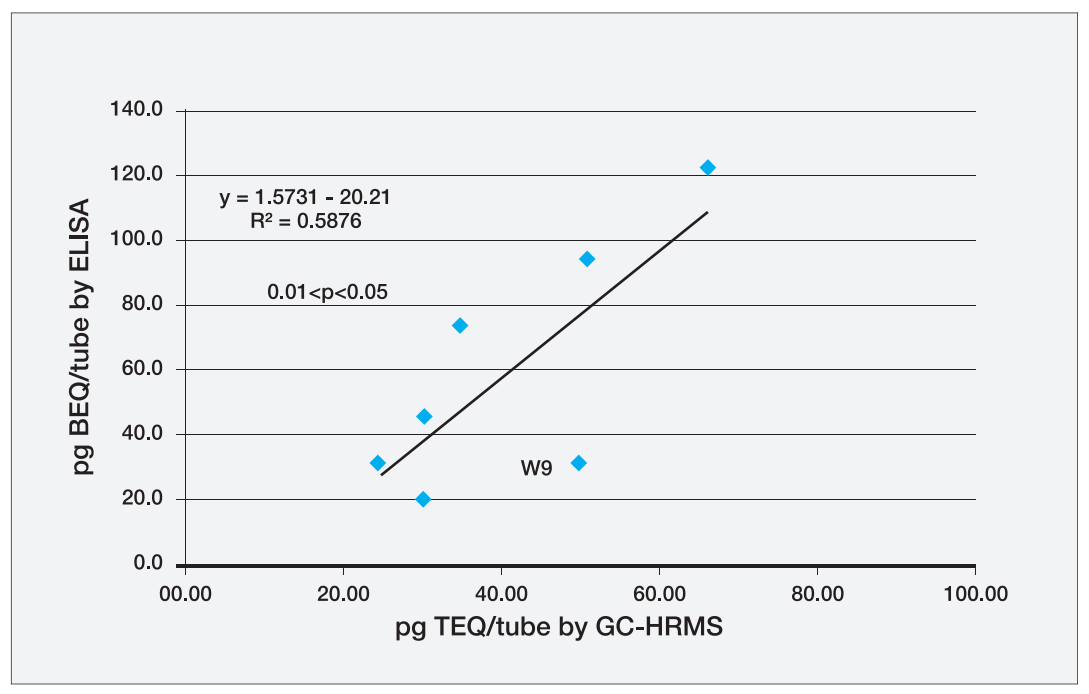


Looking at the plot, the W9 gives a visual subjective impression that the data point might be an outlier; which if true removing it might improve the correlation drastically $\left(r^{2}=0.89\right)$. Therefore, the outlier bagplot test was carried out. The result is shown in Figure 28. The median of the data set is denoted by the red asterisk. The fence circumscribing the dark blue area describes the parameter of $1 \mathrm{SD}$ while the outmost fence containing the light blue area marks the 2SD perimeter. The outlier test failed to exclude the W9 as an outlier data point. Since the sample size did not provide the resolving power to statistically identify W9 as an outlier, there was no legitimate reason to delete it from the data set. Therefore, the plot remained the way it is.

Figure 29. Bagplot (Bivariate Boxplot) for outlier testing

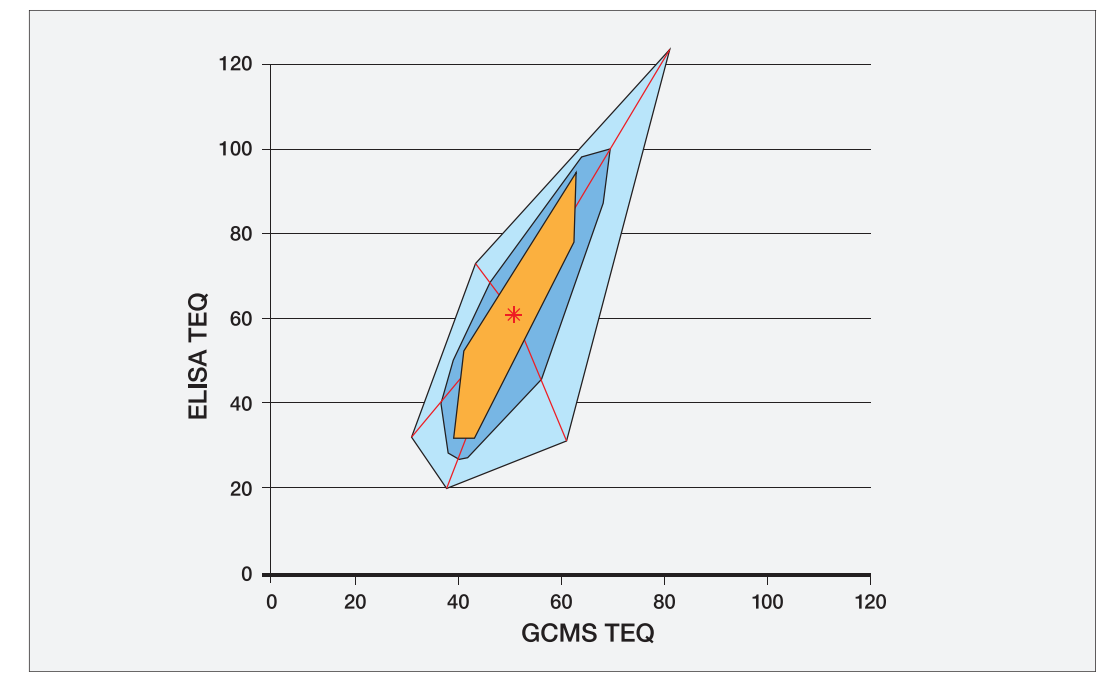

Reiner et al., 2006 reports that there is possibility that compounds competing for the same site might antagonize or synergize each other and exhibit overall unexpected toxicity. Although evidence to support this argument are limited, an investigation on congener profiles was carried out to determine the extent of variability on mass fraction of congeners from different weeks. The mass fraction of $1234678-\mathrm{HpCDD}$ and OCDD in sample from W9 was noticeably higher from the rest. The cross reactivity of HpCDD and OCDD are 0.0002 and 0.00001 respectively. Although the concentration of the two congeners is considerably high, the low cross reactivity would off set the overall contribution in ELISA BEQ based on additive model (contribution of individual congeners are provided in Appendix B). If the antagonizing effect of congeners hypothesis holds true, then the unexpected low BEQ of W9 might be explainable. However, no research was found in open literature to determine whether dioxin congeners have synergizing or antagonizing effects and if they do to what extend. This hypothesis might need numerous 
analyses to investigate the mutual effect of huge number of possible combinations of congeners.

The second consideration for the unexpected result of W9 might be related to temperature fluctuations. Hites and Harless, 1991 and Hippelein, 1996 and others report that lower chlorinated dioxins are found to a greater extent in vapor phase. The exchange of a specific congener between particle and gas phase is controlled by specific congener vapor pressure, the atmospheric temperature, and the particles concentration in atmosphere. For a given congener, the portion in gas phase increases with the increase in temperature and decreases with the increase in particle concentrations. Since only particle phase dioxins were examined in this study, it was expected that the dioxin concentration would increase with the decrease in temperature. No data existed on particle concentrations in air and data from ELISA-Temperature comparison (Figure 30) did not exhibit any trend, hence no speculation or conclusion could be drawn and the reason for W9 result remained unexplained.

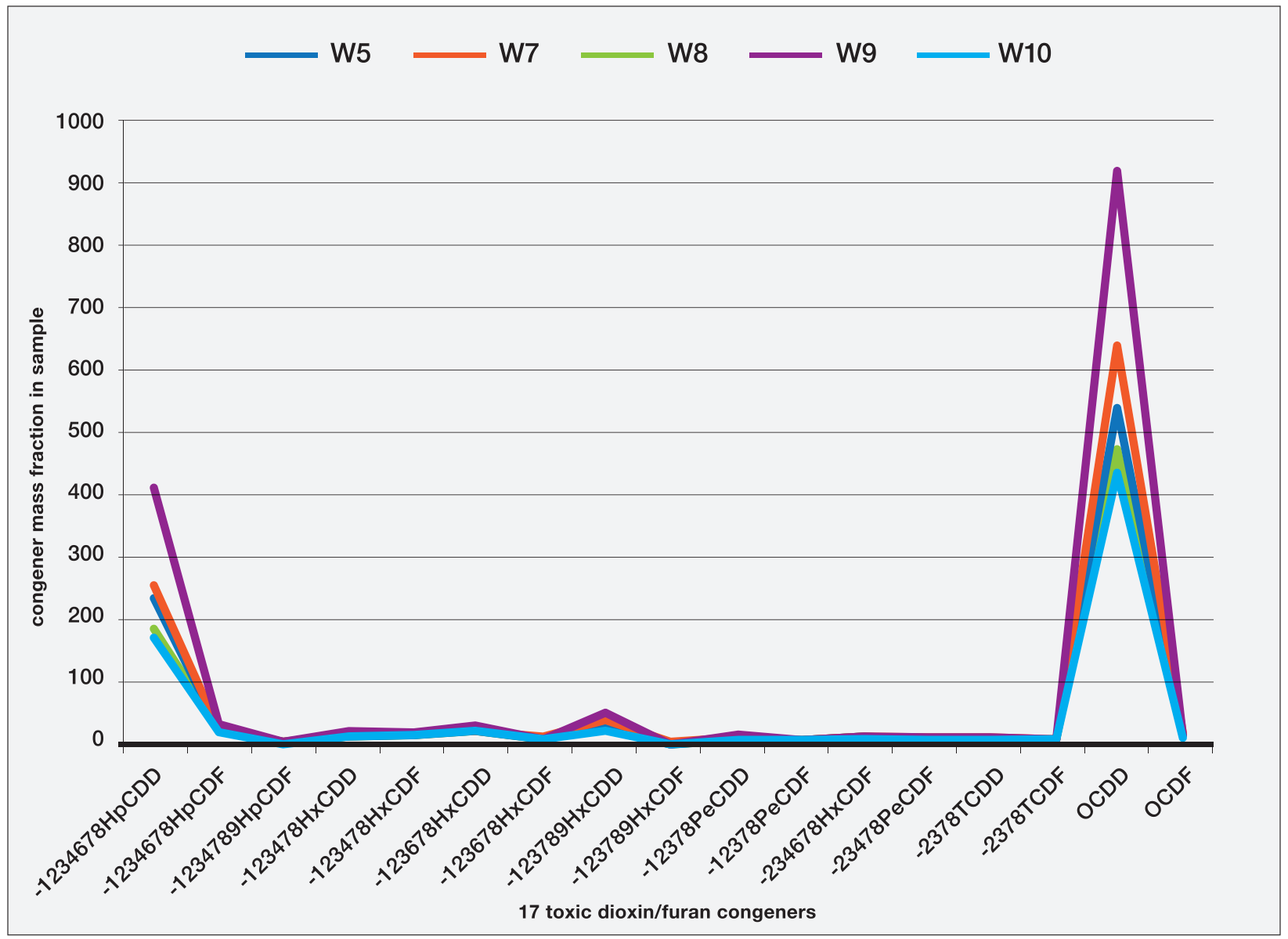

Figure 30. Dioxins and

furans mass distribution

in five field samples 
Figure 31. Comparison

of ELISA results

with temperature

fluctuations

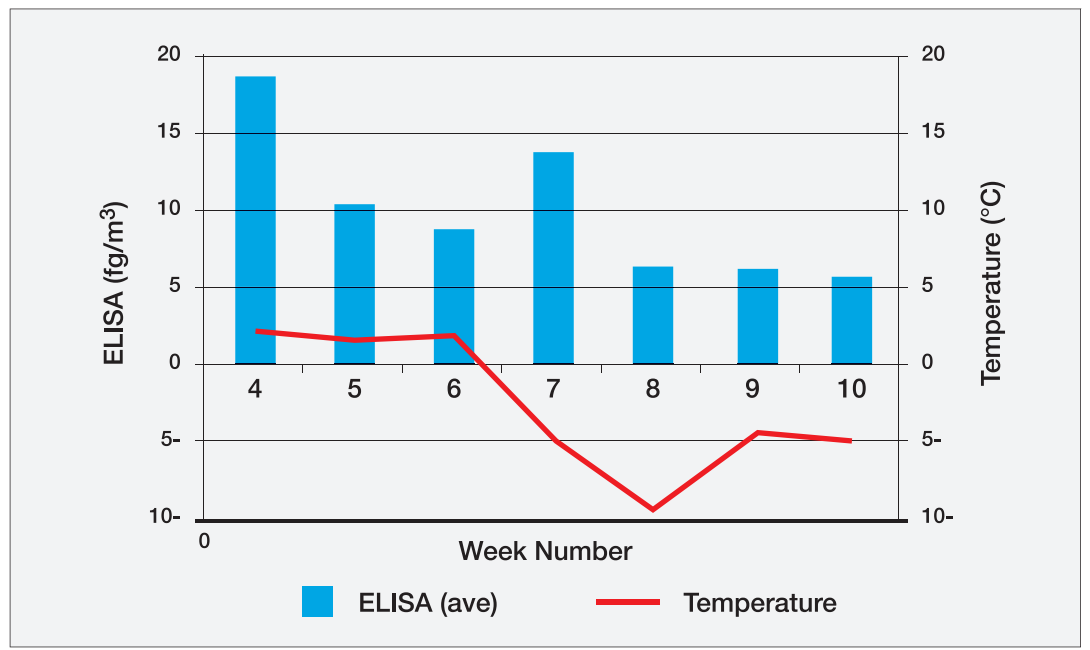

A Bland \& Altman quantitative analysis was perform on seven samples with known GC-HRMS results ( two samples are overlapped) to determine the extent of differences in measurements between ELISA and GCHRMS. The observation from this assessment verified the finding from Buan, 2009 study that ELISA overestimates the dioxin, specifically in mid-high range of concentrations (30-80 pg/tube). The observation showed that ELISA overestimation increases with the increase in dioxin concentrations.

Figure 32. Bland \& Altman ELISA GC-HRMS mean-difference chart

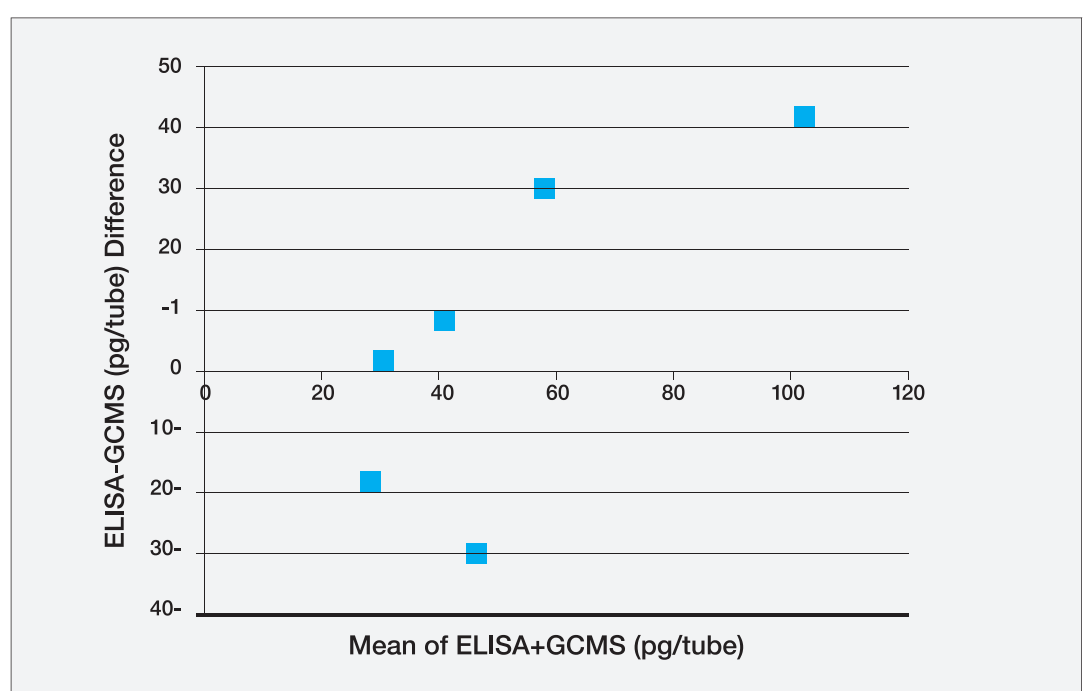

Although ELISA and GC-HRMS results did not agree on all individual samples analyzed, the average concentration in ambient air from both measurements agreed perfectly. The average atmospheric concentration of dioxins in Burlington with GC-HRMS analysis of five field samples was found $10.04 \mathrm{fgTEQ} / \mathrm{m}^{3}$ and the finding from this study on 10 field samples within the same period of sampling samples estimated the atmospheric dioxins concentration to be $9.96 \mathrm{fgTEQ} / \mathrm{m}^{3}$. This agreement shows that ELISA can be employed as a screening tool to produce a reliable estimate for dioxins concentration in air. 


\section{CHAPTER FIVE}




\section{Conclusion}

The finding of this study illustrated that automated pressurized liquid extraction method using hexane and acetone as extraction solvent (70:30) with subsequent acid silica carbon mini-column cleanup procedure is capable of extracting low concentrations of dioxins in ambient air samples. The automated sample preparation combined with ELISA could estimate the average dioxins concentration in ambient air collected from Burlington, Ontario $\left(9.7 \mathrm{fg} / \mathrm{m}^{3}\right)$. The value was in agreement with the result of GC-HRMS on air samples $\left(10.04 \mathrm{fg} / \mathrm{m}^{3}\right)$ collected over the same period of sampling. However, due to limited number of samples, the apparent correlation between the results of GC-HRMS and ELISA could not be statistically established.

The sample processing method was further improved by extending the toluene evaporation to half an hour or higher. Recovery from high and medium concentrations of dioxins was increased from an average of $45 \%$ to $82.4 \%$ and $89 \%$ respectively. Recovery for low concentrations was observed to be $56.3 \%$. Subsequently two evaporation correction factors were defined for correcting the high and medium concentrations of ELISA BEQs. The application of evaporation correction factors increased the agreements between ELISA and GC-HRMS results. The improved method demonstrated over $85.7 \%$ recovery, which is well over the minimum acceptable recovery rate for monitoring purposes (70\%).

The automated pressurized liquid extraction has many advantages over the manual method. The automated method eliminates the use of carcinogen dimethylformamide for dioxins extraction from sampling media by substituting the mixture of hexane and acetone at elevated temperatures. It 
eliminates the use of fuming sulphuric acid for removing interfering co-extracted chemicals by utilizing acid silica carbon column for cleanup. Another advantage of automated method is the capacity to extract up to 24 samples simultaneously unattended overnight, which reduces the time for extraction to 25 minutes per samples and reduces labour and human error. Furthermore, automated method reduces down the use of solvent for extraction to $34 \mathrm{ml}$ per samples. Finally this method is more in line with the methods currently used for extracting other persistent organic pollutants in air.

The three performance characteristics of PLE/ELISA are (1) result of CRM (7\% overestimation). (2) Average $85.7 \%$ recovery. (3) Good agreement with GC-HRMS. These performances indicates that PLE / ELISA can be used as a screening tool to monitor the dioxins in ambient air, which in Canada has been discontinued due to high cost of GC-HRMS analysis after 2012 (CMC, 2014). 
CHAPTER SIX 


\section{Recommendation}

This study demonstrated that PLE / ELISA is capable of estimating the low concentrations of dioxins in ambient air. The average dioxin concentration over the two winter months was observed $9.96 \mathrm{fg} / \mathrm{m}^{3}$, which agrees with the result of GC-HRMS. However, due to limited number of samples correlation between two methods was inconclusive. Therefore, the first recommendation would be to continue the research by analyzing more samples to help to identify whether the results of PLE / ELISA correlates to those of GC-HRMS.

The observed average concentration $\left(9.96 \mathrm{fg} / \mathrm{m}^{3}\right)$ in ambient air agrees with $10 \mathrm{fg} / \mathrm{m}^{3} \mathrm{LLOQ}$ target for virtual elimination. However, the result attributes to the limited number of samples over a short period of time. Taking into consideration that dioxins concentration in some samples was noticeably higher than LLOQ, it is recommended to continue monitoring over a longer period of time in order to provide the time trend distribution and a more accurate estimation of dioxins average concentration in air.

PLE / ELISA can be incorporated to improve the NPRI database. Dioxins producers report their annual release using mathematical equations and incorporating emission factors. The noticeable uncertainty in emission factors increases the uncertainty in results. Therefore, NPRI database fail to reflect the real dioxins emission into air. The PLE / ELISA can be adapted for periodic monitoring and evaluation of the accuracy of the reports and evaluation of potential sources of emission that have been missed from NPRI reporting list. 
Adaptation of PLE / ELISA for periodic monitoring would help to evaluate the effectiveness of CWS pollution prevention strategies put into practice by priority sectors in order to meet the final goal of dioxins virtual elimination.

Finally, smoke from forest fires or industrial incidents can pose a health risk. The decision to evacuate a community because of smoke can be risky, disruptive and costly. PLE/ELISA as a fast screening tool can be beneficial for detecting dioxins in fire incidents. It can assist for emergency decision making to whether or not evacuate a community. 
APPENDIX 


\section{APPENDIX A - Standard operating procedure for air filter}

\section{Samples}

This draft Standard Operating Procedure (SOP) describes the general methodology that has been developed to prepare samples in ambient air matrix using Enzyme-Linked Immunosorbent Assay (ELISA). It has been written to describe the changes needed for dioxin and furans sampled from air filter samples based on MOE Draft Method 3486 (Lo and Clarke, no date) and so it only includes sample weighing and evaporation. These four steps are a modified version of the methodology presented by Cape Technologies (Cape-Tech, 2002). Sample volume reduction has adapted from Environment Canada SOP for PAHs. The Oxidation (cleanup) is a modified version of methodology presented by Cape Technologies for soil samples.

\section{APPARATUS}

\subsection{Equipment}

1.1.1. Sample Weighing

Digital scale - Sartorius 2007 MP

Calibration weights

Fume hood

\subsubsection{Extraction and Volume Reduction}

Dionex ASE 200 Accelerated Solvent Extraction System.

Turbovap-200

Fume hood

1.1.3.Cleanup

Fume hood

\subsubsection{Evaporation}

Parker Balston Nitrovap Generator

Accublock Digital Dry Bath

Bucket for nitrogen purge

Nitrogen drying apparatus

Fume hood

Vortex mixer 


\subsection{Labware}

\subsubsection{Sample Weighing}

Blue capped centrifuge tube -1 for each sample

Gloves

Kimwipes

Labelling tape

Metal scoopula

Protective breathing mask

Small $50 \mathrm{~mL}$ beaker

Stainless steel scissors

Teflon-capped glass vial - 1 for each sample

Telfon-coated steel forceps

\subsubsection{Extraction and volume reduction}

Dionex stainless steel extraction cells, $11 \mathrm{ml}$.

Graduated cylinders, Pyrex 500 mL.

Pasteur pipettes, 9 inches, borosilicate, disposable, Kimble, $2 \mathrm{~mL}$ capacity

Beakers, $10 \mathrm{~mL}, 100 \mathrm{~mL}, 200 \mathrm{~mL}$ capacity.

Conical funnels, $7.5 \mathrm{~cm}$ dia., long stem, Kimble 58 USA.

Volumetric pipette, $0.5 \mathrm{~mL}, 1 \mathrm{~mL}$ capacity, and pipette bulb

Stainless steel forceps.

Stainless steel tweezers.

Aluminum foil, Reynolds.

Graduated centrifuge tubes, $5 \mathrm{~mL}$, Lassale Scientific, $0.1 \mathrm{~mL}$ graduations.

Vials, amber, $2 \mathrm{~mL}$, wide-mouth, robo vial with marking spot, Canadian Life Science, PTFE/silicone/

PTFE, $11 \mathrm{~mm}$.

Vials, clear, $2 \mathrm{~mL}$, wide-mouth, robo vial with marking spot, Canadian Life Science, PTFE/silicone/PTFE, $11 \mathrm{~mm}$.

Stainless steel containers, $4 \mathrm{~L}$

Turbovap tubes, $50 \mathrm{~mL}, 200 \mathrm{~mL}, 500 \mathrm{~mL}$ capacity, Zymark

Dionex solvent reservoirs, $1 \mathrm{~L}$ Collection vials $60 \mathrm{~mL}$, with screwcaps, ultra clean septa, Dionex.

Solvent rinsing bottles, $500 \mathrm{~mL}$, PTFE.

Gloves, latex, powder free, Fisher Scientific, small, medium, large.

Gloves, nitrile, powder free, Fisher Scientific, small, medium, large.

Beakers, stainless steel, $1 \mathrm{~L}$. 
1.2.3. Cleanup

Acid silica column

Carbon mini-column

High density polyethylene rack

Needle funnel

6 solvent resistant 3-way luer stopcoks

6 port Manifold with 1-way luer stopcock

Solvent resistant $15 \mathrm{~mm}$ pressure cap

Gloves

6 male luer plugs

2 female luer

6 glass reservoir

Basin or other receptacle(s) to catch waste from column cleanup procedure.

\subsubsection{Evaporation}

Aluminum foil

Gloves

Kimwipes

Parafilm

Pasteur pipettes to connect to the drying apparatus - one for each sample

Protective Eyewear

\subsection{Reagents}

\subsubsection{Sample Weighing}

Anhydrous Sodium Sulphate

\subsubsection{Extraction and volume reduction}

Hexane

Acetone

Toluene

Isooctane

\subsubsection{Evaporation}

None 


\section{GENERAL CONSIDERATIONS}

The sample weighing, extraction, oxidation and evaporation steps are written for the preparation of one air sample at a time. Samples can be sealed with parafilm and stored in the fridge at any point in the procedure listed here. It was also written to take the sample algorithm into consideration.

\section{LABORATORY PROCEDURE}

Note: as samples may contain high levels of dioxins and other contaminants, be sure to always wear gloves and a protective breathing mask and always work in a fume hood.

\subsection{Sample Preparation}

3.1.1. Clean a pair of stainless steel scissors. The cutting-edge of the scissors should be soaked into a $16 \mathrm{~mm}$ borosilicate tube containing approximately $10 \mathrm{ml}$ of DCM solution for at least 5 minutes in succession of three tubes.

3.1.2. Clean a style of Teflon-coated steel forceps with flat tips. The tip of the forceps should be soaked into a $16 \mathrm{~mm}$ borosilicate containing approximately $8 \mathrm{ml}$ of DCM solution for at least 5 mins in succession of three tubes. NOTE: Avoid using pointed forceps that may cause damage the filter surface.

\subsubsection{Prepare 5 pieces of aluminum-foil with dimension of $10^{*} 10 \mathrm{~cm}$}

3.1.4. Leave the scissors and forceps separately on two pieces of aluminum foil until dry. Then, wrap them in the other aluminum-foil.

3.1.5. Carefully open the aluminium-foil envelopes contain air filter samples. NOTE: The surface of the filter should only be touched with pre-cleaned instruments to avoid contamination.

3.1.6. Use only the pre-cleaned scissors and forceps to cut up the filter sample into 4 quarters with equal weight (approximately $0.20 \mathrm{~g}$ ). Place one quarter of the filter onto a piece of aluminum foil, the remaining 3 quarters should be returned to the original foil-envelop for storage under $40^{\circ} \mathrm{C}$. Update the label accordingly.

3.1.7. Record the exact weight of the quarter filter sample.

3.1.8. After weighing, fold the filter using forceps and place in ASE-200 clean cell and cap tightly 3.1.9. Use a metal scoopula to measure approximately $0.5 \mathrm{~g}$ of anhydrous sodium sulphate and transport into the $15 \mathrm{ml}$ glass vial containing samples. Record the weight. Make sure to wipe the scoopula clean before proceeding to the next step. 


\subsection{Extraction}

3.2.1. Prior to beginning the extraction, turn on the printer capture screen on the Hamilton Microlab PC in order to be able to print the ASE method and ASE diagnostic information that will be generated for this particular extraction. Click on the ASEprint.ht icon. Answer NO to the question configuring a modem connection. Select TRANSFER from the menu and select CAPTURE TO PRINTER. All the printouts from the ASE will now be sent to a spool file on the Epson Fx 850 printer located on the Microlab system. When the ASE goes to completion, select TRANSFER from the menu of the microlab PC and then CAPTURE TO PRINTER. The printer will now print out the diagnostic information that was generated with the extraction.

3.2.2. Fill solvent reservoir $C$ with fresh acetone and reservoirD with hexane. Ensure that the caps are sealed and that the air pressuring line is not submerged in solvent. Place reservoir $\mathrm{C}$ in position $\mathrm{C}$ and reservoir $\mathrm{D}$ in position $\mathrm{D}$ of the reservoir basin.

3.2.3. Turn on the ASE power. Open the nitrogen and compressed air cylinders and ensure the pressure settings are 150 psi and 100 psi respectively. Ensure the pressure settings are set at 10 psi for the solvent bottle, 50 psi for the system air and 130 psi for the oven compression. Press the RINSE button to clean the system=s solvent lines and rinse cells. The system rinses the rinse cell located between positions 1 and 24. It is a good idea to rotate each of the 4 rinse cells around the system so that they all get used.

3.2.4. Remove the GFF samples (contained in manila envelopes) from the freezer and allow to stand at ambient temperature for 30 minutes in the fumehood.

3.2.5. Match the numbered caps (top and bottom) with the corresponding extraction cell body and handtighten the bottom cap to the cell body.

3.2.6. Using clean forceps, fold each sample GFF four times to form a small cone. Place the GFF into the extraction cell and spread the cone open using tweezers prerinsed with acetone. Hand-tighten the top caap to the cell body.

3.2.7. Using a pasteur pipette, rinse the collection vials with a 70:30 HEX:acetone solvent mixture and dispose of the rinsings into a hydrocarbon waste container. Cap the vial using a clean screw cap and new septum with the teflon side facing the sample. Label each vial with the sample name. This must correspond with the extraction cell.

\subsection{Volume Reduction (Acetone evaporation)}

3.3.1. The Zymark Turbovap II 200 is used in concentrating the ASE extracts. Every three months the 
water should be drained and fresh water added to the turbovaps. At this time add approximately 10 drops of clear bath solution to the water to prevent the growth of bacteria. Prior to each blowdown, the deionized water level should be brought up to the same level as the ASE extracts.

\subsubsection{Set the temperature to $38 \mathrm{EC}$ and turn on the power.}

3.3.3. The turbovap nitrogen lines have to be purged to clear out ambient air and contaminants. Insert a tube containing approximately $5 \mathrm{~mL}$ of acetone into each of the six positions of each turbovap unit. All positions are to be purged even if only some will be used in concentrating samples. Select SENSOR ENDPOINT to allow the nitrogen gas to flow through the lines until the endpoint (approximately $0.5 \mathrm{~mL}$ ) is reached. Open the bellows valve and set the pressure on the pressure regulator to 5 psi. Begin the sample blow down. Increase the pressure on the TV II by turning the regulator located on the side of the TV II until the pressure just reads 6 psi. This is the pressure reading that should be used (with the valve open) in blowing down ASE extracts. The end of the concentration is indicated by an alarm. If the alarm does not sound, bubbles may be blocking the sensor. Remove the bubbles with a bubble remover. The turbovap units are now ready for use.

3.3.4. Place the turbovap tubes containing the GFF ASE extract samples into the turbovap II evaporator. If there are insufficient samples to fill the six spaces, place an extra tube containing water in the empty space. This is to ensure constant blowdown times. With the cover open, press the RESET button. Close the cover and allow nitrogen to flow to the turbovap tubes. Follow the same procedure as in 2.12.1.3 to set the pressure to 6 psi.

3.3.5. The alarm will sound when the evaporation is complete. Remove the sample from the turbovap and replace the sample with a tube containing water. This is to ensure a consistent flow to all the samples and consistent recoveries of the more volatile PAHs. Repeat until all samples have been reduced to $0.5 \mathrm{~mL}$.

3.3.6. Using a pasteur pipette, transfer the $0.5 \mathrm{~mL}$ sample to a graduated centrifuge tube. Using a Hamilton syringe add $0.5 \mathrm{~mL}$ of ISO to the turbovap 200 tube and rinse the sides of the turbovap tube using the same pipet that was used in transferring the sample to the centrifuge tube. Transfer the rinsings to the centrifuge tube to make up a $1.0 \mathrm{~mL}$ volume. Transfer the $1.0 \mathrm{~mL}$ aliquot from the centrifuge tube to a labelled amber vial, cap and store the sample in the freezer to await cleanup procedures.

\subsection{Cleanup}

The cleanup procedure has adapted from Cape Technologies Application Note-008

\subsubsection{Prepare coupled column system}


3.4.2. Remove both end caps and put column into rack

3.4.3. Add $10 \mathrm{~mL}$ hexane to top of column

3.4.4. When hexane begins dripping from tip, rinse outside of tip with $1-2 \mathrm{~mL}$ hexane

3.4.5. Attach carbon mini-column with no air bubbles

3.4.6. Insert stopper/stopcock assembly into top of acid silica column

3.4.7. Pressurize to allow hexane to flow through column into waste basin

3.4.8. Release pressure to stop flow when hexane level reaches $1-2 \mathrm{~cm}$ above bed of acid silica column

3.4.9. Remove stopper/stopcock assembly

3.4.10. Transfer hexane diluted extract to top of prepared acid silica column

3.4.11. Replace stopper/ stopcock assembly, and pressurize as before

3.4.12. Release pressure to stop flow when level reaches $1-2 \mathrm{~cm}$ above top of acid silica column

3.4.13. Complete sample loading onto carbon mini-column by adding $30 \mathrm{~mL}$ hexane wash (in 2 or 3 separate portions) and pressurize as before

3.4.14. At end of $30 \mathrm{~mL}$ wash, release pressure to stop flow when air begins to penetrate bottom (neutral silica) portion of column

3.4.15. Remove carbon mini-column and place on clean reservoir

3.4.16. Discard used acid silica column

3.4.17. Place carbon column and reservoir in rack and add $6 \mathrm{~mL}$ of $1: 1$ toluene:hexane to reservoir

3.4.18. Pressurize as before and allow solvent to flow through to waste

3.4.19. Release pressure to stop flow when level reaches tip of reservoir

3.4.20. Reverse carbon mini-column on same reservoir

3.4.21. Add $12 \mathrm{~mL}$ toluene

3.4.22. Pressurize as before and capture eluate in glass evaporation tube

3.4.23. Add keeper and cover the test tube mouth with foil and wrap with parafilm, keep in freezer 


\subsection{Evaporation}

3.5.1. Turn on the waste air stream with tubing that leads to the white waste bucket. Leave the air running for 10 minutes to purge the system of any dust.

3.5.2. Attach a new Pasteur pipette for each sample that is to be evaporated to one of 24 hose endings coming from the drying apparatus connected to the dry bath. Make sure that all unused hose endings also have Pasteur pipettes attached as this prevents nitrogen from leaking from an open ending.

3.5.3. After running the waste air stream for 10 minutes, close this air valve and open the adjacent valve that is connected to the Nitrovap system. Turn the lever on the Nitrovap system from 'Standby' to 'Nitrogen On'. Nitrogen should now be flowing to the drying apparatus.

3.5.4. Adjust the nitrogen flown rate to $0.1 \mathrm{psi}$ using the pressure gauge next to the drying apparatus.

3.5.5. Turn on the dry bath and adjust the temperature to $80^{\circ} \mathrm{C}$.

3.5.6. Place the sample tube in a dry bath slot and slip the clean Pasteur pipette connected to the hose ending through the slotted scaffolding supports so that the pipette tip is blowing nitrogen onto the top of the sample tube.

3.5.7. Readjust the pressure again so that the nitrogen is swirling the liquid in the tube but the surface seems undisturbed. Blowing too much nitrogen will evaporate the sample too quickly and will lead to an excess loss of analyte.

3.5.8. Wrap the dry bath with a layer of tin foil to conserve the heat and protect the sample from any dust. 3.5.9. Periodically check the sample so that it can be removed as soon as it is finished evaporating. It is finished when there is only a small portion of Keeper remaining on the bottom of the tube and there is no detectable hexane odour from the tube. Do not over dry the sample.

3.5.10. Once the sample has evaporated, remove it from the bath, seal it with an aluminum foil cover and parafilm it closed.

3.5.11. Turn off the dry bath, close the air valve feeding into the Nitrovap system and turn the lever on the Nitrovap system from 'Nitrogen On' to 'Standby'.

\subsection{Standard Preparation}

Standard Preparation for ELISA

3.6.1. Prepare eight $16^{\star} 100 \mathrm{~mm}$ tubes on the rack (in fumehood near centrifuge); pour $10 \mathrm{~mL}$ toluene into one tube. 
3.6.2. Use a Hamilton syringe $(1 \mathrm{~mL})$ to transfer $1 \mathrm{~mL}$ of toluene into each tubes

3.6.3. Get a clean baby tube $(12 \times 75 \mathrm{~mm})$, place it on a rack. Transfer $700 \mu \mathrm{L}$ keeper into the baby tube using $100 \mu \mathrm{L}$ microdispenser.

3.6.4. Add $62.5 \mu \mathrm{L}$ of keeper into each of the 8 tubes containing toluene.

3.6.5. Vortex vials containing Karen's standards for at least $1 \mathrm{~min}$. Then add certain amounts of KS standards into each tube according to the KS Standards table. Vortex for 10 seconds after addition.

3.6.6. Turn on dry bath at $72^{\circ} \mathrm{C}$; evaporate the tubes to dryness. *Make sure to run the nitrogen for 10 minutes before use*.

\subsection{ELISA}

3.7.1. Put all the evaporated $2016^{\star} 100 \mathrm{~mm}$ borosilicate tubes ( 8 standards and 12 samples) into the centrifuge; use program 1 (30 min @ 2000g).

3.7.2. Prepare three $16^{\star} 100 \mathrm{~mm}$ tubes with approx. $12 \mathrm{~mL}$ of methanol in each tube. Wash microdispensers with the methanol, rinsing $4 x$ in each tube).

3.7.3. Only fixed $50 \mathrm{uL}$ microdispensers are needed for KS standards; tubes for glassware background testing are treated the same way as the KS standards. Rice samples in other matrix should be treated as $\mathrm{KS}$ standard as much as possible (which means adding the same amount of methanol - $50 \mathrm{uL}$; and use the same operating procedures.

3.7.4. Take one pouch of ELISA tubes (20 tubes inside) and the bottle of sample diluent (part of CAPE dioxin/furan kit) out of the fridge the night before, so they are warmed to room temperature. Check that the desiccant inside the ELISA tube pouch is blue-purple in colour.

3.7.5. Take the 20 ELISA tubes out of the pouch and place them on the ELISA tube magnetic rack (different from racks for $16^{*} 100 \mathrm{~mm}$ tubes); label them 1 to 20 (1-2 are NC; 3-8 are KS standards; 9-20 are samples to be tested).

3.7.6. Attach the correct tip (with DDW or water label on it) to the Eppendorf Repeator Pipettor: pipette 5 $\mathrm{mL}$ of DDW into each ELISA tube; and let the tubes sit for at least 5 mins. Use a different tip for each reagent dispensed with the Eppendorf Repeator pipettor to avoid reagent cross-contamination, especially between conjugate and substrate. (Use the properly labelled tip) Note: Refer to the table in the Eppendorf booklet to determine what setting coordinates with the size of tip and amount of liquid pipetted.

3.7.7. Detach the $50 \mathrm{~mL}$ DDW tip, and attach the $10 \mathrm{~mL}$ tip with the label "Sample Diluent". Use DDW to 
rinse all the tips before the attachment; rinse both inside and outside. Dispense the sample diluent at the centre of the tube, but not directly in the tube, just on the surface. Any remaining diluent is returned to the reagent bottle.

3.7.8. Pour the water out of the tube and tap inverted tube on absorbent material to remove excess water.

3.7.9. Dispense $500 \mathrm{uL}$ of Sample Diluent into each ELISA tube; they are ready for the sample addition. Sample Reconstitution (Samples 9-20 reconstituted first; then KS standards)

3.7.10. Prepare a $16^{\star} 100$ borosilicate tube with $10 \mathrm{~mL}$ of methanol.

3.7.11. Use methanol-washed $50 \mathrm{uL}$ microdispenser to transfer $50 \mathrm{uL}$ of methanol to the first sample tube out of the 12 sample tubes; inside on the side, just above the residue. Vortex the tube for 15 seconds to dissolve the keeper and the sample completely. The tube should be held upright to minimize any splashing of the solution onto the sides or top of the tube. Put this sample tube 9 back on the rack.

3.7.12. Use methanol-washed $50 \mathrm{uL}$ pipette to transfer $50 \mathrm{uL}$ of methanol to the second sample tube out of the 12 sample tubes: inside on the side, just above the residue. Vortex the tube for 15 seconds to dissolve the keeper and the sample completely. The tube should be held upright to minimize any splashing of the solution onto the sides or top of the tube.

3.7.13. Put the two glass tubes (first and second sample tubes) with methanol, keeper and dioxin extract in the centrifuge; Cover tubes with aluminum foil; use program 2 (1000g @ 2 min.). Take the two centrifuged tubes out, and place them on the rack.

3.7.14. Use a clean fixed $50 \mathrm{uL}$ microdispenser to transfer all the remains in the glass tube into the corresponding ELISA tube according to the pre-made ELISA worksheet. The solution MUST be dispensed directly into the liquid and NOT above the liquid surface or onto the side of the tube.

3.7.15. Immediately after addition, vortex each ELISA tube briefly ( 10 seconds $)$ until the appearance of the solution is homogeneous. The vortex speed is set to slow, about 1/3 turn of the dial (in the red zone), to avoid splashing up the tube.

3.7.16. Repeat steps 3.5.11 through 3.5.15 for the rest of the samples.

3.7.17. After, the samples are reconstituted and transferred into ELISA tubes; KS standards are treated the same way. For KS standards, use 50 uL microdispenser to transfer the mixed remains into ELISA tube; then use $25 \mathrm{uL}$ or $10 \mathrm{uL}$ microdispenser to transfer the last little bit of remains to make sure all the liquid goes into the ELISA tube.

3.7.18. After all the 20 samples are transferred into ELISA tubes, use small pieces of parafilm (in triangle shape) to cover each of the 20 ELISA tubes. 
3.7.19. Cover all the ELISA tubes with a piece of aluminum foil, and place on a shaking plate for incubation. Record the time and write it down on the Runform. The Incubation lasts approximately 3hrs.

3.7.20. Start making Wash I solution during incubation time. When making solution, use graduated cylinder labelled "sterile DDW only". Used "Eppendorf pipette and tips" to add Triton x-100 (from kit) to stirring DDW. Pipette slowly due to thick quality of Triton.

3.7.21. Remove test tube rack from incubator box and record the end of the incubation time. Pour out the ELISA tube contents into an appropriate waste container (Dump liquid in empty plastic container, then dab any drips using "papertowel" plastic container"). Remove hanging droplets by tapping the inverted tubes on absorbent material placed in another suitable waste container to prevent contamination.

3.7.22. Dispense $1 \mathrm{~mL}$ of Wash I solution $100 \mathrm{ppm}$ into each ELISA tube using the Repeator pipettor equipped with the $50 \mathrm{~mL}$ pipette tip. Vortex the tubes briefly $(\sim 5 \mathrm{sec})$. Pour out the ELISA tube contents into an appropriate waste container. Remove hanging drops by tapping the inverted tubes on absorbent material placed in another suitable waste container. Repeat this wash procedure three more times for a total of four washes. Change absorbent material before every new ELISA test. Be sure to shake or tap out as much wash solution as possible at each wash step, especially the last one.

3.7.23. Add 500 uL of "competitor-HRP conjugate" using the Repeator pipettor with the pipette tip labelled "conjugate" into each ELISA tube. Return unused portion into the conjugate bottle. Record "competitor-HRP conjugate" lot number.

3.7.24. Tubes are vortexed ( $\sim 5 \mathrm{sec})$ and allowed to stand at room temperature for 20 minutes. ${ }^{*}$ Timing for these steps is very crucial since it is the most important step of the ELISA process. * Rapid and accurate addition of the conjugate, as well as consistent incubation times, are necessary to maintain equal treatment within and among runs. If conjugate is no good, other good conjugate bottles are available in cold room. Dump tube contents after 20 minutes.

3.7.25. Repeat the wash procedure for a total of four washes as described in step 3.5.21, except use $2 \mathrm{~mL}$ of sterile DDW instead of $1 \mathrm{~mL}$ of Wash 1 . At this time using the pipette, place $1 \mathrm{~mL}$ of sterile DDW into an ELISA tube to be used as a BLANK. After use, the ELISA tube designated for blank is stored at room temperature and reused for the next ELISA. Foil is put on top, and is found next to spectrophotometer.

3.7.26. Before dispensing, turn off lights in lab before opening cap to substrated bottle. Dispense 500 uL of "HRP substrate solution" using the Repeator pipettor with the pipette tip labelled "substrate" into each ELISA tube. Return unused portion into the substrate bottle. Vortex the tubes briefly ( $5 \mathrm{sec})$. Record "HRP substrate solution" lot number. If substrate is blue before addition to the ELISA tubes, do not use. Contact the manufacturer. 
3.7.27. Use a piece of aluminum foil to cover the whole rack, and incubate tubes at room temperature for 40 minutes in the dark.

3.7.28. After the incubation period, add 500 uL of "stop solution" using the Repeator pipettor with the pipette tip labelled "stop" into each ELISA tube. Vortex the tubes briefly ( $5 \mathrm{sec})$. The stop solution converts the developed colour to yellow. Record "stop solution" lot number. If the stop solution is not added, all tubes will eventually turn dark blue. Note: Total volume should be $1 \mathrm{~mL}$ after addition of stop solution.

3.7.29. Read OD values as soon as possible after stop solution has been added; the yellow colour is only stable for 30 minutes. Procedure to use spectrophotometer

3.7.30. Turn on the spectrophotometer 15 minutes into the substrate incubation time. The first display by the spectrophotometer is "Select Command".

3.7.31. A designated blank tube containing $1 \mathrm{~mL}$ of sterile DDW is ready. Do not insert into the photometer slot yet. Note: Use a Kimwipe to wipe clean all ELISA tubes before placing it in the spectrophotometer slot. 


\section{Appendix B}

Table B1. TEQ and expected BEQ calculation for CRM

\begin{tabular}{|l|l|l|l|l|l|l|l|}
\hline Congener & $\begin{array}{l}\text { Average } \\
\text { Compo- } \\
\text { sition in } \\
\text { Urban } \\
\text { Dust (ug/ } \\
\text { kg) }\end{array}$ & $\begin{array}{l}\text { WHO } \\
\mathbf{1 9 9 8} \\
\text { TEF }\end{array}$ & $\begin{array}{l}\text { WHO } \\
\mathbf{2 0 0 5} \\
\text { TEF }\end{array}$ & $\begin{array}{l}\text { ELISA } \\
\text { cross re- } \\
\text { activity }\end{array}$ & $\begin{array}{l}\text { Expexted } \\
\text { TEQ WHO } \\
1998\end{array}$ & $\begin{array}{l}\text { Expected } \\
\text { TEQ } \\
\text { WHO } \\
2005\end{array}$ & $\begin{array}{l}\text { Expected } \\
\text { BEQ Urban } \\
\text { Dust }\end{array}$ \\
\hline 1234678-HpCDD & 17.1 & 0.01 & 0.01 & 0.007 & 0.171 & 0.171 & 0.1197 \\
\hline 1234678-HpCDF & 3.44 & 0.01 & 0.01 & 0.0002 & 0.0344 & 0.0344 & 0.000688 \\
\hline $1234789-H p C D F$ & 0.436 & 0.01 & 0.01 & 0.0002 & 0.00436 & 0.00436 & 0.0000872 \\
\hline $123478-H x C D D$ & 0.226 & 0.1 & 0.1 & 0.016 & 0.0226 & 0.0226 & 0.003616 \\
\hline $123478-H x C D F$ & 0.987 & 0.1 & 0.1 & 0.004 & 0.0987 & 0.0987 & 0.003948 \\
\hline $123678-H x C D D$ & 0.654 & 0.1 & 0.1 & 0.079 & 0.0654 & 0.0654 & 0.051666 \\
\hline $123678-H x C D F$ & 0.377 & 0.1 & 0.1 & 0.01 & 0.0377 & 0.0377 & 0.00377 \\
\hline $123789-H x C D D$ & 0.522 & 0.1 & 0.1 & 0.39 & 0.0522 & 0.0522 & 0.20358 \\
\hline $123789-H x C D F$ & 0.041 & 0.1 & 0.1 & 0.033 & 0.0041 & 0.0041 & 0.001353 \\
\hline $12378-P e C D D$ & 0.086 & 1 & 1 & 1.05 & 0.086 & 0.086 & 0.0903 \\
\hline $12378-p e C D F$ & 0.088 & 0.05 & 0.03 & 0.046 & 0.0044 & 0.00264 & 0.004048 \\
\hline $234678-H x C D F$ & 0.507 & 0.1 & 0.1 & 0.049 & 0.0507 & 0.0507 & 0.024843 \\
\hline $23478-P e C D F$ & 0.28 & 0.5 & 0.3 & 0.17 & 0.14 & 0.084 & 0.0476 \\
\hline $2378-T C D D$ & 0.008 & 1 & 1 & 1 & 0.008 & 0.008 & 0.008 \\
\hline $2378-T C D F$ & 0.041 & 0.1 & 0.1 & 0.2 & 0.0041 & 0.0041 & 0.0082 \\
\hline OCDD & 196 & 0.0001 & 0.0003 & 0.00001 & 0.0196 & 0.0588 & 0.00196 \\
\hline OCDF & 6.15 & 0.0001 & 0.0003 & 0.00001 & 0.000615 & 0.001845 & 0.0000615 \\
\hline Composite Toxic Equivalency $(\mu \mathrm{g}$ TEQ/kg dust) & & 0.803875 & 0.786545 & 0.5734207 \\
\hline
\end{tabular}


Table B2. Congener correction factor calculation for CRM

\begin{tabular}{|c|c|c|c|c|c|c|}
\hline Congener & $\begin{array}{l}\text { Urban } \\
\text { Dust GC } \\
\text { congener } \\
\text { profile } \\
\text { CCIW } \\
\end{array}$ & $\begin{array}{l}\text { Percent } \\
\text { Composition }\end{array}$ & $\begin{array}{l}\text { WHO } \\
1998 \\
\text { TEF }\end{array}$ & $\begin{array}{l}\text { ELISA } \\
\text { cross } \\
\text { reactivity }\end{array}$ & $\begin{array}{l}\text { Contribution } \\
\text { toward } \\
\text { composite } \\
\text { TEF }\end{array}$ & $\begin{array}{l}\text { Contribution } \\
\text { toward } \\
\text { composite } \\
\text { cross reactivity }\end{array}$ \\
\hline 1234678-HpCDD & 17.1 & 7.5 & 0.01 & 0.007 & 0.075349317 & 0.052744522 \\
\hline 1234678-HpCDF & 3.44 & 1.5 & 0.01 & 0.0002 & 0.015157991 & 0.00030316 \\
\hline 1234789-HpCDF & 0.436 & 0.2 & 0.01 & 0.0002 & 0.001921187 & 3.84237E-05 \\
\hline 123478-HxCDD & 0.226 & 0.1 & 0.1 & 0.016 & 0.009958448 & 0.001593352 \\
\hline 123478-HxCDF & 0.987 & 0.4 & 0.1 & 0.004 & 0.043491097 & 0.001739644 \\
\hline 123678-HxCDD & 0.654 & 0.3 & 0.1 & 0.079 & 0.028817809 & 0.022766069 \\
\hline 123678-HxCDF & 0.377 & 0.2 & 0.1 & 0.01 & 0.016612101 & 0.00166121 \\
\hline 123789-HxCDD & 0.522 & 0.2 & 0.1 & 0.39 & 0.02300137 & 0.089705345 \\
\hline 123789-HxCDF & 0.041 & 0.0 & 0.1 & 0.033 & 0.001806621 & 0.000596185 \\
\hline 12378-PeCDD & 0.086 & 0.0 & 1 & 1.05 & 0.037894978 & 0.039789727 \\
\hline 12378-peCDF & 0.088 & 0.0 & 0.05 & 0.046 & 0.001938813 & 0.001783708 \\
\hline 234678-HxCDF & 0.507 & 0.2 & 0.1 & 0.049 & 0.022340411 & 0.010946802 \\
\hline 23478-PeCDF & 0.28 & 0.1 & 0.5 & 0.17 & 0.061689499 & 0.02097443 \\
\hline 2378-TCDD & 0.008 & 0.0 & 1 & 1 & 0.003525114 & 0.003525114 \\
\hline 2378-TCDF & 0.041 & 0.0 & 0.1 & 0.2 & 0.001806621 & 0.003613242 \\
\hline OCDD & 196 & 86.4 & 0.0001 & 0.00001 & 0.00863653 & 0.000863653 \\
\hline OCDF & 6.15 & 2.7 & 0.0001 & 0.00001 & 0.000270993 & 2.70993E-05 \\
\hline & 226.943 & Composite TEF & & & 0.003542189 & \\
\hline & & \multicolumn{3}{|c|}{ Composite cross reactivity } & & 0.002526717 \\
\hline & & \multicolumn{2}{|c|}{ Correction factor } & & & 1.40 \\
\hline
\end{tabular}


Table B3. Congener profile for $\mathrm{n}=5$ air samples and W9 congener contribution in BEQ

\begin{tabular}{|l|l|l|l|l|l|l|l|}
\hline Congener & $\begin{array}{l}\text { W5-\% } \\
\text { con- } \\
\text { gener }\end{array}$ & $\begin{array}{l}\text { W7-\% } \\
\text { conge- } \\
\text { ner }\end{array}$ & $\begin{array}{l}\text { W8-\% } \\
\text { congener }\end{array}$ & $\begin{array}{l}\text { W9-\% } \\
\text { congener }\end{array}$ & $\begin{array}{l}\text { W10-\% } \\
\text { congener }\end{array}$ & $\begin{array}{l}\text { ELISA } \\
\text { cross } \\
\text { reactivity }\end{array}$ & $\begin{array}{l}\text { W9 congener } \\
\text { contribution } \\
\text { in BEQ }\end{array}$ \\
\hline $1234678-H p C D D$ & 25.75 & 24.06 & 23.69 & 26.65 & 23.89 & 0.007 & 0.186545925 \\
\hline $1234678-H p C D F$ & 2.35 & 2.25 & 2.33 & 1.89 & 2.47 & 0.0002 & 0.000377749 \\
\hline $1234789-H p C D F$ & 0.42 & 0.42 & 0.43 & 0.06 & 0.13 & 0.0002 & $1.16429 \mathrm{E}-05$ \\
\hline $123478-H x C D D$ & 0.79 & 0.89 & 0.94 & 1.05 & 0.88 & 0.016 & 0.01686934 \\
\hline $123478-H x C D F$ & 1.26 & 1.15 & 1.36 & 0.89 & 1.31 & 0.004 & 0.003570505 \\
\hline $123678-H x C D D$ & 2.01 & 1.62 & 1.49 & 1.73 & 1.67 & 0.079 & 0.13694696 \\
\hline $123678-H x C D F$ & 0.56 & 0.52 & 0.52 & 0.46 & 0.68 & 0.01 & 0.004592497 \\
\hline $123789-H x C D D$ & 3.14 & 2.69 & 2.96 & 3.12 & 2.78 & 0.39 & 1.21843467 \\
\hline $123789-H x C D F$ & 0.15 & 0.11 & 0.16 & 0.06 & 0.13 & 0.033 & 0.001921087 \\
\hline $12378-P e C D D$ & 0.55 & 0.67 & 0.83 & 0.66 & 0.61 & 1.05 & 0.692755498 \\
\hline $12378-p e C D F$ & 0.20 & 0.28 & 0.28 & 0.24 & 0.29 & 0.046 & 0.011009056 \\
\hline $234678-H x C D F$ & 0.71 & 0.67 & 0.67 & 0.46 & 0.68 & 0.049 & 0.022503234 \\
\hline $23478-P e C D F$ & 0.51 & 0.45 & 0.58 & 0.34 & 0.57 & 0.17 & 0.058279431 \\
\hline $2378-T C D D$ & 0.04 & 0.07 & 0.10 & 0.04 & 0.08 & 1 & 0.038809832 \\
\hline $2378-T C D F$ & 0.42 & 0.78 & 1.02 & 0.67 & 0.90 & 0.2 & 0.13454075 \\
\hline OCDD & 58.82 & 60.63 & 60.22 & 59.51 & 60.28 & 0.00001 & 0.000595084 \\
\hline OCDF & 2.32 & 2.74 & 2.42 & 2.16 & 2.67 & 0.00001 & $2.16041 \mathrm{E}-05$ \\
\hline
\end{tabular}


REFERENCES 


\section{REFERENCES}

Alexander, D. E. (1999). Bioaccumulation, bioconcentration, biomagnification. Environmental Geology,pp 43-44. DOI: 10.1007/1-4020-4494-1_31.

ATSDR (1998). Draft Update Toxicological Profile for Chlorinated Dibenzo-p-dioxins. Prepared by Research Triangle Institute for U.S. Department of Health and Human.

http://www.atsdr.cdc.gov/toxprofiles/tp104.pdf

Ahlborg, U., Becking, G., Birnbaum, L., Brouwer, A., Derks, H., Feeley, M., . . Yrjanheikki, E. (1994). Toxic equivalency factors for dioxin-like PCBs. Chemosphere, 28(6), 1049-1067.

BaccarelliA, Mocareli P, Patterson DG, Bonzini M, Pesatori AC, Caporaso N, et al. (2002). Immunologic effects of dioxin: new results from Seveso and comparison with other studies. Environ Health Perspect. 110, 1169-73.

Ballschmiter K, Bacher R. Dioxine. VCH, Weinheim. (1996), pp 507.

Bertazzi, P., Zocchetti, C., Guercilena, S., Consonni, D., Tironi, A., Landi, M. And Pesatori, A. (1997). Dioxin exposure and cancer risk: a 15-year mortality study after the "Seveso accident". Epidem, 8(6), 646-652.

Billets, S. CAPE Technologies LLC DF1 Dioxin/Furan Immunoassay Kit, PCB TEQ Immunoassay Kit. EPA/540/R-05/004. U.S. Environmental Protection Agency; Las Vegas, NV: 2005. Innovative technology verification report: Technologies for monitoring and measurement of dioxin and dioxin-like compounds in soil and sediment.

Birnbaum, L. and Tuomisto, J. (2000). Non-carcinogenic effects of TCDD in animals. Food Add Contam, 17( 4), 275-288.

Birnbaum, L. S. (1994). The mechanism of dioxin toxicity: relationship to risk assessment. Environmental Health Perspectives, 102 (Suppl 9), 157-167.

Boening DW. (1998). Toxicity of 2,3,7,8-tetrachlorodibenzo-p-dioxin to several ecological receptor groups: a short review. Ecotoxicol Environ Saf, 39, 155-63.

Bowman, R.E. et al. Unpublished results as cited in: N.C. Weerasinghe and M.L. Gross. 1985. Origins of polychlorodibenzo-p-dioxins (PCDD) and polychlorodibenzofurans (PCDF) in the environment. In: Dioxins in the Environment. M.A. Kamrin and P.W. Rodgers (Eds). Hemisphere Publishing Corp., Washington, DC. 133-151. 
Brzuzy, L. P., Hites, R. A. (1996). Global Mass Balance for Polychlorinated Dibenzo-p-dioxins and Dibenzofurans, Environ. Sci. Technol, 30, 1797-1804

Buan, E., Lo, C., Zhang, W., Li, J. (2010). Correction of discrepancies in dioxin quantification between immunoassay and gas chromatography-high-resolution mass spectrometry. Anal Bioanal hem, 398,2233-2242.

Buan, E. (2009). Development of a laboratory analytical method beneficial to the polocies of the Canadawide standards for dioxins and furans. Master's thesis, Ryerson University.

[CCME] Canadian Council of Ministers of the Environment. (2009). Canada-Wide Standards for Dioxins and Furans. Pulp and Paper Boilers Burning Salt Laden Wood, Waste Incineration, Iron Sintering Plants, Steel Manufacturing Electric Arc Furnaces and Conical Municipal Waste Combustion. PROGRESS REPORT. http://www.ccme.ca/files/Resources/air/dioxins_furans/df_2009_prgs_rpt_e.pdf

[CCME] Canadian Council of Ministers of the Environment. (2006).conical waste combustion of municipal waste - review report http://www.ccme.ca/files/Resources/air/dioxins_furans/conical_waste_munic_waste/d_f_cwc_report.pdf [CCME] Canadian Council of Ministers of the Environment. (2004). Status of Activities Related to Dioxins and Furans Canada- Wide Standards.

http://www.ccme.ca/files/Resources/air/dioxins_furans/d_f_2004_sector_status_rpt_e.pdf

[CCME] Canadian Council of Ministers of the Environment. (2003). Iron Sintering Plants http://www.ccme.ca/files/Resources/air/dioxins_furans/iron_sintering/dnf_sintering_cws_e.pdf

[CCME] Canadian Council of Ministers of the Environment. (2002). Canadian Soil Quality Guidelines for the Protection of Environmental and Human Health-Polychlorinated dibenzo-p-dioxind and polychlorinated dibenzofurans (PCDD/Fs).

http://ceqg-rcqe.ccme.ca/download/en/275

[CCME] Canadian Council of Ministers of the Environment. (2001). Canada-Wide Standards for Dioxins and Furans.

http://www.ccme.ca/files/Resources/air/dioxins_furans/waste_incinerators_coastal_pulp/d_and_f_ standard_e.pdf

[CEC] Commission for Environmental Cooperation. (2014). Assessing Comparability of atmospheric PCDD, PCDF and coplanar PCB data from North American Ambient Air Monitoring Networks. Montreal, Canada. 256pp. 
[CEPA]Canadian Environmental Protection Act. (1999).

http://laws-lois.justice.gc.ca/eng/acts/c-15.31/

[Cape-Tech] Cape Technologies (2004). Calculation Module C.

http://www.cape-tech.com/literature/rawdatafiles/modC.xls.

[Cape-Tech] Cape Technologies (2003a). AN-008 application note.

http://www.cape-tcch.com/AN-008.pdf.

[Cape-Tech] Cape Technologies (2003b). Insert for DFJ dioxin/furan immunoassay kit, http://www.cape-tcch.com/IN-DFI .pdf.

Chang, Y., Kim, E., Lee, D. (2002). Distribution of polychlorinated dibenzo- p-dioxins 87 and dibenzofurans (PCDD/Fs) in different sizes of airborne particles. Atmospheric Environment, 36(32), 5109-5117.

Commoner, B., Bartlett, P. W., Eisl, H., Couchot, K. (2000). Long-range Air Transport of Dioxin from North American Sources to Ecologically Vulnerable Receptors in Nunavut, Arctic Canada Executive Summary.

Couture LA, Abbott BD, Birnbaum LS. (1990). A critical review of the developmental toxicity and teratogenicity of 2,3,7,8-tetrachlorodibenzo-p-dioxin: recent advances toward understanding the mechanism. Teratology, 42, 619-627.

Croghan, W. C, US-EPA, Research Triangle Park, NC, and Egeghy, P.P, US-EPA, Las Vegas, NV. Methods of Dealing with Values Below the Limit of Detection using SAS (Nodate).

Dyke P, Coleman P, James R. Dioxins in ambient air, bonfire night (1994). Chemosphere, (1997) 34,1191-201. Environment Canada. (1998). Ambient Air Measurements of Polycyclic Aromatic Hydrocarbons (PAH), Polychlorinated Dibenzo-p-Dioxins (PCDD) and Polychlorinated Dibenzofurans in Canada (1987-1997).

Environment Canada. (1990). Priority substances list assessment report no. 1 -polychlorinated dibenzodioxins and polychlorinated dibenzofurans.

Fiedler, H. (2007). National PCDD/PCDF release inventories under the Stockholm Convention on Persistent Organic Pollutants. Hemosphere, 67(9), S96-S108.

Fiedler, H. (2003). Dioxins and Furans. In Persistent Organic Pollutants. The Handbook of Environmental Chemistry, 30, 123-196.

Fiedler H. (1998). Thermal Formation of PCDD/PCDF - A Survey. Environ. Eng. Sci. 15(1), 49-58.

Firestone, D., M. Clower, A.P. Borsetti, R.H. Teske and P.E. Long. 1979. Polychlorodibenzo-p-dioxin and pentachlorophenol residues in milk and blood of cows fed technical pentachlorophenol. Agric 
Food Chem, 27, 1171-1177.

Fries, G.F. (1996). Ingestion of sludge applied organic chemicals by animals. Sci Total Environ, 185, 93-108. Geusau, A., Abraham, K., Geissler, K., Sator, M.O., Stingl, G., Tschachler, E. (2001). Severe 2,3,7,8-tetrachlorodibenzo-p-dioxin (TCDD) intoxication: Clinical and laboratory effects. Environ Health Perspect,109, 865-869,

Geyer, H.J., I. Scheunert, J.G. Filser and F. Korte. (1986). Bioconcentration potential (BCP) of 2,3,7,8-tetrachlorodibenzo-pdioxin (2,3,7,8-TCDD) in terrestrial organisms including humans. Chemosphere,15, 1495-1502.

Hahn, M.E., Stegeman, J.J., 1994. Regulation of cytochrome P4501A1 in teleosts: sustained induction of CYP1A1 mRNA, protein, and catalytic activity by 2,3,7,8- tetrachlorodibenzofuran in the marine fish Stenotomus chrysops. Toxicol. Appl. Pharmacol. 127, 187-198.

Hagenmaier, H., Lindig, C., She, J. (1994). Correlation of environmental occurrence of polychlorinated dibenzo-p-dioxins and dibenzofurans with possible sources. Chemosphere, 29, 2163-2173.

Haag-Gronlund M, Johansson N, Fransson-Steen R, Hakansson H, Scheu G, Warngard L. (1998). Toxicol Appl Pharmacol, 152, 153-165.

Harrison, R.O., Carlson, R.E., 1999. Immunoassay analysis of dioxin in soil: validation of TEQ screening at 500 ppt using rapid extraction and cleanup. Organohalogen Compd. 36, 129-132.

Harrison, R.O., Carlson, R.E., 1998. Measurement of PCDD/F TEQ by immunoassay: demonstration using real world samples. Organohalogen Compd. 35, 43-46.

Harrison, RO., Carlson, RE. An immunoassay for TEQ screening of dioxin/furan samples: Current status of assay and applications development. (1997). Chemosphere, 34, 915-928.

Hatfield Consultants (2009). Comprehensive Assessment of Dioxin Contamination in Da Nang Airport, Viet Nam: Environmental Levels, Human Exposure and Options for Mitigating Impacts. North Vancouver and Office of the National Steering Committee 33, MONRE, Ha Noi.

Haws, LC., Su. S.H., Harris, M., Devito, M.J., Walker, N.J., Farland, W.H., Finley, B., Birnbaum, L.S. (2006). Toxicol Sci, 89, 4-30.

Hippelein, M., Kaupp, H., Dörr, G., McLachlan, M., \& Hutzinger, O. (1996). Baseline contamination assessment for a new resource recovery facility in Germany part II: Atmospheric concentrations of PCDD/F. Chemosphere, 32(8), 1605-1616.

Hites, R.A., Harless, R.L. (1991) Atmospheric transport and deposition of polychlorinated dibenzo-pdioxins and dibenzofurans. Research Triangle Park, NC: U.S. Environmental Protection Agency, Office of 
Research and Development. EPA/600/3-91/002.

Holsapple, MP., Morris, DL., Wood, SC., Snyder, NK. (1991). 2,3,7,8- Tetracllorodibenzo-p-dioxin-induced changes in immunocompetence:possible mechanisms. Annu Rev Pharmacol Toxicol, 31, 73-100.

Hope, D. (2014). Low cost dioxin analysis-Simplified manual sample clean-up using disposable preparation columns combined with Thermo Scientific TSQ 8000 GC-MS/MS [Video file]. Retrieved from https:// www.youtube.com/watch?v=Fts1StLOjOk.

Huff, J.E., Salmon, A.G., Hooper, N.K., Zeise, L. (1991). Long-term carcinogenesis studies on 2,3,7,8-tetrachlorodibenzo-p-dioxin and hexachlorodibenzo-p-dioxins. Cell Biol Toxicol, 7(1), 67-94.

Hutzinger, O., Blumich, M.J., van der Berg, M., Olie, K (1985). Sources and fate of PCDDs and PCDFs: an overview. Chemosphere, 14, 581-600.

Jensen, D.J., Hummel, R.A., Mahle, N.H., C.W. Kocher and H.S. Higgins. (1981). A residue study of beef cattle consuming 2,3,7,8-tetrachlorodibenzo-p-dioxin. Agric Food Chem, 29, 265-268.

Kimball, J. (2008). Enzyme-linked immunosorbent assay (ELISA). From Kimball's online biology pages. http://users.rcn.com/jkimball.ma.ultranet/BiologyPages/E/Elisa.html.

Kaupp, H., Towara, J., \& McLachlan, M. S. (1994). Distribution of polychlorinated dibenzo-pdioxins and dibenzofurans in atmospheric particulate matter with respect to particle size. Atmospheric Environment, 28(4), 585-593.

Kenaga, E.E. (1980). Correlation of bioconcentration factors of chemicals in aquatic and terrestrial organisms with their physical and chemical properties. Environ Sci Technol, 14, 553-556.

Kerkvliet, NI. (2002). Recent advances in understanding the mechanisms of TCDD immunotoxicity. Int J Immunopharmacol, 2, 277-91.

Kimbrough, R. D., Krouskas, C. A., Carson, M. L., Long, T. F., Bevan, C., \& Tardiff, R. G. (2010). Human uptake of persistent chemicals from contaminated soil: PCDD/Fs and PCBs. Regulatory Toxicolgoy and Pharmacology, 1-9.

Kobica, R.J., D.G. Keyes, J.E. Beyer, R.M. Carreon, C.E. Wade, A.D. Dittenber, R.P. Kalnins, L.E. Frauson, C.N. Park, S.D. Barnard, R.A. Hummel and C.G. Humiston. (1978). Results of a two-year chronic toxicity and oncogenicity study of 2,3,7,8-tetrachlorodibenzo-pdioxin in rats. Toxicol Appl Pharmacol, 46, 279-303.

Kulkarni P, Crespo J, Afonso C. (2008). Dioxins sources and current remediation technologies. Elsevier, 43, 139-153. 
Kurokawa, Y., Matsueda, T., Nakamura, M., Takada, S., \& Fukamachi, K. (1996). Characterization of nonortho coplanar PCBs, polychlorinated dibenzo- $\mathrm{p}$-dioxins and dibenzofurans in the atmosphere. Chemosphere, 32(3), 491-500.

Kutz, F., Barnes, D., Bottimore, D., Greim, H. and Bretthauer, E. (1990). The international toxicity equivalency factor (1-TEQ) method of risk assessment for complex mixtures of dioxins and related compounds. Chemosphere, 20(7-9), 751-757.

Lee, A. K., (2011). Feasibility of establishing an enzyme-linked immunosorbent assay (ELISA) laboratory for the detection of dioxins in economically marginalized and developed countries. Mater's thesis, Ryerson University. Li, J., Lo, C., Chen, E., Sun, F., Zhang, W., Wang, C., Lee, A. (2010) The screening of dioxins in fish using enzyme-linked immunosorbent assay (ELISA). Fresenius Environmental Bulletin, 19(5), 783-789.

Lohman, J., Jones, K. C. (1998). Dioxins and furans in air and deposition: A review of levels, behavior and processes. Elsevier, 219, 53-81.

McConnell, EE., Moore, JA. (1979). Toxicolpathology characteristics of the halogenated aromatics. Ann NYAcad Sci, 320, 138-150.

Mckay, D., Shiu, W.Y., Ma K.C. (1991). Illustrated Handbook of Physical- Chemical Properties and Environmental Fate for Organic Chemicals Vol. II Polynuclear Aromatic Hydrocarbons, Polychlorinated Dioxins and Dibenzofurans. Boca Raton, Florida: Lewis Publishers.

McKay, G. (2002). Dioxin characterisation, formation and minimisation during municipal solid waste (MSW) incineration: review, Chem Eng journal, 86, 343-368

Mandai, P. (2005). Dioxin: a review of its environmental effects and its aryl hydrocarbon receptor biology. J Camp Physiol B, 175(4), 221-230.

Martinez, J., DeVito, M. et al. "Toxicology of dioxin and dioxin-like compounds", In Dioxins and Health, (Wiley, Hoboken, 2003), 855-892.

MacConnell, S. and Healy, A. (2008). €125m of pork to be destroyed in biggest food scare since BSE as cited in Buan, 2009.

McLachlan, M.S., Horstmann, M., Hinkel, M., (1996). Polychlorinated dibenzo-p-dioxins and dibenzofurans in sewage sludge: sources and fate following sludge application to land. Sci Total Environ, 185, 109-123.

Mukerjee, D., (1998). Health impact of polychlorinated dibenzo-p-dioxins: A critical review. The Journal of the Air \& Waste Management Association, 48, 157-165. 
Nash, R.G., and M.L., Beall. (1980). Distribution of silver, 2,4-D and TCDD applied to turf in chambers and field plots. J. Agric. Food Chem, 28, 614-623.

[NPRI] National Pollutant Release Inventory. (2003). Dioxins/Furans and Hexachlorobenze.

Nording M., Nichkova M., Spinnel E., Persson Y., Gee S.J., Hammock B.D., Haglund P. (2006). Rapid screening of dioxin-contaminated soil by accelerated solvent extraction/purification followed by immunochemical detection. Anal. Bioanal. Chem, 385, 357-366.

Notes on Chemical-Specific Parameters - Physical and Chemical Properties (no date). Retrieved from https://fortress.wa.gov/ecy/clarc/FocusSheets/Physical\&ChemicalParameters.htm.

Oberg, L.G., Anderson, R., Rappe, C. (1992). De novo formation of hepta- and octachlorodibenzo-pdioxins from pentachlorophenol in municipal sewage sludge. Organohalog Compd, 9, 351-4.

OGDEN, T. L. Handling results below the level of detection (2010).

Okey, A. B. (2007). "An aryl hydrocarbon receptor odyssey to the shores of toxicology: The Deichmann lecture". International congress of toxicology-XI. Toxicological Sciences 98 (1), 5-38.

Okey AB, Riddick DS, Harper PA (1994) Toxicol Lett 70:1-22.

Okuyama, M., Kobayashi, N., Takeda, W., Anjo, T., Matsuki, Y., Goto, J. (2004). Enzyme-linked immunosorbent assay for monitoring toxic dioxin congeners in milk based on a newly generated monoclonal anti-dioxin antibody.

Parker, C.E., Jones, W.A. Matthews, H.B. McConnell, E.E. Hass, J.R. (1980). The chronic toxicity of technical and analytical pentachlorophenol in cattle. II. Chemical analysis of tissues. Toxicol Appl Pharmacol, 55, 359-369.

Partition Coefficients and distribution models. Retrieved from http://homepage.env.dtu.dk/stt/ PhD\%20course\%202013website/Day1/11Partition\%20coefficients.pdfhttps://fortress.wa.gov/ecy/clarc/ FocusSheets/Physical\&ChemicalParameters.htm\#koc.

Pelclova, D., Fenclova, Z., Preiss, J., Prochazka, B., Spacil, J., Dubska, Z., Okrouhlik, B., Lukas, E. and Urban, P. (2002). Lipid metabolism and neuropsychological follow-up study of workers exposed to 2,3,7,8- tetrachlordibenzo- p-dioxin. Int Arch Occup Environ Health 75(Suppl), S60-S66.

Pesatori, A., Consonni, D., Bachetti, S., Zocchetti, C., Bonzini, M., Baccarelli, A., Bertazzi, P. (2003). Short- and long-term morbidity and mortality in the population exposed to dioxin after the "Seveso accident". Ind Health, 41, 127-138.

Pohjanvirta R, Tuomisto J (1994) Pharmacol Rev 6:483-549. 
Poland A, Knutson JC (1982) Annu Rev Pharmacol Toxicol 22:517-554.

Qin, H. (2006). Neuronal functions of ahr-1, the caenorhabditis elegans homolog of the aryl hydrocarbon receptor.

Rappe C. (1992). Sources of PCDDs and PCDFs -introduction - reactions, levels, patterns, profiles and trends. Chemosphere, 25, 41-44.

Reiner, E. J., Clement, R. E., Okey, A. B., \& Marvin, C. H. (2006). Advances in analytical techniques for polychlorinated dibenzo-p-dioxins, polychlorinated dibenzofurans and dioxin-like PCBs. Analytical and Bioanalytical Chemistry, 386(4), 791-806.

Rogan, W.J., Gladen, B.C., Hung, K-L, Koong, S-L, Shih, L-Y, Taylor, S., Wu, Y-C, Yang, D., Ragan, N.B., Hsu, C-C. (1998). Congenital poisoning by polychlorinated biphenyls and their contaminants in Taiwan. Science, 241, 334-336.

Safe, S. (1998). Development validation and problems with the toxic equivalency factor approach for risk assessment of dioxins and related compounds. J Anim Sci, 76, 134-141.

Safe, S. (1997). Limitations of the toxic equivalency factor approach for risk assessment of TCDD and related compounds, Teratog Carcinog Mutagen, 17, 285-304.

Safe S. (1990). Polychlorinated biphenyls (PCBs), dibenzo-r-dioxins (PCDDs), dibenzofurans (PCDFs) and related compounds: Environmental and mechanistic considerations which support the development of toxic equivalency factors (TEFs). C.R.C. Crit. Rev. Toxicol. 21, 51-88.

Saito K., Takekuma M., Ogawa M., Kobayashi S., Sugawara Y., Ishizuka M., Nakazawa H., Matsuki Y. (2003). Enzyme-linked immunosorbent assay toxicity evaluation method for dioxins in human milk. Bull. Environ. Contam. Toxicol, 70, 636-643.

Schmidt J. V., Bradfield, C. A. (1996). Ah receptor signaling pathway. Annual Review of Cell and Developmental Biology, 12:55-89.

Schroll, R., and I. Scheunert. (1993). Uptake pathways of octachlorodibenzo-p-dioxin from soil by carrots. Chemosphere, 26, 1631-1640.

Sidhu S, Edwards P. Role of phenoxy radicals in PCDD/F formation. Int J Chem Kinet (2002), 34, 531-41. [NPRI] National Pollutant Release Inventory. (2003) Dioxins/Furans and Hexachlorobenze. Schecter, A., Birnbaum, L., Ryan, J. and Constable, J. (2006). Dioxins: an overview. Environ Res, 101(3), 419-428.

Sheffield, A. (1985). Sources and releases of PCDD's and PCDF's to the Canadian environment. Chemosphere, 14(6), 811-814. 
Stansbury K. H., Flesher J. W., Gupta, R. C. (1994) Mechanism of aralkyl-DNA adduct formation from benzo[a]pyrene in vivo. Chemical Research in Toxicology, 7:254-259.

Stockholm Convention on POPs. (2004). Section V.D.2. Guidance by source category: Annex C, Part II Source Categories, Sinter plants in the iron industry. Guidelines on Best Available Techniques (BAT) for Sinter Plants in the Iron Industry.

Sugawara, Y., Saito, K., Ogawa, M., Kobayasi, S., Shan, G., Sanborn, J. R., Hammock, B. D., Nakazawa, H., Matsuki, Y. (2002). Development of dioxin toxicity evaluation method in human milk by enzyme-linked immunosorbent assay-validation for human milk. Chemosphere, 46,1471-1476.

Sugawara, Y., Gee, S.J., Sanborn, J.R., Gilman, S.D., Hammock, B.D. (1998). Development of a highly sensitive enzyme-linked immunosorbent assay based on polyclonal antibodies for the detection of polychlorinated dibenzop-dioxins. Anal. Chem. 70, 1092-1099.

Suzuki, G., Nakano, M., Nakano, S. (2005). Distribution of PCDDs/PCDFs and Co-PCBs in Human Maternal Blood, Cord Blood, Placenta, Milk, and Adipose Tissue: Dioxins Showing High Toxic Equivalency Factor Accumulate in the Placenta. Bio sci Biotechnol Biochem, 69, 1836-1847.

Sweeney, M. H., \& Mocarelli, P. (2000). Human health effects after exposure to 2,3,7,8-TCDD. Food Additives and Contaminants, 17, 303-316.

Toyoshiba, H., Walker, NJ., Bailer, AJ., Portier, CJ. (2004). Toxicol Appl Pharmacol, 194, 156-168.

Trindade, M., Nording, M., Nichkova, M., Spinnel, E., Halund, p., Last, M.S., Gee, S., Hammock, B., Last, J. A., Saienza, G., Brena, B.M. (2008). Enzyme-linked immunosorbent assay for screening dioxin soil contamination by uncontrolled combustion during informal recycling in slums. Environ Toxicol Chem, 27, 2224-2232.

Turner, J.N., Collins, D.N. (1984). Liver morphology in guinea pigs fed pyrolysis products of a polychlorinated biphenyl transformer fluid continuously for 90 days. Toxicol Appl Pharmacol, 73, 464-477.

Tysklind, M., Fangmark, I., Marklund, S., Lindskog, A., Thaning, L., Rappe, C. (1993). Atmospheric transport and transformation of polychlorinated dibenzo-pdioxins and dibenzofurans. Environ Sci Technol , 27, 2190-7.

[UNEP] United Nations Environment Programme (2005). Standardized Toolkit for Identification and Quantification of Dioxin and Furan Releases.

[UNEP] United Nations Environment Programme (2003). Standardized Toolkit for Identification and Quantification of Dioxin and Furan Releases, p. 60. 
[UNEP] United Nations Environment Programme (1999). Dioxin ad Furan Inventories- National and Reginal Emissions of PCDD/PCDF.

[US EPA] United States Environmental Protection Agency (2006b). Method 4025-Screening for polychlorinated dibenzodioxins and polychlorinated dibenzofurans (PCDD/Fs) by immunoassay. http://www.epa.gov/solidwaste/hazard/testmethods/pdfs/4025.pdf

[US EPA] Environmental Protection Agency (2000c). Draft exposure and health reassessment of 2,3,7,8-tetrachlorodibenzo-p-dioxin (TCDD) and related compounds. EPA/600/P-00/001Ab-Ae, Ag. Environmental Protection Agency (EPA), Office of Research and Development (ORD), National Center for Environmental Assessment (NCEA), Washington, DC.

[US EPA] Environmental Protection Agency (1998). The Inventory of Sources of Dioxin in the United States. http://www.epa.gov/ncea/pdfs/dioxin/dioxin.pdf

[US EPA] United States Environmental Protection Agency (1994). Estimating exposure to dioxin-like compounds - Review Draft. U.S. Environmental Protection Agency, Washington, DC. 3 volumes. (2000). Exposure and human health reassessment of 2,3,7,8-tetrachlorodibenzo-p-dioxin (TCDD) and related compounds. Draft final. Exposure Assessment and Risk Characterization Group. National Center for Environmental Assessment - Washington Office. Office of Research and Development. EPA/600/P-00/00/Ac.

Van Birgelen AP, Van der Kolk J, Fase KM, Bol I, Poiger H, Brouwer A, Van den Berg M. (1994). Toxicol Appl Pharmacol, 127, 209-221.

Van den Berg, M., Birnbaum, L. S., Denison, M., De Vito, M., Farland, W., Feeley, M., . .Peterson, R. E. (2006). The 2005 world health organization reevaluation of human and mammalian toxic equivalency factors for dioxins and dioxin-like compounds. Toxicological Sciences, 93(2), 223-241.

Viluksela M, Stahl BU, Birnbaum LS, Rozman KK. (1998). Toxicol Appl Pharmacol 151, 70-78.

Walker NJ, Crockett PW, Nyska A, Brix AE, Jokinen MP, Sells DM, Hailey JR, Easterling M, Haseman JK, Yin M,Wyde ME, Bucher JR, Portier CJ .(2005). Environ HealthPerspect, 113, 43-48.

Werner, C., Prum, C., Wirling, J. (2005). Reducing dioxin emission in electric steel mills.

Whitlock, J. (1990). Genetic and molecular aspects of 2,3, 7,8-tetrachlorodibenzo-p-dioxin action. Annual Rev Pharmacol Toxicol, 30, pp 251-277.

World Health Organization (1998). Assessment of the health risk of dioxins: re-evaluation of the tolerable daily intake (TDI), Geneva, Switzerland.

[WHO] World Health Organization (1998). Assessment of the health risk of dioxins: re-evaluation of the 
tolerable daily intake (TDI), Geneva, Switzerland.

Yu, ML., Guo, YL., Hsu, CC., Rogan, WJ .(2000). Int J Epidemiol, 29, 672-677

Zennegg, M., Harrison, R.O., Shmid, P. (1998). Application of a PCDD/PCDF immunoassay for the development of TEQ in fly ash--a comparison with GC/MS data. Organohalogen Compd, 35, 213-215.

Zennegg, M., Shmid, P. (1999). Determination of TEQ in chimney soot by PCDD/PCDF enzyme immunoassay-a comparison with GC/MS data. Organohalogen Compd, 36,317-319.

$\mathrm{Zi}$, Nan. (2013). Monitoring particle-phase dioxins in downtown Toronto ambient air using enzyme-link immunosorbent assay (ELISA). Master's thesis, Ryerson University. 